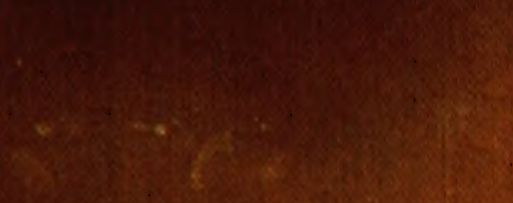




\section{QH}

\section{7 \\ $\theta 75$}

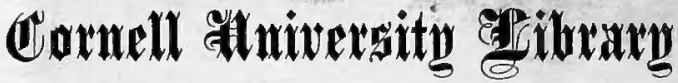

BOUGHT WITH THE INCOME FROM THE

SAGE ENDOWMENT FUND

$$
\begin{aligned}
& \text { พtenxy ซึ. 5ane } \\
& \text { I89I }
\end{aligned}
$$

A.53301 


\section{The date shows when this volume was taken.}

\section{HOME USE RULES.}

All Books subject to Recall.

MAR 2 4 1954 H Books not needed for instruction or re( search are returnable AD APR 2 1 b. within 4 weeks.

Volumes of periodicals and of pamphlets R R APR $29 ' 55$ are held in the library as much as possible. For special purposes they are given out for a limited time.

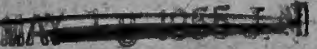

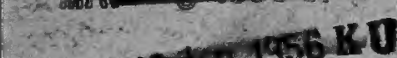

Borrowers should not use their library privileges for the benefit of other persons.

Books not needed during recess periods should be returned to the library, or arrangewents made for their return during borrower's absence, if wanted.

Books needed by more than one person are held on the reserve list.

Books of special value and gift books, when the giver wishes it, are not allowed to circulate.

Marking books sirictly for. bidden.

Readers are asked to report all cases of books marked or muti. lated. 


\section{Cornell University Library}

The original of this book is in the Cornell University Library.

There are no known copyright restrictions in the United States on the use of the text. 


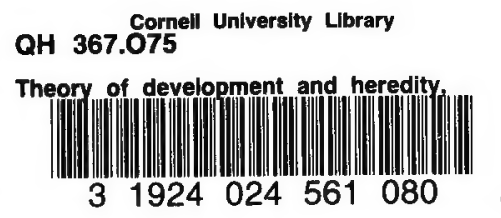

A THEORY OF

\section{DEVELOPMENT AND HEREDITY}


Sx 


\section{6ol:1'11

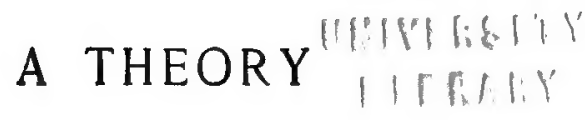

OF

\section{DEVELOPMENT AND HEREDITY}

BY

HENRY B. ORR, Ph.D.

.Professor at the Tulane University of Louisiana

"Biology must put forward a conception of life applicable to all its stages, from the organic process of nutrition in its simplest forms to the most ideal process of feeling or thought." - HARALD HÖFFDING, Outlines of Psychology, p. 25 .

New 咀ork

MACMILLAN AND CO.

AND LONDON

1893

All rights reserved

(B)

un 


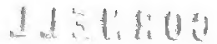

$$
\begin{aligned}
& \text { lotestily } \\
& \text { Iflitil. }
\end{aligned}
$$

\section{A. 53301}

Copyright, 1893 ,

By MACMILLAN AND CO.

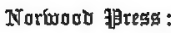

J. S. Cushing \& Co. - Berwick \& Smith.

Boston, Mass., U.S.A. 


\section{PREFACE.}

IN presenting in so small a volume a subject of such broad scope, and of such great importance as must pertain to a theory of development and heredity, I have been actuated by several reasons. The theory is based upon the broadest generalisations of natural science, and accordingly it rests upon facts which may be grouped together in great classes. It is necessary to mention only one fact of each class in order to suggest a host of similar familiar facts. As the facts and generalisations are so well known, I have thought it sufficient to give them briefly and only a few examples in each class. At this time, after the critical and minute investigation to which biological phenomena have been subjected for the last thirty years, it is not to be expected that we should suddenly discover some new and recondite fact, far removed from ordinary observation, which should revolutionise all our views in regard to biological phenomena. In announcing, therefore, a theory of development and heredity, I do not pretend to have made any such discovery. But I believe that, 
by a critical review of the facts of biology in the light of the great conclusions derived from the allied sciences of physics and psychology, we may obtain a view of the great phenomena of life which shall bring into harmony a more extensive range of facts, and explain intelligibly relations which have hitherto been hidden. In the following pages I have attempted to bring together a number of facts and conclusions which have not generally been supposed to be related. The success which has attended the effort to find in this way explanations for phenomena which were before inexplicable, has convinced me that the theory which has forced itself upon me is a real advance in the right direction. Rather than attempt to perfect the theory before publishing it, I desire to put it in a form that it may be discussed, so that what is good in the theory may become of general use; and, in adapting anything for general use, many heads are better than one. Then, too, the experimental tests of the theory can be carried out by many better than by one, - if the theory shall fortunately arouse so much interest. 


\section{CONTENTS.}

CHAPTER I.

PAGE

Evolution. - Limits of Natural Selection. - Statement of the Problem to be Solved . . . . . I I

CHAPTER II.

Source of Organic Energy. - Constitution of Matter.Action of Forces upon Living Matter . . . 25

CHAPTER III.

Proof of the Action of Forces of the Environment upon Organisms. - Effect of Changes of Environment . 4I

CHAPTER IV.

Action of the Nervous System intermediate between the Forces of the Environment and the Ultimate Effects in the Organism. - Universality of Nervous Activity, or the Nervous Property in Living Matter

\section{CHAPTER V.}

Nervous Activity and also Development dependent on Association and Repetition 


\section{CHAPTER VI.}

Theory of Development and Heredity illustrated among

Protozoa . . . . . . . . 102

\section{CHAPTER VII.}

Application of the Theory to Multicellular Organisms, and the Relation of the Germ-cells to the Body . . 120

CHAPTER VIII.

The Inherited Impulse of Development, or Tendency of Growth

\section{CHAPTER IX.}

Illustration of the Method of Growth and Development, and of the Origin of Variations . . . . . 146

CHAPTER $\mathrm{X}$.

Correlation of Growth . . . . . . 171

\section{CHAPTER XI.}

Dimorphism and Polymorphism in Species . . $\quad 183$

CHAPTER XII.

Degeneration and Laws of Variation . . . . . 198 


\section{CHAPTER XIII.}

PAGE

Embryonic Organs. - Metamorphosis and Alternation of

Generations

- 207

CHAPTER XIV.

Origin and Significance of Sex . • • • • 226

CHAPTER XV.

Conditions of Development. - Death. - Conclusion . 237 



\title{
DEVELOPMENT AND HEREDITY.
}

\author{
CHAPTER I.
}

EVÓLUTION, - LIMITS OF NATURAL SELECTION. -

STATEMENT OF THE PROBLEM TO BE SOLVED.

THE present state of the theory of organic evolution may best be understood by a brief reference to its history. Lamarck, the first to propose a theory of evolution similar in scope to the present theory, believed that effort, or the striving of an animal after a certain thing, influenced its growth toward the more ready attainment of that end. Thus use of organs caused their further growth and development, and disuse caused their degeneration. Every change of environment necessitated a change in the manner of activity, thus entailing changes in the organism, which were cumulatively transmitted to each succeeding generation, until finally two widely separated generations in the same line of descent bore no resemblance to each other. In this way Lamarck supposed the diversity of animals 
to have been caused. He applied his conception inaccurately, and it was generally found to be too limited or too indefinite to be intelligibly applicable to the known facts. It is worthy of remark, however, that Lamarck's theory was one which attempted to explain the origin of variations, and though, as such, it has been abandoned, yet it has never been supplanted. Darwin based his theory on the fact of variation, supposing it to be universal, and not at first attempting to account for it further than to point. out that in some unknown way it was made more pronounced by a change of environment. The great strength of Darwin's theory was "natural selection"; that is, the universal struggle for existence, and the survival of those individuals whose "fortuitous" variations made them fittest for their environment. Later in his study of variations, Darwin adopted to some extent a modification of Lamarck's view of the origin of variations. Thus the use and disuse of organs was admitted as a factor of evolution, and it was thought there was some ground for believing that all variation was due in some way to changing environment. Professor W. K. Brooks embodied this view in his mechanical theory of heredity, ${ }^{1}$ and the idea obtained largely among other students of the subject, that

${ }^{1}$ Heredity', IV, K. Brooks, Baltimore, 1883. 
there was a causal relation between environment and useful variations. That this causal relation existed to a limited degree has been generally recognised in the accepted theory of the growth or degeneration of organs through use or disuse, the effects of which were supposed to be inherited. Also, the acquired habits of animals were supposed to become the instincts of their later posterity. The reaction of an animal to the influences of its environment was thus supposed to produce-certain changes in the animal, - changes which were called acquired characters, as distinguished from hereditary characters, - and these acquired characters were supposed to be inherited by the posterity of the animal, and thus become hereditary characters. This theory suggests the only clue to a relation between environment and useful variations and development. The biologists who have adhered to these views have been dubbed the "Neo-Lamarckian School," while differing from them are others bearing the name of "Neo-Darwinian School."

In these two schools we have represented the tendencies of the two conceptions of evolution which have existed since Darwin's time. The Neo-Darwinists have held that natural selection - the potency of which was universally recognised - was alone sufficient to account for all the phenomena 
of evolution. According to them, in the severe struggle for existence, every slightest variation must tell; no matter how slight, it must be either useful or detrimental to the individual. Even the further degeneration of an already useless and degenerate organ is held to be advantageous as a saving of energy, which will help the individual in the struggle for existence. So acute is the action of natural selection that each slight degeneration of the eye of cave-dwelling animals is a useful variation - an economy of energy - which is acted upon by natural selection. Also the degeneration of parasites in the flesh of their hosts - where food is superabundant, and where warfare with fellow-parasites does not occur - is also brought about by natural selection for the purpose of saving energy, even though energy in the shape of food be so abundant. According to this view, while it is not denied that environment may cause variation, it is not thought that environment can in any way determine the variation for the advantage of the individual, which means that it is equally liable to be detrimental: and thus the whole matter of organic evolution resolves itself into the one factor of natural selection. Indeed, Professor Weismann ${ }^{1}$ has expressed the opinion that the keenest action ${ }^{1}$ Essays upon Heredity. Authorised trans., Oxford, 1889. 
of natural selection is necessary to keep animals from degenerating - thus apparently implying that variations are even more likely to be detrimental than useful.

In connection with this belief in the sole efficacy of natural selection, the old theory of the inheritance of acquired characters has been abandoned, and in its place has been substituted Professor Weismann's theory of heredity, according to which the inheritance of acquired characters is absolutely impossible. This theory may be briefly stated as follows: In the germ-cells of animals there is a certain amount of "germ-plasm," a substance of very complex physicochemical composition, of which one part gives rise to the development of the incipient animal and is thereby used up; but the other part remains in the body of the developing animal, unchanged in composition but increasing in quantity. This unchanged part then forms the germ-plasm from which the next succeeding generation develops and receives its share of the unchanged germ-plasm. The same process is repeated in all generations, one part of the germ-plasm being used up to produce the bodies of each generation, the other part of the germplasm remaining forever unchanged. As all the generations arise from the same germ-plasm, they are therefore alike, with this exception (which is 
omitted above for simplicity's sake), that each animal arises from the fusion of the germ-plasms of two individuals, and this fused germ-plasm from which the animal grows and which he transmits, is slightly different from either original germ-plasm - being a cross between the two. Therefore the animal differs slightly from either parent. This is the origin of variation. The union of the two germ-plasms determines all the characters of the animal which is to arise from it, and all the tendencies which he will transmit to his offspring. Whatever happens to the animal during his lifetime cannot change these tendencies; for they are inherent in the germ-plasm, and the composition of the germ-plasm became fixed by the union of the two germ-plasms of the parents. Thus the transmission of acquired characters is impossible.

The fundamental truths on which this theory is based are too well known to need repetition. The theory itself is at once seen to involve the most extreme phase of the natural selection theory, disclaiming everything like a causal relation between environment and favourable variation; and necessitating the action of natural selection on the most minute variations, as, for instance, those necessary to produce the human eye. There is another remarkable part of the theory of variation which. 
Professor Weismann sets forth. It seems that among the Protozoa the single cells were changed by the influences of different environment, and when each cell clivided itself into two or more parts, the changes were naturally propagated in the different parts. Thus arose a diversity among the Protozoa. When some of the Protozoa became Metazoa, this diversity continued and expressed itself as differences in the germ-plasms of the higher group. From this point onward variation depended alone on the mixture of two different germ-plasms, because the germ-cells were hidden from the influence of the environment, and only the body-cells were exposed to it.

This theory of heredity increases the difficulty in explaining evolution, as it necessitates an explanation by natural selection alone: in addition, the theory seems to have its own weak points. In the first place, our knowledge of the laws of crossbreeding makes it seem certain that when other conditions remain unchanged, the general result of crossing two dissimilar animals is an animal intermediate in form between the two parents. If this be a general law, then the original differences of the Metazoa would tend to disappear, for each generation would contain only forms intermediate to the forms of the preceding generation. Thus 
variations would become ever smaller and smaller and eventually disappear. If the Metazoa separated into groups, the same process would occur in each group. Artificial selection has proven that where only similar animals are allowed to interbreed, the stock is kept pure and variations are not likely to occur.

Another objection to this theory of heredity and it seems to me insuperable - lies in the supposition that the germ-plasm may exist in the body, undoubtedly a living part of it, and still be no more affected by the changes which pass over the body, than if it were enclosed in an hermetically sealed vial. This idea seems to be based on a peculiar assumption in regard to the individuality of a cell, as though the neighbouring cells of the same organism were as distinct from each other physiologically as they are morphologically; or that the cell walls are such firm and impermeable barriers that the molecular condition of one cell might be changed without affecting its neighbour. We shall have occasion to consider this subject in a later chapter.

In accordance with this theory of variation and heredity, Professor Weismann and his school deny that the environment causes variations of growth for the advantage of the organism. They believe in an 
indefinite variation, that is, a variation without relation to the needs of the organism or the demands of the environment; and consequently they believe in a natural selection which takes note of the minutest deviation of growth. To test this idea, let us consider for a moment the millions of generations which compose the line of ancestry of the mammals, and the inconceivable number of millions of variations that have taken place along the line. If the struggle for existence be so severe, and natural selection so relentlessly active and acute as it is claimed to be, then all these variations must have been useful, or the mammal's ancestors would have died - perhaps as the Devonian fishes or Silurian invertebrates. Each one of this inconceivable number of variations must have occurred, not only at the right period of geological time, but also at the right moment in the life of the individual in whom it first appeared: some of them occurred in embryonic stages, some in adult stages; many of them were complex and correlated, that is, advantageous only when accompanied by certain other variations. In each case there could have been only one chance for a useful variation against countless chances for detrimental variations: for an organism is a delicate piece of machinery, and while there is, perhaps, one point where a slight change will make it more per- 
fect, there are a thousand points where an equally slight change would make it less perfect. When we endeavour to unite the conception of this vast uninterrupted series of useful variations with the idea that the detrimental variations are just as likely to occur as the useful ones, we discover that the two ideas are incompatible. Especially is this the case when we recognise the fact that it has not been a single individual nor a single pair which has survived in each generation, but a species or variety, composed probably of as many individuals as we find to-day in a species or variety. In fact, we would expect it nearly always to have been what Darwin called a "dominant species." When we remember the many cases of wholesale destruction of animals, - for instance, the killing of countless fishes by a sudden change in the temperature of the ocean, the killing of birds and insects by cold and storms of wind and rain, and the killing of myriads of organisms of all kinds by circumstances over which they could have no control, and from which no mere individual variation could save them, - we are led by these facts to doubt that natural selection acts with such mathematical certainty and accuracy in accumulating slight individual variations. It seems more plausible to suppose, since organisms are generally adapted to their environment, and 
progressively adapt themselves to changes in the environment, that therefore environment must, in some way, be the cause of their variation, and must determine what that variation shall be. ${ }^{1}$ Even could the theory of the mixture of germ-plasms be shown to be the only means of causing variations, we would find that we had made but a single step in advance, and were again confronted by the same problem as to why variations occur along certain lines tending toward the better adaptation of the species.

There is another point of view, however, from which this whole subject may be regarded. In a mechanical theory of evolution, natural selection cannot be regarded as a cause of evolution. It is

1 "It is plain that the useful additions which have constituted certain genera, families, orders, etc., what they are, must have been produced as a consequence of the existence of a need for them; or, on the other hand, being created first, they must have sought for use and found it. But what are the relative chances of truth for these two propositions? In the second case, admitting evolution as proved, we perceive that an almost infinite chance exists against any usual amount of variation as observed, producing a structure which shall be fit to survive, in consequence of its superior adaptation to external circumstances. It would be incredible that a blind or undirected variation should not fail, in a vast majority of instances, to produce a single case of the beautiful adaptation to means and ends which we see so abundantly around us. The amount of attempt, failure, and consequent destruction would be preposterously large, and in nowise consistent with the facts of teleology as we behold them." - Professok E. D. COPE, Origin of the Fittest. 
merely a negative factor, and can only nullify those influences (the crossing of useful with detrimental variations) which would retard or end the career of development. Upon analysis, it is found that the actual working of natural selection has been merely to cut off without posterity all organisms except the direct ancestors of the present generation. It may do as a form of popular expression to say that, because the less fit are killed, therefore the fittest survive, but, in nature, organisms do not continue to live because some others die. The causes of life and death are totally distinct, and the death of one organism does not cause the continued life and development of others. It might, perhaps, be regarded as a secondary reason for their not being other than they are, but it is in no true sense the cause of their being what they are, any more than the fact that the earth was not destroyed by an astral collision a thousand years ago is the cause of our living to-day in our present state of civilisation. The development and the civilisation we know to be each the combined effects of a multitude of real causes.

Natural selection merely prevents the retardation of the more developed individuals, by preventing their crossing with the less developed - the latter being killed off. Such retardation has, however, 
occurred, so that evolution has been slow, and a great number of individuals have progressed together, kept abreast of each other by crossing. Marvellous adaptations have been developed, but they were not caused by natural selection. Natural selection, like the stone walls of a labyrinth of lanes and avenues, shows limits over which evolution cannot go; but as to why evolution should sweep through all the intricate paths open to its progress, and how it effects this progress, natural selection offers no clue. Natural selection is a barrier to progress in certain directions, not a cause producing progress. The cause of this progressive development we must seek in the properties of living matter and in the forces which act upon it. For instance, the properties of living matter which are displayed in the phenomena of heredity must surely affect in some way the progressive development of organisms.

The present theories of organic development are based chiefly upon evidence drawn from the corporeal structure of plants and animals. Their anatomy and the minute structure of their parts have been analysed, compared, and classified, and in this manner their genetic relationship has been made apparent. While this method is sufficient to show their relationship, and while observations of breeding and artificial and natural selection show that there is an 
evolution among animals and plants, yet there is still a large class of phenomena in the nervous activity and psychic life of organisms, which is barely taken into account in summing up the conclusion as to the essential nature of evolution. That this latter class of phenomena should not contradict the conclusions drawn from the bodily structure, was apparently all that could be expected from it. But the vast importance which intelligence, instinct, and reflex nervous activity have for organisms, demands for these phenomena a more careful study, especially in regard to the light they shed upon the ultimate nature of living matter, and consequently upon its developmental activity.

It is really just among the phenomena of this class that we shall find the clearest proof of the inheritance of acquired characters, as I shall endeavour to show.

From the results obtained by the science of physiological psychology it is evident that what we know as psychical development must have its correlative physical development. Nor must we forget that even in the higher realms of psychical life these two terms merely express different views of the same thing. It has been sometimes supposed that psychic activity is the antecedent cause of growth changes in the nervous matter of the brain, 
- that the psychic action moved the molecules. But unless the fundamental conclusion of physiolog. ical psychology be wrong, psychic action is simultaneous and co-existent with change in the material particles of the brain. Thus we may consider the one as indicative of the other.

According to this principle, an animal which for a lifetime has been meeting with new experiences, new conditions, and new demands upon its ingenuity, and acquiring new habits, must have at the end a more developed and more complicated nervous structure than it had at the beginning of its life. In such an animal there have arisen new nervous co-ordinations, new actions are possible, its discharges of nervous force are more concentrated and efficient, and the purely reflex mechanical actions are performed in a more perfect way. The nervous mechanism of the animal has been improved, and the brain, the material substratum of its psychic life, has been changed in structure. Moreover, we know that this development, viewed as a physical change, must have occurred according to the laws of matter in motion and the law of the conservation of energy. The material change, the new arrangement of the molecules or atoms, is the effect caused by the action of the stimuli or forces of the environment upon the animal. Were these same 
stimuli withheld from a growing animal, the same development would fail to occur. In this case, therefore, although we are unable to analyse the details of the process, we have, without doubt, a certain amount of development directly caused by forces of the environment acting upon the animal.

But the amount of development which we can ascribe to causes acting thus directly from the environment, seems small when compared with that which takes place during the embryonic period of the life of an animal. At first sight, this latter appears to be of an entirely different nature. It seems to be spontaneous. But we know that in the embryonic life, as well as in later life, the changes in material structure are only effects caused according to physical laws: therefore the nature of embryonic development cannot differ from that of the adult, except in the origin of the forces which cause the activity. In each case, the movements of the particles in building up the organism must proceed according to physical and chemical laws.

We cannot follow the different steps of development of the nervous system in the embryo by observing the correlative psychical activity; but when in the normal embryological development of an animal we see marked physical changes taking place in the brain, must we not infer that they 
have their orderly psychical correlatives? We see the brain going through successive changes of shape and structure until it arrives at such a stage in the new-born animal that it is capable of directing highly complex instinctive actions. At what point in this succession of changes does the psychical element appear? can we imagine it as suddenly arising in the brain as the new-born creature draws its first breath? If instinct be correlated with certain material structures of the brain, as we have reason to believe, can we suppose that those structures have been produced by a method of development totally different from that of all the other organs. The general course of development of any organ is from the simple to the complex; and the development of the organ in the individual is a repetition of the development of the organ in the race. Thus it seems probable that a bird, which, at one period of its embryonic development, with its gill-clefts and unjointed rudimentary limbs, so strongly resembles a fish, should also have passed through a stage of brain development or a potential psychical condition somewhat similar to that stage at which the fishes have remained. So far as may be judged by the appearance of the brain, we may conclude that such a stage has been passed through by the bird, for 
there is a period in the growth of the bird's brain when there are nervous fibres in the base of the brain while it is roofed over merely by a cellular membrane, - thus reproducing a condition of the brain which is characteristic of the majority of fishes throughout their lives. The embryonic development of the vertebrate brain corresponds closely to what the study of morphology has shown to be its probable phylogenetic development.

But whether we can or cannot infer the psychical development of the embryo from its physical development, we can at least compare the psychical result of the embryonic development with the psychical result of the later development. And from the similarity of the two results we can infer a similarity in the processes which produced them. As the result of the embryonic development we have instinct; and as the result of the development which takes place in later life we have that intelligence which is derived from perception and experience. There is such a close and constant interaction between instinct and intelligence, that the material changes accompanying the two phases of psychic activity must often form parts of an uninterrupted series, as closely united as are in us the brainchanges accompanying an unbroken train of thought. An action may have an instinct for its main cause, 
and yet, throughout its whole performance, may display intelligence in its details. It has been observed that young birds do not build their nests as perfectly as older birds. The later improvement in building such a complicated structure as a bird's nest cannot be due wholly to the experience-in the ordinary sense of the word - of an animal which has not sufficient intelligence to loosen a slip-knot tied around its leg. The old bird has, however, acquired a greater general intelligence, which enables its instinct to find more perfect expression. We cannot doubt that it is instinct which determines the general plan of a bird's nest, - its architecture and the materials used; and yet the selection of a particular site for building, and the adaptation of the structure to the peculiar necessities of the location, we must believe to depend on intelligence. For the instincts of last year's birds could not have been so perfectly adapted to the requirements of this year's branches, as to account for the adaptation of nest to branch, that we find existing. If the entire matter of selecting a site and building a nest were dependent purely on instinct, it would be impossible to conceive how each pair of birds found the particular shape of branch demanded by the separate instincts of each one of them; and many birds would, for this reason, die without posterity. We must believe that intelli- 
gence comes to the aid of instinct; and thus instinct and intelligence are most intimately connected.

The observation of the nesting of birds shows further how closely instinct resembles the result of intelligent experience. The common American blackbird arrives in the north in the cold season, before the deciduous trees have put out their foliage, and accordingly the blackbirds frequent the pines, spruces, balsams, etc., enjoying their shelter for nests, and their dry twigs for building material. The robin arrives in the north during the wet and muddy weeks of spring, and builds its nest largely of mud. The bobolink comes when the meadowgrass is high, and finds security for its nest under the tall grasses. The yellow-bird arrives when the willows are scattering their downy seeds, and uses these and other cotton-like material for its nest. The several methods of the nesting habits of these birds are so invariable, that they may, without hesitation, be classed as instinctive, and yet we can hardly conceive of this remarkable adaptation to circumstances as having originated in any other way than by experience and intelligent choice of that which was the most suitable. If it were due to an undirected variation, we ought to find some trace of such variation; but we do not hear of such cases as blackbirds, robins, and bobolinks failing to rear their young 
because the first two nested on the ground, and the last in a pine tree. It seems to be very seldom the case that birds lose their young by mistakes in location or manner of building, such as could have been guarded against by the foresight of such intelligence as a bird may be supposed to possess. Yet it is exactly such odd and unintelligible mistakes which are demanded by the theory of undirected variation and selection, in order to produce the nesting instincts. On the other hand, in the change of the nesting habits of the chimney-martins and barnswallows, from hollow trees and rocks, to chimneys and barns, we find two cases of change of instinct which there is no ground for assuming to be the result of the general destruction of a hypothetical number of birds which refused to make the change. That the kea-bird of New Zealand has learned to dig the kidney fat out of living sheep since the introduction of sheep into that country, is another wonderful instance of change of instinct hardly to be accounted for by means of natural selection, but rather as the result of intelligent experience.

If we could conceive of a species as having one long uninterrupted mental existence, in which generation after generation of individuals replace each other in some way without interrupting the mental 
development of the species, as the material particles of the brain replace each other without interrupting the mental unity of the individual, then the difficulty as to the origin of instinct would vanish, and instead of what we call the instincts of the present generation we would recognise only the accumulated experience of past generations of ancestors, naturally adapted and made use of by the intelligence which acquired it.

We know that the material structures of the brain, which are the correlates of instinct, are reproduced by the power of heredity. The question arises, can we conceive of animal reproduction as reproducing those material changes of the brain which are produced by contact with environment and which are the physical presentments of what we know as experience? The general tendency of living things to reproduce themselves not only in general form, but also in minute details, is too well known to need a repetition of its proofs; and since instinct and intelligence are so closely interwoven in the psychic life of animals, why should not the structural changes correlated with intelligent action be reproduced by the process of inheritance as well as those material conditions and changes correlated with instinct? For, as we have seen, we have reason to believe that the embryonic development of instinct 
in the individual is a gradual process, and the acquisition of experience is likewise a gradual process, occurring later in the same organ.

Viewing just the plain facts as they stand before us, so striking is their relation to one another that we cannot escape the conviction that an instinct is an inherited idea - an inherited plan of action. We see in it the inheritance of knowledge which has been acquired by ancestors. From the physical point of view we see in it the inheritance of structural changes which were caused in the nervous system by the action of the forces of the environment upon each individual ancestor. This seems to be a well-defined case of the inheritance of acquired characters. We cannot deny that the idea or knowledge has been acquired, neither can we deny that it has been inherited. To refuse this plain inference and then to appeal to natural selection as explanation of the evolution of instincts, is to argue wide of the mark; for we must believe that knowledge is the direct result of an intelligent creature's contact with its environment, and not the result of any fortuitous happenings or undirected variations inside the animal.

The problem to be solved is: how are changes brought about in the structure of organisms, and how are these changes transmitted to succeeding genera- 
tions? In attempting a solution of this problem, we must inquire how matter is affected by the forces which act upon it, and especially how living matter is affected by the forces of its environment. We must study the nature of living matter and the source and transformations of its energy. Finally, we must consider the natural operation of this peculiar form of matter under the action of the forces of the environment. 


\section{CHAPTER II.}

SOURCE OF ORGANIC ENERGY, - CONSTITUIION OF MATTER. - ACTION OF FORCES UPON LIVING MATTER.

IN considering the problems of living matter, it must never be forgotten that we are studying but a subdivision of science, and that the limited range of phenomena which we have before us forms but a portion arbitrarily selected from the great body of natural phenomena. From this great body of phenomena have been drawn certain fundamental generalisations which by a vast preponderance of evidence are shown to be universally applicable as laws. We must therefore believe that biological phenomena, as well as all others, are governed by these laws, unless it can be definitely proven that biological phenomena are excepted from their general application.

Biology is bordered on one side by the science of physics, and on the other side by psychology; so that the laws discovered in these two branches of 
science cannot be neglected in biological research. The law of the conservation of energy which is fundamental in the science of physics, when analysed in detail in its application to the phenomena of living matter, has a most extensive import and profound significance. It means that whatever forces of growth and development may be displayed by living organisms, these forces must have their sufficient physical causes. We can only regard them as transformations of the general sum of energy. That any conceivable part of the energy now displayed by living matter in its various forms should have originally resided in the ancestral forms of life, is unimaginable. We have no ground to suppose that protoplasm in its lowest form, and at its first appearance on the earth, possessed any powers except those which are found to be its universal properties to-day, - just as the amœba now does not contain in itself the forces necessary to produce a mammal. So long as nourishment was supplied, and the proper chemical changes kept up in this original living matter, so long would life continue; but all changes in shape, and all changes in the method of activity, must have been the result of additional force from without. Therefore if we are to account for the various forces displayed by living organisms, either in their individual activity and growth or in their racial devel- 
opment, and at the same time regard the law of the conservation of energy, then we must believe that those forces have their origin in the environment. The form of organic matter, i.e. the shape of an organism, is dependent on the forces from the outside acting on the organic matter, - meaning by forces from the outside every transfer of energy to the organism, as by heat, light, food, blows, pressure, gravity, etc.

It is a distinguishing characteristic of living matter that it undergoes perpetual changes. The changes in living matter are of two kinds: first, chemical changes in the composition and constitution of the molecules; and, second, changes consisting in the motions of molecules and masses, such as heat, contraction of parts, circulation, locomotion, etc. The chemical changes follow the laws of chemistry which universally prevail when different elements and compounds are brought into contact. The changes of the motion of molecules and masses must, in like manner, follow the laws of dynamics. These latter changes are of an exceedingly complex character. They include the acquiring of nutrition, its transportation to different parts of the body, and deposition at certain points, and all the phenomena of growth and the successive changes of growth which are classified under the head of development. Each of these 
motions of matter requires a certain definite amount of energy to bring it about; and we find a corresponding source of energy in the chemical changes which convert the potential energy of nutriment into kinetic energy. But it is evident that this simple liberation of energy by chemical action is not of itself sufficient to account for the ensuing wonderfully complex motions of the parts of the organism. To guide masses of matter through the devious courses necessary to build up the body of a living organism, it is necessary not only to have a sufficient energy of motion, but at certain definite points along the line that motion must meet with a resistance sufficient to deflect and guide the mass to its given destination. The forces of cohesion and gravity undoubtedly have some effect, but the great complexity of results cannot be attributed to so small a number of simple constant forces. What, then, is the source of this energy of resistance? The energy of the primary motion and the energy of resistance cannot have the same source, for it is a fundamental principle that masses set in motion by energy from a common source tend to pursue a straight line, and so, moving radially from the centre, they cannot interfere with each other. Therefore, while we ascribe the primary motion of the masses to the energy set free by chemical action, we must ascribe the modi- 
fications in the form and nature of that motion to other sources; namely, the external forces acting upon the body from various directions.

These two sets of forces, the internal and the external, are not the only factors which determine the ultimate form of bodies, - another and very important factor is the nature of the substance of which they are composed, whether it be rigid, or elastic, solid, liquid, or viscous.

In order to understand the phenomena of living matter as a display of physical forces, we must take the most comprehensive view of the action of forces upon matter in general, - the inanimate as well as the animate. We must take note not only of those effects which are made evident by experiment, but also of those which are rendered probable by deduction, - remembering that in the apparent dissipation of a force, even after it has escaped the observation of our senses and the analysis of our instruments, it still acts undestroyed - in a state where we can follow it only with our imagination. We must dismiss from our minds all ideas of motionless, changeless matter, and picture to ourselves a universe where nothing is at rest, where every atom is quivering in ceaseless vibration, where each minutest particle of matter is held in its line of motion through space, by the action of opposing forces, pulled now this way, 
then that way, by the resultant action of an almost infinite number of forces, - forces of attraction, repulsion, and gravitation, which extend toward us from the extremest region of the stars and forever change in form and in the endless complication of their interaction.

A mass of matter appears to be at rest, because the forces which act upon its component particles are in a state of equilibrium. As the forces emanating from each particle act upon all the other particles, no particle can be taken away or added without altering the statical condition of the whole mass and changing the co-ordination of its form-conserving forces, so that a new state of equilibrium must result, in which each particle stands in a new relation to every other particle. Further, every change in the external forces which act upon a mass of matter must cause a change in the equilibrium of the mass, necessitating either the movement of the mass as a whole or some change in the internal relations of its particles. This change in the relation of the particles may be permanent or it may be temporary.

These principles are fundamental, and they are so important for our present inquiry that I quote here a few illustrations of the subtle nature of the changes produced upon inanimate matter by various forces, and of the persistence of the effects. The first 
is from Professor W. R. Grove's essay on the Correlation of Physical Forces, relating experiments of M. Niepce de St. Victor :-

"An engraving which has been kept for some days in the dark is half covered by an opaque screen, and then exposed to the sun; it is then removed from the light, the screen taken away, and the engraving placed opposite, and at a short distance from photographic paper; an inverted image of that portion of the engraving which has been exposed to the sun is reproduced on the photographic paper, while the part which has been covered by the screen is not produced. If the engraving, after exposure, is allowed to remain in contact with white paper for some hours, and the white paper is then placed upon photographic paper, a faint image of the exposed portion of the engraving is reproduced. Similiar results are produced by mottled marble exposed to the sun; an invisible tracing on paper by a fluorescent body, sulphate of quinine, is, after insolation, reproduced on the photographic paper. Insolated paper retains the power of producing an impression for a long period, if it is kept in an opaque tube hermetically closed."

The following is from the same source:-

"As with heat, light, and electricity, the daily accumulating observations tend to show that each 
change in the phenomena to which these names are given is accompanied by a change, either temporary or permanent, in the matter affected by them, so many recent experiments on magnetisation have connected magnetic phenomena with a molecular change in the subject-matter. Thus M. Wertheim has shown that the elasticity of iron and steel is altered by magnetisation, the coefficient of elasticity in iron being temporarily, in steel permanently, diminished.

"He has also examined the effect of torsion upon magnetised iron, and concludes from his experiments, that in a bar of iron, arrived at a state of magnetic equilibrium, temporary torsion diminishes the magnetism, and that the untwisting, or return to its primitive state, restores the original degree of magnetisation.

"M. Guillemin observed that a bar of iron, slightly curved by its own weight, is straightened by being magnetised. Mr. Page and Mr. Marrion discovered that a sound is emitted when iron or steel is rapidly magnetised or demagnetised, and Mr. Joule found that a bar of iron is slightly elongated by magnetisation.

"Again, with regard to diamagnetic bodies, $\mathrm{Mr}$. Matteucci found that the mechanical compression of glass altered the rotary power upon a ray of polarised light which it transmitted." 
The following quotation is from Professor P. G. Tait's book on the Properties of Matter. It relates to an experiment in which a vertical wire, fastened above and suspending a heavy weight below, was first twisted and then allowed of itself to untwist and return to its original position :-

"We have already seen that even brittle bodies may be completely changed in form by small but persistent forces. And there is no doubt that all elastic recovery in solids is gradual; so that, for instance, in the torsion vibrations which we have just considered, even when there is no sensible viscous resistance, the middle point of the range does not coincide with the original untwisted position of the wire. It is always shifted toward the side to which torsion was applied, and to a greater extent the longer the wire has been kept twisted before being allowed to vibrate. With every vibration, however, it creeps slowly back towards the original undisturbed position, but usually comes to rest before reaching it. But even after the oscillations have ceased, the wire still continues to untwist, more and more slowly, sometimes not even approximately reaching its undisturbed position until hours or even days have passed.

"These phenomena are seen in a more striking form when we dispense with oscillation. Thus, for 
example, suppose the wire to be kept twisted through $90^{\circ}$ to the right for six hours, then for half an hour $90^{\circ}$ to the left, and then so gradually let go that there is no oscillation. When it is left to itself, it turns slowly toward the right, gradually undoing part of the effect of the more recent twist, then stops, and twists still more slowly to the left, thus undoing part of the quasi-permanent effect of the earlier twist. Thus the behaviour of such a wire, strictly speaking, is an excessively complex one, depending, as it were, upon its whole previous history; though, of course, the trace left by each stage of its treatment is less marked, as the date of that stage is more remote."

Professor J. Clerk Maxwell has expressed this last idea in almost the same words, "the stress at any given instant depends not only on the strain at that instant, but on the previous history of the body."

From all of this we may learn, first, how slight a force may change the structure of a body; second, how complex may be its results; and third, how subtle and persistent may be the effects of a force upon a body even though its action be only temporary. The nature of the changes which various forces cause in bodies, will be more fully understood by a careful consideration of the following account of the constitution of bodies, quoted from Professor Maxwell's article on that subject, in the British Encyclopedia:- 
"We know that the molecules of all bodies are in motion. In gases and liquids the motion is such that there is nothing to prevent any molecule from passing from any part of the mass to any other part; but in solids we must suppose that some, at least, of the molecules merely oscillate about a certain mean position, so that, if we consider a certain group of molecules, its configuration is never very different from a certain stable configuration about which it oscillates.

"This will be the case even when the solid is in a state of strain, provided the amplitude of the oscillations does not exceed a certain limit; but if it exceeds this limit the group does not tend to return to its former configuration, but begins to oscillate about a new configuration of stability, the strain in which is either zero, or at least less than in the original configuration.

"The condition of this breaking up of a configuration must depend partly on the amplitude of the oscillations, and partly on the amount of strain in the original configuration; and we may suppose that different groups of molecules, even in a homogeneous solid, are not in similar circumstances in this respect.

"Thus we may suppose that in a certain number of groups the ordinary agitation of the molecules 
is liable to accumulate so much that every now and then the configuration of one of the groups breaks up, and this, whether it is in a state of strain or not. We may in this case suppose that in every second a certain proportion of these groups break up, and assume configurations corresponding to a strain uniform in all directions.

"If all the groups were of this kind, the medium would be a viscous fluid.

"But we may suppose that there are other groups, the configuration of which is so stable that they will not break up under the ordinary agitation of the molecules, unless the average strain exceeds a certain limit, and this limit may be different for different systems of these groups.

"Now if such groups of greater stability are disseminated through the substance in such abundance as to build up a solid frame work, the substance will be a solid, which will not be permanently deformed except by a stress greater than a certain given stress.

"But if the solid also contains groups of smaller stability and also groups of the first kind which break up of themselves, then when a strain is applied the resistance to it will gradually diminish as the groups of the first kind break up, and this will go on till the stress is reduced to that due to the 
more permanent groups. If the body is now left to itself, it will not at once return to its original form, but will only do so when the groups of the first kind have broken up so often as to get back to their original state of strain.

"This view of the constitution of a solid, as consisting of groups of molecules, some of which are in different circumstances from others, also helps to explain the state of the solid after a permanent deformation has been given to it. In this case, some of the less stable groups have broken up and assumed new configurations, but it is quite possible that others, more stable, may still retain their original configurations, so that the form of the body is determined by the equilibrium between these two sets of groups; but if, on account of rise of temperature, increase of moisture, violent vibration, or any other cause, the breaking up of the less stable groups is facilitated, the more stable groups may assert their sway, and tend to restore the body to the shape it had before its deformation."

According to the theory expressed in the preceding paragraphs, it appears that the effect of a force acting upon a body is greater in its molecular displacement, and also more permanent, where all the groups of molecules have a small degree of stability. Thus the effects would be more permanent in a 
viscous body than in a rigid or elastic body. Furthermore, it follows from the theory, that the less homogeneous the body acted upon by an external force, the more complicated will be the resulting changes in the body.

We might, therefore, expect the action of the various kinds of forces upon such a viscous body as living matter to be very pronounced and permanent. Also the results ensuing from the viscous nature of living matter would be still further intensified by two conditions. First, living matter is not homogeneous ; $i t$ is formed of a mixture of different compounds ranging in their physical states from solid particles to liquids. This fact must add greatly to the complexity of the molecular changes. The second condition is also a source of further complexity, and makes living matter peculiar among viscous substances; for not only does living matter change in the configuration of its groups of oscillating molecules, as do other viscous bodies, but it is also undergoing a constant chemical change in its molecules, thus increasing its physical instability by adding thereto a chemical instability.

Living matter is therefore a substance which is eminently fitted to respond readily to the forces acting upon it, and to retain the impression of those forces. It is in a state of mobile equilibrium, which 
may be compared with a hoop rolling down an inclined plane, - if the stroke of a stick disturb its balance, the hoop wabbles and the curves followed by every point in the hoop are changed throughout the rest of its course. In living matter, so long as the chemical substances combine and separate in constant, regular flow, and so long as no change occurs in the forces acting upon the molecules, there exists a steady mobile equilibrium. But let there be at some point a little less heat or light, and the conditions of chemical combination are changed; there may be a falling off in the assimilation of some element, the composition of the molecules is changed, and as a consequence they assume a new configuration of oscillation, which produces a new condition of strain affecting the mass, and an almost endless series of effects ensue, the chemical changes producing physical changes, and vice versa.

It is evident that the combinations of forces which maintain living matter in its state of mobile equilibrium must be exceedingly complex. Every particle of living matter has its own peculiar motion in the body of an organism, now carried along in circulating fluids, then perhaps deposited in some appendage where it performs a great variety of movement, and eventually it is cast off 
and its place taken by other similar particles. To account for all these movements of each particle, we are compelled to suppose a certain combination of forces acting in a variety of directions, and impelling the particle through its devious course so long as it remains a part of the living aggregate. Fvery movement of each particle means that a certain amount of energy has been imparted to it, and every time the motion of the particle deviates from the straight line, we know that an additional amount of energy has acted upon it. We know that part of this energy in the organism has its source in the oxidation of the food; but this alone, coming from a single source, could not maintain a mobile equilibrium of forces. The only other source of energy for the organism lies in the existence and movements of matter outside of its own body. The energy of such movements is transmitted to the organism in the form of pressure, impacts, strains, heat, light, electricity, atmospheric vibrations, etc.

If we expect to explain organic phenomena as mechanical processes we must allow due weight to these forces of the environment as causes of organic change. 


\section{CHAPTER III.}

PROOF OF THE ACTION OF FORCES OF THE ENVIRONMENT UPON ORGANISMS. - EFFECT OF CHANGES OF ENVIRONMENT.

THE action of the forces of the environment upon the organism can not be accurately measured with the present means at our command, but that such forces do act, and profoundly affect the organism, may be sufficiently proven. We do not understand the laws of this action well enough to predict in all cases what the effects will be; but when we see a change in the forces of the environment followed by a change in the forces displayed by the organism, then we must believe that the former change is the cause of the latter change, for every change must have its cause. We are concerned here only with those changes appearing in the organism, which we call growth and development: we can be satisfied when we can trace the cause of these changes either to 
forces outside of the organism or to energy in the living matter which composes the organism. A very minute portion of energy and matter is sufficient to compose a germ; all the rest of the matter and energy which has to be added before the germ becomes an adult organism must accordingly be received from the environment. Thus we see at once how dependent each individual organism is upon its environment. A few illustrations will make clearer the relation of the organism to the forces of its environment.

Among the higher animals all individuals begin their existence in the same manner. Each one is dependent on the energy of heat for its first development, and each is dependent on the peculiar combination of forces which make up its nutriment. The peculiar nutriment, and also the other peculiar environment of each individual, such as the medium in which it exists, are absolutely essential to its development. It is, perhaps, a general idea that all this peculiar environment has merely a passive value for the germ's development; and that when the germ is removed therefrom it dies, not for want of the forces which have sustained its life, but because of the fatally aggressive action of a new environment. A moment's reflection must show how unwarranted such an idea is. The 
germ in its proper environment is caused to live and develop by the action of the same forces that have acted on the germs of its ancestors for an immense number of generations, and caused the development of each in turn. If the forces be altered beyond certain narrow limits, or removed, then malformation, arrested development, or death, is the result.

It is impossible for us to observe, or to imagine with any degree of accuracy, the action of the forces which affect the organism while it is yet within the membrane of the egg. We know, however, that these forces must act almost exactly alike for all individuals of the same race. This is shown by the similarity of the results. But when the organism comes out of the egg-membrane, is hatched or born, - it is still lacking a large part of its complete development. During this later period of development we can trace to some extent the particular effects of some of the forces which cause development. Of the first importance in this respect is the food of the organism. Without this, of course, no growth nor development would occur. The quantity and quality of food seem also to have a decisive effect on the degree and direction of development, beside influencing the general strength and activity of the organism. The 
whole system of medicine rests upon the fact that certain elements taken into the body have power to influence the growth, or repair, or development, of the different organs of the body. The effect of a change of food is shown by Daubenton's statement that the intestine of the domesticated cat is considerably longer than that of the wild cat. One of the most striking facts of this connection is that reported by Dr. Born, and also by Professor E. Yung, in regard to the influence of food on the sex of tadpoles. According to these experiments, ${ }^{1}$ the feeding of an unmixed diet to the larvæ until after their metamorphosis, has a tendency to produce females. Among 1443 tadpoles thus fed until after metamorphosis, and then examined by Dr. Born, ninety-five per cent were found to be females and five per cent males. These were raised in a number of different aquaria, and in some of the aquaria the proportion of females was one hundred per cent. In one of Dr. Born's aquaria, which received accidentally a mixture of diet, the males were found in the proportion of twenty-eight per cent. These latter specimens were also larger, approaching, in

${ }^{1}$ G. Born, "Experimentelle Untersuchungen ueber d. Entstehung d. Geschlechtsunterschiede," Breslauer ärtalicher Zeitschrift, I88I. E. Yung, "De l'influence des milieux physico-chemiques sur les êtres vivants," Archives des Sciences phy'siques et naturelles, Mars, I882, troisième periode, tome vii. 
size and general development those which grew in their natural surroundings. Dr. Born has shown that in their natural conditions of development the number of males among the young is equal to the number of females.

Professor Yung's experiments were carried on primarily to determine the effect of different foods on the general development of the tadpoles. He had six glass jars arranged, so that all the conditions of light, temperature, etc., should be as much the same as possible, and so that the only differences in the six jars should be the different food placed in each one. At the beginning of the experiment, on the first of April, fifty specimens in the earliest tadpole stage were placed in each jar. The mortality was very great, and on the thirtieth of June, there remained of the three hundred tadpoles, seventy-four which had completed their metamorphosis into frogs. In two of the jars, all died without metamorphosis, and in the other four, the proportion of females ranged from seventy to seventy-five per cent. Professor Yung's general results were as follows: "I. That tadpoles of the frog, taken from the same batch of eggs, develop in a very different manner, according to the kind of food which they receive. 2. The different kinds of food in question, taken as a single article of diet, favour development in the following order, - flesh of 
beef; fish; coagulated albumen of hen's egg; yellow of hen's egg; albuminoid substance of frog's egg with liquid albumen of hen's egg, substituted later in the experiment; vegetable substances (algæ). 3. A purely vegetable diet is insufficient to transform the tadpole into the frog." These experiments afford conclusive evidence that food is not merely the source of supply of raw energy to a developing organism; and also that the innate forces in the organism do not wholly control its development. Food is one of the stimulating forces which guide and determine the developmental reactions of the organism.

The effects of heat on life and development are so marked and the universal necessity for its presence so well known, as for example, in hatching eggs and germinating seeds and sustaining all life, that this part of the forces of the environment needs but a bare mention. Heat and light are original sources of almost all of the energy which displays itself in the structure and movements of living things. ${ }^{1}$ The peculiar effects of light upon animals, however, have

1 Professor Guyot has expressed a "Law of Development and Life" as follows: "Throughout the entire realm of nature, in the animal world as well as in the vegetable, the development of life increases in energy, and in the variety and perfection of the types, with the increasing intensity of light and heat, from the poles to the equator." Guyor's Physical Geography. 
not been so generally recognised. Professor Yung in his series of highly ingenious experiments has reported some very interesting and important facts in this connection. He conducted with great care an experiment in which a number of tadpoles were allowed to develop under lights of different colours. None of those in coloured light developed so well as those which were in the natural light of day. There were certain marked differences in the development under the different lights. Thus tadpoles under a violet light increased faster in size, but were not so active as those under white or yellow light. Under violet they grew better, but did not develop as well as under yellow light. Professor Yung's observations proved unmistakably that light may exert a potent influence upon the developing organism.

The most apparent phenomenon resulting from the action of light on the animal kingdom is the development of pigment. Certain transparent animals being excepted, it is an almost universal rule that animals exposed to light develop some pigment in the skin. This pigment increases in quantity or brilliancy as we approach the equator, where the light is most intense. There is thus a direct ratio between the amount of light and amount of pigment. This ratio appears also in another manner which is so universal that it must have great significance. I 
refer to the fact that the parts of the same animal which receive less light develop less pigment. Thus there is less colour on the under side of all quadrupeds, snakes, fishes, crawling insects, crustaceans, worms, mollusks, echinoderms, and sea-anemones. Among many of the flying insects and many birds this condition is less marked or absent for the obvious reason that while in the air they are exposed to a nearly equal light on all sides. Further, it is a matter of general observation that animals which during their lives are not exposed to light do not develop pigment. Such animals, whether they live as parasites buried in the flesh or in the alimentary canal of other animals, or whether they live in caves where no light penetrates, remain colourless, often semi-transparent; and if they have eyes no pigment develops in them. This has been explained as the result of natural selection, which is supposed to act in such a way as to prevent the waste of the energy that would be necessary to produce pigment where it is not necessary to the life of the organism. But the facts just mentioned are so striking and universal, that it is difficult to imagine how natural selection could have acted to produce the same result in all cases under such varying conditions, especially when we remember the prodigal way in which energy is wasted in producing ornamental 
colours and useless corrugations and excrescences, and in reproducing such a number of useless rudimentary organs. The plain facts lead to the conclusion that pigment is caused by light acting upon the tissues, and where there is no light there can be no pigment.

In the case of the rooster described by Darwin, which was reared in the dark, and never crowed, but grew up with the instincts of a hen, we have an instance of arrested and distorted development which shows how extremely important the lighț is for the proper development of an animal whose race has always lived in the light. Professor Yung's experiments showed not only the importance of light, but that different kinds of light have a distinctly different effect upon the development of an organism. Ordinary white light, as shown by Professor Yung, is most favourable to the normal development.

Of the light that falls on an animal, a part is absorbed or reflected by the pigment in the skin, and a part is transmitted through the semilucent tissues beneath. It is this latter portion of light which penetrates the body, which we would naturally expect to influence the organism's vital functions. Other things being equal, a light coloured or white skin admits more light, and a dark or black skin less light. In nature, therefore, the 
colour of the light thus admitted to act in the interior of the tissues of the body, is dependent on the colour reflected by the environment of the animal, and also on the colour absorbed or turned back by the skin. If a brown or yellow colour should be everywhere reflected on an animal by its environment, this colour would preponderate in the light which entered the body, perhaps to the disadvantage of the animal's internal physiological functions; but since in such cases the same colour is reflected back by the pigments of the animal, there would thus be a tendency to restore the normal balance of white light, which is most favourable to organic functions. Living matter seems to be in a general way capable to a certain extent of photographing colours when exposed for many generations. An example is found in the fishes, crabs, shrimps, worms, polyzoa, and hydroids, which live among the masses of yellow sea-weed found floating in the Gulf Stream, and which all partake of the yellow colour of the weed. Another instance is that of the animals of the great Sahara desert, all of which, both those preying and those preyed upon, share alike the tawny colour of the desert. The fact that the colouration of animals increases toward the equator leads easily to the supposition that the lack of pigment or whiteness of animals 
in the extreme north may be primarily due to the small amount of light in those regions. ${ }^{1}$

The arrangement of the pigments in organisms seems to be governed by some peculiar law of colour relations; a law which seems to be determined more by the nature of light and of living matter than by the particular nature of the organism. The existence of such a law is suggested by the repetition of the same colours and combinations of colours in widely different plants and animals. Thus we find the brilliantly coloured spot on the peacock's tail-feathers almost exactly reproduced both in form and colour on the fins of certain flying-fish found among the Bahama Islands. Dr. James $\mathrm{McCosh}$ has stated that patches of colours which adjoin each other on plants and animals are generally complementary colours, or else they are separated only by a white or black streak. How generally true this is may be observed in any good collection of stuffed birds. But it is not universally true, as is shown by the brilliant Central American macaw. This wonderful bird presents

1 In all these cases the same colour prevails in all the classes of animals, both in those which are offensive and those which are the prey of others, and this universality of the colour seems not to be wholly accounted for by the theory of protective colouration; nevertheless the view here advanced and the theory of protective colouration are in nowise mutually exclusive. 
all the colours of the spectrum in their proper sequence, running from red on the head to violet on the tail. This case is so remarkable that it alone seems to prove that the colouration of animals is dependent on some peculiar reaction of the physiological forces toward light, and not solely on the protection or ornamentation of animals.

Every organism which is capable of motion is influenced in its growth by the external resistance which is offered to its bodily motions, thus changing the strain and pressure upon the various parts. The ordinary exercise of its organs which a young animal, stimulated by the forces of its environment, performs during the period of its post-natal development, we know to be of great importance for the proper growth of the animal. By exercise of the legs and wings the nervous co-ordinations are perfected which control the walking and flying. This principle is recognised and acted upon by the trainers of racing colts. Not only are the nervous coordinations perfected in this way, but the full growth of bone and muscle, and of the other organs of the body, are dependent upon exercise. The effects of exercise in the training for athletic contests and gymnastic feats are so well known that it is hardly necessary to mention them. What I wish to emphasise is the influence of the ordinary 
motions and exercise of young animals as one of the causes of their development. In a young mam. mal, if compelled to live without motion, there would undoubtedly be a lack of muscular and nervous development; also there would be a most imperfect circulation of the blood, causing a host of effects which would stunt the growth and eventually probably kill the animal. The cruelty of the experiment has probably prevented its ever being tried, but the evidence of this sort to be found among the human race is only too convincing. Every animal has a limited number of methods of motion and exercise which are demanded by any normal environment. This limited number of motions must influence the development of the animal in certain definite directions, favouring some points of growth more than others; just as many forces acting in various directions on a body resolve themselves into one single resultant direction of force along which the body moves.

The records of pathology are full of evidence showing the effects of abnormal forces upon the tissues of the human body. Almost all diseased growths of tissues may be traced as resulting from some change in the normal forces acting on the tissues, or to the introduction of a totally new force or stimulus. The change of a living surface 
of mucous membrane into skin, when exposed permanently to the air, is a case of this kind, showing the effect of a change of medium. If now we admit the effect of a change of forces, or the introduction of new forces, as a cause of disease, then we must attribute an equal power to the unchanged forces, for the normal life and growth of tissues is as much a phenomenon of organic forces and reactions as is the diseased growth.

A striking illustration of the effects of abnormal action of forces on growth is shown in the change in the shape of the human foot which results from the pressure of the shoe. We see how the foot fits itself into the shoe as though pressed into a mould, and toward middle life, becomes thus permanently distorted. This manner of growth under pressure throws light on the problem of how the internal organs of the body, and the muscles and bones which press against each other, are moulded to fit with a perfect contact of surfaces. So we must conclude that mechanical pressures and strains play a large part in modelling the shape of the body.

These illustrations, drawn from the more readily observable phenomena of animal life, might be multiplied indefinitely, both in kind and number. While we can observe these facts more readily among the higher animals, we cannot suppose that the lower 
animals are exempt from a similar action of similar forces.

Illustrations of the influence of various external forces upon growth are found in great number among plants. Thus, the sunlight may cause plants to grow toward it, or away from it; and the amount of light modifies the growth of plants in many other ways. Gravity also has a powerful influence upon the general direction of growth, and moisture determines the direction of growth of roots.

A number of experiments of very great interest for our present enquiry have been very ably discussed by Professor Detmer ; ${ }^{1}$ and his observations seem so important, that I give here extensive quotations from his paper - only taking the liberty to translate the quotations into English.

"In the botanical realm a long series of facts have been ascertained, which teach us that the influence of external conditions upon the plant is often very profound. Their operation modifies not only the outward appearance of the parts of the plant, but in a most striking manner changes even the anatomical structure.

"If one prepare a cross-section of the bipennate twig of Thuja occidentalis, it will be found, upon

1 Detmer, "Zum Problem der Vererbung," Pfuger's Archiv f. Physiologie, Bd.4I, 1887 . 
microscopical examination, that the mesophyllum, the - upper side of the twig, is differently constructed from that of the lower side. The green cells on the upper side are rich in chlorophyll bodies, and have a pallisade-like form: the cells on the under side are poor in chlorophyll, and have a nearly iso-diametrical form. The dorsi-ventral structure of the Thuja twig expresses itself in other ways, which, however, we will not discuss here. Let the Thuja twigs be taken in early spring, before the growth of the buds has started, and without separating the twigs from the plant, let them be tied in an inverted horizontal position, so that the natural under side is turned toward the zenith, - it will then be found, as was first shown by Frank, that the year's additional growth certainly assumes a dorsi-ventral nature, but is essentially different in its anatomical structure from those parts of the twig which were of previous growth. The upper side of the newly grown parts of the twig, although it is the continuation of the under side of the older part, has an anatomical structure like the upper side of the older part. Thus, the dorsi-ventral structure of the Thuja twig, which appears in the development of palisade-parenchym on the upper side, and soft parenchym on the under side, is the result of the working of an external force; and in this case, according to all that we know, we must regard the light as the cause. 
"Kohl has proved by experiment that the leaves of Tropaolum plants display different properties according as they are grown in a moist or a dry atmosphere, the other conditions of growth being the same. The leaves grown in dry air are provided with a thick cuticle, and under the epidermis is a strong growth of collenchym tissue; while the leaves raised in moist air show a thin cuticle and no collenchym.

"According to Stahl's observations, the anatomical structure of the leaves of some plants shows a great difference as a result of having developed in strong light or in shadow. The assimilative parenchym of beech leaves which grow in sunlight, for example, consist almost entirely of palisade cells, while the palisade cell in the leaves grown in shadow are very few; a circumstance which, though it cannot be discussed here, is of great significance for the function of the leaves. Heinreicher also gives examples from which it appears that the conditions of light have a decided influence upon the anatomical structure of the leaves of different individuals of the same species of plant. The newer botanical literature has acquainted us generally with numerous facts concerning the relations between the morphological and anatomical peculiarities of plants, and the climatic influences or other conditions of life to which the organisms are exposed." 
From the facts in the previous paragraphs of this chapter, it will be clearly seen that organisms do not become what they are in their adult form, by a simple unfolding of innate energy. Their development, and even life itself, is dependent upon and caused by the never-ceasing action of the forces of their environment. As an eminent physiologist has said, generation after generation are the same because they live and develop under the same conditions. If the forces of the environment change, the growth of the organism must also change. Hence the effects of domestication on animals and plants, the degeneration of northern dogs, etc., in tropical regions, and the modifications of feral races. 


\section{CHAPTER IV.}

ACTION OF THE NERVOUS SYSTEM INTERMEDIATE BETWEEN THE FORCES OF THE ENVIRONMENT AND THE ULTIMATE EFFECTS IN THE ORGANISM.-UNIVERSALITY OF NERVOUS ACTIVITY, OR THE NERVOUS PROPERTY, IN LIVING MATTER.

WE have seen in the previous chapter that the life and development of an organism are sustained and moulded by the forces acting upon the organism from the environment. When these forces are altered the growth and development are altered or life may cease. The manner of the transmutation of the force in the environment to the force displayed by the organism is very obscure. We can assert, however, that the forces of the environment must very readily affect that instable chemical and molecular condition which we have seen to be a characteristic of living matter. This alteration in the chemical and molecular constitution must produce the effects which we see as movements of the mass and changes of its shape. 
When we look for the immediate effects of the external forces, we find that they are not the movements and changes of shape and growth of the organism. We find that there is an intermediate link which physiology describes as nervous activity. In the same way, when we look for the immediate causes of movement and change of shape and growth, we find that they are not the external forces, but consist in this same nervous activity. This idea, from the psychologist's point of view, has been expressed by Professor. Ladd as follows :"The forces of external nature continually storm the peripheral parts of the animal's body. In order that any of these forces may act as the stimuli of sensations, they must be converted into molecular motions within the tissues of the body. In order, further, that the masses of the body may constantly be readjusted to the external changes of which the sensations are signs, the molecular motions must, in turn, be converted into movements of these masses. In other words a process of constant interchange must take place between the animal organism and external nature." 1

We know that those forces which act from without upon living matter, have their immediate action chiefly or wholly upon the nervous organisation.

${ }^{1}$ Ladd's Elements of Physiological Psychology, p. 220. 
They cause chemical and molecular changes in the nervous system. This is most easily observed where there is a nervous system with end-organs capable of being very sensibly affected by the slightest variation in the forces of the environment, as, for example, the eyes are affected by variations in the intensity of light, and the skin by variations of temperature. But even in cases where there is no nervous system, all organisms are affected by light and heat, and there is reason to believe that could we test the other forces equally well, we would find that they produce an equally great effect upon living matter, whether a nervous system were present or absent.

When the forces of the environment enter the mass of living matter, it cannot be that they are destroyed. If they be no longer recognisable in their original form as light, heat, etc., they must be transmuted to some other of the various forms of energy. The only other form of energy which can be discovered as these forces vanish at the periphery of the living mass, is that form of energy which appears as nervous activity. Therefore, we may safely conclude that the energy of the forces acting from without, persists within the living matter as nervous activity and change of nervous condition.

On the other hand, when we look for the imme- 
diate causes of the motions, changes of shape, and functions of animals, we find in like manner that it is the nervous system which is implicated. If we examine all the changes that take place in an animal, it appears that before most of them occur, there is a peculiar activity of the nervous system. Whatever may be the primary source of the forces causing the change, we know from the science of physiology that every display of physiological forces, the performance of every function, is subject to the control of the nervous system. The swallowing of food, the secretion of the juices which digest it, its propulsion through the alimentary canal, the absorption of nutriment through the walls of stomach and intestine, the distribution of the nutriment throughout the body, respiration and circulation, glandular secretion, assimilation in the various parts of the body, reproduction, locomotion, muscular action, both voluntary and involuntary, - all of these are caused by the activity of the nervous system. A nervous disturbance which is at first purely mental may check or alter the whole nutrition and growth of a body, - as when a person loses appetite and grows thin in consequence of a severe mental shock or disappointment. While appetite or hunger is a sensation localised in the stomach, in reality it is caused by the excessive consumption of the nutriment in the 
blood by means of the assimilation taking place throughout the body. Loss of appetite therefore means a cessation of assimilation. Thus we see that the nervous system controls all the functions of the living body, as a unit. The result of the combined functions of the body, is the sustenance and growth of the body.

Since growth is controlled by the nervous system, it follows that development also must be to a certain degree controlled by the nervous system; for development is either a change in the direction of growth or it implies new growth, i.e. the addition of new material to some part even though the material be taken from an adjacent part. Growth cannot be simply an excess of assimilation above waste. The new material added by growth must form new tissues and new parts. So long as these tissues and parts which are added to an organ, remain of the same nature as the rest of the organ, and cause no considerable change of function, the organ is said to grow; but when the addition of new parts makes the performance of new functions possible, then development is said to occur. A little reflection on the matter will show how arbitrary is the distinction. For no development can take place without growth, and no growth can take place in any organ without modifying in some degree, however slight, the func- 
tion of that organ. All researches into the bistory of organic evolution, point to the conclusion that all development has occurred gradually by slightly additional growth of various parts, in successive generations, - the different parts assuming new functions as their changes of mass and form made the performance of the new functions possible.

When development occurs, therefore, it means that growth takes place at a certain definite point. Now what is the cause which determines that new material shall be added at this particular point, rather than anywhere else? We have seen, in the previous chapter, that a great variety of forces in the environment constantly act upon the organism and produce a variety of effects; but we cannot suppose that these are the immediate causes of the complicated processes of growth. Since the activity of the nervous system regulates all the functions of the body and controls its assimilation as a whole, we, must suppose that it also controls the growth or development of each part. The nervous system is, of all parts of an organism, the most sensitive to change, and the forces of the environment must act chiefly upon the nervous system, and through it upon the whole organism. In view of all we know of the nervous system and its functions, and from analogy of its known control over other organic processes, we 
must conclude that it is a nervous activity which immediately controls the machinery of growth, and thus determines the growth or development of any and every particular part.

The facts concerning the nervous system, which have been referred to above, have been attained chiefly by the study of man and the higher vertebrate animals, but few will doubt that they hold true equally of all the lower animals possessing a nervous system. For, in the first place, their tissues are similar in composition and form of elements; and, moreover, the investigations of the physiology of the snail, ${ }^{1}$ and other invertebrate animals, show that they are affected similarly by various drugs, and that in their physiological economy they are generally the same as the higher animals. The different functions of their organs have also been shown to be under the control of a central nervous system. But there is a great difference in the extent of control which the visible central nervous system exercises over the bodies of different animals. As a general rule, the lower the animal in the scale of organisation the less centralised is the control exercised by the nervous system over the component organs. The organs may be able to perform their

1 Contribution à l'histoire physiologique de l'escargot (Helix pomatia), par Emile Iung. Bruxelles, I887. 
functions when all connection with the meagre central nervous system is cut off. In many cases no nerves can be traced to certain organs, and yet they perform their functions perfectly. The lower we descend in the scale of life the less noticeable does the visible central nervous system become both in its structure and in its function. The organs seem to act independently of visible nervous structures, and yet they act harmoniously for the maintenance of the entire organism. In many of the lowest animals no trace of a visible nervous structure has been found; yet here also the organs perform all their functions as a harmonious whole. All the actions and functions necessary for the life of the individual and of the race are performed with as much regularity and perfection as among animals possessing highly developed nervous structures. The functions of a nervous system are performed, though the nervous structures are not discernible. So great is the similarity in motions and in the performance of all the functions of life between these nerveless organisms and the higher animals, that we are compelled to believe that, just as some of the lowest animals can digest food in all parts of their minute bodies, so also the nervous property may reside in all parts. Since the same results of nutrition, growth, etc., are accomplished among the low- 
est as among the highest animals, we must conclude that the controlling nervous activity is everywhere of the same fundamental character. A distinct, separate, and visible nervous structure is therefore not essential to the display of nervous activity. In fact an elementary form of nervous activity is recognisable in that sensitiveness or irritability, which is common to all living matter. The movements which result from this so-called irritability, we must believe to be caused by internal molecular changes of the mass; and these molecular changes must in turn be caused by the action of some external force.

As there are certain animals, of a low degree of organisation, which possess no nervous structures, so also there is a period in the life of each of the higher animals when there is no nervous structure present. At the beginning of their individual existence, all of the higher animals resemble closely the full-grown forms of the very lowest of animals. They consist of a single cell, and even after many cells have developed, there is still no trace of nervous structures. Yet during this time the functions of nutrition, assimilation, growth, and development are performed harmoniously, all the activities of the organism uniting to produce a common result. Long before the cells of the nerve tissues have attained their com- 
plete development, muscular action has begun in the rhythmic pulsation of the heart. Evidently, the nervous forces are active before the nervous structures appear. There is no moment in the embryonic life of an animal when we can say, "now the nervous system assumes control over the life processes." The nervous activity does not appear suddenly, nor suddenly concentrate itself in the nervous structures. This nervous activity is something co-extensive with the life of the animal. The nervous system is a mechanism which has developed gradually - both in the individual and in the species, - as the increasing bulk and complexity of organisation made it necessary for a more perfect action of the nervous force. We must not allow ourselves to be blinded by a terminology which is, unfortunately, inexact; but we must always bear in mind that it is not the visible material substance of the nervous system which controls the organism, but it is the forces which act through the material substance, building up the potential energy of the nervous system, and controlling and-determining its growth, as well as the growth of the rest of the body.

When we turn from the animal to the vegetable kingdom, we find that the general rule holds good, and that plants display certain forms of nervous activity. All plants, under certain circumstances, show 
the fundamental property of irritability. As related in character to this irritability, may be classed the phenomena of some of the experiments of the previous chapter, in which the forces, - for example, the sunlight, - may be supposed to act directly upon the parts of the plant which are affected and changed. But there is another class of phenomena, in which the connection of the change of forces and the change in manner of growth, while none the less certain, is much more obscure and complicated, and indicates a co-ordination of the internal forces, which must partake of the nature of nervous co-ordination. An illustration of this class is found in an experiment referred to by Professor Detmer, in which the tip end of a young pine tree is broken off. The result of the removal of the tip is that one of the sidebranches turns upward, and, losing its own function and flat-spreading shape, it assumes the function and symmetrical shape of the lost tip of the vertical pinestem. The side branch thus undergoes a complete change in the manner of its growth. Another striking experiment of this class relates to a habit of growing plant-stalks, according to which the stalk bends sideways or downwards, while the tip end swings slowly in a circle around the main stem, a process called nutation. The following description 
of the experiment is taken from a review ${ }^{1}$ of Dr. Max Scholtz's "paper on the nutation of the flower-stalk in poppies and of the terminal shoots in Virginian creeper. In both cases, the nutation is dependent on the action of gravity, but has nothing to do with the weight of the bud. In the case of poppies, the downward curvature of the stalk takes place, with sufficient force to lift a weight equal to twice that of the flower-bud. If, however, the flower-bud be removed, there is no longer any nutation; the stalk straightens itself. Vöchting had already shown that this is the case even if the amputated bud be tied on again with thread. Dr. Max Scholtz further states that, if a weight three times as heavy as the bud is substituted for it, the stalk still straightens itself and lifts up the weight. The state of the case, then, is this: the upper part of the flower-stalk, during a certain stage of its growth, is, in a high degree, positively geotropic if it remains in connection with a developing flower-bud, but not otherwise. The author has further succeeded in determining the exact part of the flower-bud which governs the geotropism of the stalk. If the pistil is excised, nutation ceases, the stalk becoming negatively geotropic; but if all the other whorls of the flower are removed

1 "New Contributions to the Biology of Plants," hy D. HI. S., Nature, September 15, 1892. 
and the pistil left, then nutation goes on as usual. But beyond this, if the ovules are extirpated, but the wall of the ovary left standing, the nutation is stopped. Hence we arrive at the striking conclusion that the presence of developing ovules in the young ovary determines the reaction of the flowerstalk towards gravity."

In these two experiments, we see that the clestruction of a part of a plant changes that co-ordination of forces which produces the growth and controls the movement of the growing parts. When we see the effects of a local injury made apparent in a distant part of the plant, we must believe the living part of the plant to be capable of some action like nervous conductivity. And when we see that the manner of growth and movement is in part dependent upon some localised centre, we are further led to the belief that the co-ordinations of forces in the plant are similar to the nervous coordinations which control the functions of animals.

Other experiments show more clearly the nervous nature of the co-ordinations controlling the activities of plants. They show not only how these coordinations in the protoplasm of the plant react to the external forces, but also how the reaction becomes by repetition ingrained in the living matter of the plant, so that for a limited time after the 
stimulus has been removed the reaction still continues. Such cases are particularly interesting, as they show that a very simple organism without any visible nervous structures, when accustomed to performing certain actions as a result of external forces, will still continue to perform those actions from force of habit, after the external forces have been withdrawn. This is illustrated in the experiments described in the following passages from Professor Detmer's paper. (I begin the quotation with his introductory -remarks, because they seem to me so very significant, and are so harmonious with my own views.) "For many years I have entertained the conviction - which forced itself upon me first in 1876 on the occasion of my investigations of the periodicity of the root-pressure upon the sap - that the phenomena of after-effects or subsequent reactions (Nachwirkungsphänomene) differ only in degree and not in their essential nature from the phenomena of inheritance, - a view which may become the starting-point for investigations of heredity. Of course the after-effects play their part only in the individual life of an organism, whereas heredity stretches out its grasp over the individual life and onward to the next generation; but nevertheless the essential similarity of the two classes of phenomena cannot escape the attentive observer. 
"I will remark beforehand that I pass over here a line of phenomena of after-effects which may be observed in the vegetable kingdom; so, for example, the after-effects displayed in bending upward from the earth, and in the inclining toward the light. When a shoot that has been placed in a horizontal position for a while, still continues its bending growth after it has been changed to a vertical position, we see a simple case of after-effect; also when leaves that have grown in darkness and then have been illuminated for a short time, still continue to grow toward the temporary source of light after it has been removed, we see another simple case of after-effect. Both of these cases may be accounted for by saying that those movements of the plants which are produced by external influences, do not immediately cease at the instant when the external influences are withdrawn, but continue for a certain time afterwards. Other after-effects are of a much more complicated nature. They may, of course, be placed in relation to those mentioned, by intermediate connecting links.

"Let the whole top be cut off of vigorous specimens of Helianthus, Ricinus, Cucurbita, etc., which have previously developed for a long time under normal conditions; then let a glass tube be fastened over the cut end of the stump, and the whole 
object under experiment be placed in darkness with unchanging conditions of temperature and humidity. In this way, as is known, it is possible to prove that the flow of sap, which can now be observed in the glass tube, shows a periodical alternation. The root-pressure does not always drive out, from the cut end of the stump, the same amount of fluid in a given unit of time; but a variation of the sap-flow makes itself apparent in such a way that in general the maximum flow occurs in the afternoon hours, and the minimum flow occurs in the early morning hours. The sapflow may continue for days; and Baranetzky and I each concluded from our investigations of the root-pressure, that the cause of the daily periodicity of root-pressure lies in the daily and nightly alternation of light and darkness to which the plants were exposed before the experiment. In support of this view, for example, is the fact that when the tops are cut off of etiolated plants which have been raised in complete darkness, the sap under the pressure of the roots continues to flow from the stump, but no periodicity can be detected in the flow.

"It is a well-known fact that darkness has a quickening effect upon the growth of plants, while illumination makes the growth slower. When, 
therefore, suitable plants are exposed to the changes of day and night, - the other conditions remaining constant, - if the growth movements of the limbs be measured, it will be found that the growth at night is considerably greater than during the day. Now it is remarkable as Baranetzky has found, that these daily periods of growth do not disappear as soon as the plant is placed in a constant darkness, but on the contrary may be observed for a long time as after-effects.

"By observing the position of the leaves of mimosa pudica and acacia lophanta, it is found that in the day-time they are spread out, but on the approach of darkness they fold their upper surfaces together. The alternating movements which come here into consideration, have their cause in the change in the conditions of illumination. If vigorously developed specimens of mimosa or acacia be brought into constant darkness, the alternating movements continue for days (by my experiments four or five days); the leaves are folded together at night-time and spread out in the day-time. Pfeffer shut off all light from specimens of mimosa in the day-time, but illuminated them artificially all through the night. After a long time, the plants under experiment were brought into constant darkness; then they spread their leaves at evening, 
and folded them together during the day-time, proof enough that the rhythm of the after-effect movements is totally dependent upon the manner of the alternation of illumination to which the plants have been exposed.

"Many of our trees and bushes lose their foliage in the autumn and form winter-buds which do not unfold until spring, and this is evidently a peculiarity of the plants which is originally due to the climatic conditions of our latitude. If a twig covered with winter-buds be cut off in the fall, and the stem put in water and set in a hot-house, the buds will not immediately open as one might perhaps expect, but on the contrary months often pass before the buds unfold. From this it follows that the season of plants can only be considered as a phenomenon which is directly dependent on external conditions. These conditions once certainly determined the growing period of the plants, but this period has gradually become through aftereffects and inheritance, more and more fixed in the organism, until now it is not easily made to disappear. This can, however, gradually occur under the influence of changed climatic conditions. A proof is furnished, for instance, by the circumstance that our cherry has become an evergreen tree in Ceylon." 
These latter experiments bring out a fact of fundamental importance, namely, that in the constitution of the plant there must arise an association between the interval of time and the increase of activity. This association can only be regarded as of an elementary nervous or psychic nature.

The facts in the case lead to the conclusion that the greatest part of the molecular change, which is brought about in living matter by the action of external forces, is that change which occurs in the nervous organisation.

We have seen that the reactions of a piece of metal, under a given strain, are governed by the whole previous history of the metal; and the same we see may be true of organisms. We see that the changes in manner of growth, resulting from changed conditions, have a tendency when long continued, to become permanently ingrained in the constitution of the organism. There are cases where, the previous condition having been restored after a long lapse of time, the changed manner of growth still continued to show itself through several generations: though finally, under the original conditions of the race, in a few generations the normal characteristics of the race reappeared. It is well known that the same varieties of plants - wheat, etc. - germinate and ripen in the short 
summer of a cold climate more rapidly than in the longer summer of a more southerly locality. It has been shown by experiment that if wheat be taken from a southern locality to one much farther north, that the wheat will in a few generations grow and ripen as quickly as the native wheat; and further, if the seed of this same wheat be returned again, and raised in the south, it requires several generations to regain its normal rate of growth. In this case of the wheat, the difference observed in the different localities must be primarily due to a difference in the "forcing" qualities of the season, i.c. the more sudden change of temperature and other seasonal conditions gives a stronger and more effective stimulus, and a gradual change gives a weaker stimulus. However, the chief interest lies in the persistence of the effects. We have only to imagine the peculiar conditions of an environment to have acted for an indefinitely greater time, in order to account for the production of permanent methods of growth which produced the so-called "fixed" or hereditary characteristics of species. 


\section{CHAPTER V.}

NERVOUS ACTIVITY AND ALSO DEVELOPMENT DEPENDENT ON ASSOCIATION AND REPETIIION.

While investigating the causes of evolution it is always necessary to bear in mind the complex character of living matter. We must remember that in addition to those of its properties which may be visibly observed in its natural state and under experiment, and those which may be proved by chemistry, and those which it possesses in common with certain inanimate bodies, it also has one other essential property, namely, that which is expressed in its capacity for development. Not only has this capacity been the sustaining basis of the whole evolution of the various forms of life from the amœboid up to man, but it allows the process of evolution to be constantly repeated more or less imperfectly, - in each individual life. A consideration of protoplasm from this point of view, with a full appreciation of this fact, is necessary to a well-rounded conception of the fundamental 
properties of the "physical basis of life." Some have rather vaguely imagined that this capacity for development was something acquired by natural selection, or that it had originated somehow in the same manner as the generic or class characteristics originate. This supposition, however, lies beyond the limits of legitimate assumption. For if we accept any theory of evolution, we must believe the capacity for development is universal in living matter and co-extensive with life itself. The facts warrant this belief, for even the simple growth of the Protamœba implies some change and adaptation to the requirements of its increasing size,-a change which is development. This capacity for development,- for growth and change and constant repetition, - can be expressed in terms of other and perhaps more familiar phenomena, which may give us more definite ideas of its action, and of the part it plays in determining the particular directions of evolution. It may be regarded as a peculiar impressionability of living matter under the action of various forces.

We have already got some insight into the nature of the action of forces, and their effects upon matter in general : also we have observed the effects of forces of the environment upon living matter. We have seen that all the energy displayed by 
organisms has its source in the food and environment,- except perhaps those primitive forces whose interaction produces the simplest form of life, and which may perhaps be considered as somehow resident in living matter, or as properties of the component elements. But no life can continue, and no life does exist as we know it, without the constant action of forces from the environment.

The energy or combination of forces residing in the embryonic germ, and controlling and determining its development, may seem to be an exception to the above general statement. But the whole history of evolution, so far as it has been interpreted, tells us that this combination of forces, or this potential energy, has been acquired gradually through long ages. The particular form of potential energy which exists in a chicken's egg, and determines into what it shall develop, did not exist in any living thing during the palæozoic era. It must have been acquired by the action of environment upon certain organisms.

In the previous chapter we have seen that forces act upon living matter cliiefly through the nervous system, or where such a structure is absent, the forces affect what we recognise as the nervous state of the organism. We have seen that where the forces of the environment act upon the organs 
of locomotion and nutrition, it is only through the mediation of the nervous system. The nervous system is of all parts of the body the most mobile, and most sensitive to the action force: it controls the nutrition, assimilation, and growth; therefore we conclude that it is through this method of physiological activity which we know as nervous action, that the forces of the environment act upon the growth and development of the individual and of the race.

We may suppose that when the kinetic energy which acts from the environment has once passed the pariphery and entered the mass of living matter, it no longer acts according to the laws of heat or light, or whatever its external form may have been, but, operating upon a mass of different nature, it assumes a new form, and acts according to the laws of nervous activity. Therefore in order to understand the effects of the forces of the environment we must know the laws of nervous activity. For this purpose we must resort to the methods of investigation of modern psychology. It is among the higher animals, possessing well-developed nervous structures, that we must look for the most perfect display of nervous activity. Where the activity is displayed by certain definite organs, we can separate and analyse its phases and investigate its laws. 
Psychological investigation teaches us that for the causes of nervous or psychic change, we must look to the forces acting from without upon the organism. That all of the psychic changes are accompanied by the display of energy in some form of material change in the nervous structures, is the most striking and far-reaching conclusion of modern psychology. All the facts of physics and biology, which have any bearing upon the subject, render it most probable that in the nervous system, as elsewhere, no energy is destroyed and none is originated; no molecule moves without due application of force from without, and the whole mechanism thus moves perfectly subservient to the law of the conservation of energy. Yet we cannot observe the process in exactly the same manner as we observe and test other simpler physical processes. Forces which act upon living matter elude us in the wonderful intricacy of their results.

The general data of Biology go to show that no physical change can take place in a living animal without directly or indirectly affecting the psychical condition of the animal. The psychical change may follow immediately as a sensation, and may remain as a new association in memory, or it may be a subconscious nervous co-ordination; or again the psychical change may be only a gradual change of 
the state of feeling, increasing or decreasing the vitality or general nervous activity of the animal. This statement holds true in so many cases, and in such variety of cases, that it may be regarded as a general law. It means that whether or not the physical change results in any immediate action on the part of the animal, there remains recorded in its nervous mechanism some change that will affect future action, either as memory or as the beneficial result of practising some nervous coordination, thus making future action easier, or else as a generally weakening or intensifying effect on the nervous activity. We know this statement to be true, in cases where the nervous system itself has been affected, and if we believe that the nervous system has been evolved from undifferentiated living matter, then we must accept the statement in its broader application to all living matter.

While we have no exact knowledge of the nature of the molecular changes in the nervous system, nor can we in any instance form a clear conception of how they succeed each other in the sequence of stimulation and reaction, yet still we may gain a certain knowledge of the laws of their operation by studying the psychical changes which accompany the physical changes. We have in our own experience and daily observation a multitude of facts, 
showing the relation and sequence of stimuli, psychical effects, and reactions. Such facts are our knowledge of how we and our fellow-men and domestic animals are affected by all the varied stimuli which constitute our and their environment, causing conscious or unconscious cerebration which may at some time exert a decisive influence upon our movements. That this idea of the operation of energy upon living organisms may be extended to embrace even the material aspect of the higher mental functions, seems to be the conclusion of physiological psychology. Mr. Herbert Spencer has attempted the statement of the case as follows: "No thought, no feeling, is ever manifested save as a result of a physical force. This principle will before long be a scientific commonplace." Professor Wundt, without assuming a causal relation between the two series of phenomena, has given us a better conception, as follows :-

"This is what the analysis of the process of sensation comes to, viz. that logical necessity and mechanical necessity differ, not in their essence, but simply according to our way of regarding them. That which is given to us by psychological analysis as a continuity of logical operations (Schliisse), is given also by physiological analysis as a continuity of mechanical effects (Kraftwirkungen). ... Logic and mechanism are identi- 
cal ; they are both only the form of essentially the same contents (gleichartigen Inhalt)." Thus from the occurrence of psychical changes we may infer the occurrence of corresponding physical changes, even though the latter by their subtlety may be beyond detection by our present means of physical observation.

It is the peculiar property of living matter which we recognise as an elemental nervousness, and which so wonderfully transmits and transforms the forces of the environment, that I hope to show is the basis of that capacity for development which is inherent in all organisms. In order, therefore, to understand the nature of development, we must analyse the fundamental properties of nervous action. In doing this, we need not hope to establish any obscure or hitherto unnoticed nervous property as a cause of phenomena so universal as development, but shall turn our attention rather to properties that are equally universal and apparent.

If we turn to that development with which we are most familiar, and which we can most easily analyse, namely, our own later individual mental and bodily development, we find that it is clue to the effects of repetition of actions and thoughts, and to association of the same. Says Mr. Sully: ${ }^{1}$ "The com1 "Mental Elaboration," Nind, Nu, lx., October, I8go. 
mon maxims of education, - 'Exercise strengthens faculty,' 'Practice makes perfect,' - illustrate this fundamental fact of our psychic life, viz. that the results of our several actions persist, rendering a renewal of these actions easier, and also contributing to the development of higher forms of activity."

How true and universal is the maxim, "Practice" (or repetition) "makes perfect," all will admit ; but a few illustrations will make clearer its bearing upon the present subject. Thus we know that an action, at first extremely difficult, such as fingering a musical instrument, becomes, after long practice, so easy that it can be performed while the attention of the performer is directed to other matters. The successive actions follow each other without separate volitions, and when such a series of actions becomes well practised, it requires considerable effort to omit any one action in the series. Other kinds of actions may be repeated so frequently as to become habitual and be performed unconsciously, as brushing a fly from the face, or smoothing the hair or beard. The repetition of a mathematical solution, or an abstruse train of philosophical speculation, enables the mind eventually to follow the chain of reasoning with perfect ease. All of our actions and thoughts are perfected by repetition, and what at first required a long time for its performance, becomes eventually performed in 
a very brief time. In fact, were it not for the ability we possess to make our mental and corporeal actions habitual and more rapid of execution, life would be too short for us to aspire to more than its bare necessities.

We can observe this principle acting in the growth of habits among animals, especially our domestic animals, with which we may be familiarly acquainted. A young bird's first attempts at flight are very imperfect, but after repeating the action a number of times, perfect power of flight is attained. We find the same awkwardness and inability generally where we see young animals first attempting to co-ordinate their muscular efforts for a definite purpose. The same thing is evident where older animals are placed in new conditions of life, where they are required to attempt entirely new movements. The structure of the nervous system gives evidence that the same state of affairs prevails wherever we find a distinct nervous system; and the fact that all protoplasm partakes somewhat of the nature of nervous tissue, indicates that, throughout the whole realm of life, the performance of an action tends to become more easily and quickly executed by frequent repetition.

The difference in the effort with which an action is performed for the first time, and again after much practice, has its correlative in a difference of nervous 
molecular conditions. The progress of the change may be compared to the wearing away of the roughness of the machinery and the reduction of friction and resistance to a minimum. Also, new arrangement and co-ordination of the nervous mechanisms have been accomplished, for where at first each separate part of an action required a distinct impulse to start it, after practice the whole of a complicated series of actions may be produced by one initial impulse; for example, a trill played on the piano:- just as if at first five impulses had to be sent from the brain to the five fingers, and afterward only one impulse should be sent from the brain to the arm, which should then send on the five secondary impulses to the fingers. The change of structure resulting from frequent repetition of the same series of nervous molecular changes is in general a permanent one; for when an art or habit is once acquired the skill persists, and even after long lapse of disuse is more readily revived, or acquired more readily the second time than the first.

Besides rendering individual actions easier of execution, repetition has the effect of uniting successive actions when frequently performed in the same succession. A series of actions often repeated become thus so associated that when the first action of the series is performed the rest will generally 
follow without any additional stimulus. The frequent repetition of a series of nervous molecular (or material) changes, tends to make the changes in the series always follow each other in the same order. We know, when a train of ideas has often passed through the mind in a certain order, that thereafter those ideas, when the first one has been suggested, will always come to mind in the same order. This is also well illustrated in the case of recalling or humming a tune, - which we may suppose to be correlated with as many nervous molecular changes as there are musical notes. Every one knows how the different notes follow each other, associated together in measures and rhythms. The principle is the same in playing a tune on an instrument where the movements of the fingers follow in regular order. The different movements become firmly associated together. The same is true of a great many kinds of actions performed by artisans and skilled labourers who may be constantly repeating the same series of actions. The arts of knitting and spinning are good examples, as being each a series of actions that can go on indefinitely, while the attention of the operator is devoted to something else.

By the statement that the series of actions takes place without requiring attention, is meant that 
each separate act in the series can occur without a separate stimulus from beyond the local nervous co-ordination which controls the whole series, - so that, after the start, each separate act in the series has a sufficient guiding stimulus in the action immediately preceding. There are many performances where the stimulus of the preceding action is necessary for all but the initial action of the series. In a performance involving a series of associated actions, the performer often finds it impossible to start in the middle of the series and go on to the finish, but must start at the beginning in order to have for each action the guiding stimulus of the preceding action. This is true of players of musical instruments in certain musical passages which are peculiarly difficult of execution. Other performances of manual skill may have the individual movements so firmly associated that they can not be performed properly when separated. Such strength of association seems to have'its counterpart in the nest-building instinct of birds. These, when they find a nest already half-built, do not undertake to finish it, but instead they start a new nest on top of it; or else they tear it down and then start a new nest from the beginning. In the same way they frequently tear down their own half-built work, or sometimes build a second nest 
on top of one that they have already completed. In the case of the musical performer, we know that each individual action in the series must have had its own separate stimulus before there arose any subordinate nervous co-ordination, and also each stimulus must have been practically independent of the preceding action. It was only by the frequent repetition of this series of stimuli in regular order that the subordinate nervous co-ordination was effected, so that finally the initial stimulus in the series of stimuli is sufficient to guide the whole series of actions.

We know that if a certain train of ideas has passed through our minds often enough to become firmly associated, and if then a new stimulus shall call up a new idea at the end of this train, then there is a tendency for that new idea to be added on when next the train of ideas shall repeat itself in our minds. If the new stimulus should call up the new idea at the end of the associated train of ideas several times, then the new idea would remain in that association a long time; but if the new stimulus should never again occur the new idea would gradually fade away. We see how in this way the final parts of an associated series may gradually disappear when their originating stimuli wholly disappear. But it is important here to notice that 
the strength of association alone will retain and hold the idea or action in its place in the series for a long time after the originating stimulus has disappeared. Thus the final movement of a finger, in playing a well-practised trill on a piano, cannot be dropped immediately. It requires a well-directed effort and some practice to get rid of it. Neither can an action be dropped easily from the middle of such a series as we have been considering. The association with the preceding and the succeeding members of the series, is so strong that the middle member can be dropped out only with great difficulty. Another characteristic of such associated series is that the first portion of the series is more strongly associated and more deeply impressed in the nervous structure. This is readily seen when the series nas not been performed for a long time and is weakened by disuse: the first portion is more easily recalled, because, as the series was learned, the first parts were more often repeated, and the final parts were added on gradually one by one. For instance, suppose we have a series of four parts, and let number one be practised twelve times before attempting the combination of one and two; then let the combination of one and two be practised twelve times, and so on with one, two, and three: we see that number one will have been 
repeated thirty-six times before number four has been attempted; and as the performance must always begin with number one, it will always have the advantage of number four by thirty-six repetitions.

These characteristics of nervous action which have been mentioned in the few preceding paragraphs, have a very great importance in organic development. The importance, however, must not be measured by the space here devoted to them. Illustrations of the principles might be multiplied without end, and volunes of detailed facts might be collected as proof; but I believe the principles are so generally known and accepted, that it is sufficient merely to recall them to mind. Their importance consists in the fact that they are not peculiarities of a certain few processes of thought and action, but are universal characteristics of nervous action, so far as we can trace that action; and accordingly they are dependent upon some fundamental property of living matter. As we believe nervous action to be dependent upon the nervous system, so we must believe that the laws of nervous action must be similar according as the different nervous systems are similar. In the gradation of instinct and intelligence which we find as we ascend from the lower animals to the higher, we have a large body of evidence lead- 
ing us to the conclusion that the differences which we find in the nervous action of animals, are differences of degree only and not of kind. The difference lies in the complexity of organisation, and not in the essential properties on which nervous activity is based. We may infer, therefore, that these fundamental properties and laws of nervous activity are the same for all animals which have a nerrous system. As the evolution of nervous systems from undifferentiated protoplasm and undifferentiated tissues, is a corollary of evolution - and we see it occur in the development of each individual - therefore we may expect to find these properties existing in some degree wherever we find living matter. We have already had proof in a previous chapter of the existence in plants of that fundamental nervous property which displays so remarkably the effects of repetition; and we saw also how the effects of the repetition remained for some time after the periodic stimulus had been withdrawn. It may be objected that I have assumed too much in stating that the power of association and the effects of repetition are so universal among organisms, but every co-ordination of movements shows a power of associations; and every animal whose actions are intelligible to us, seems to be able to learn, - and plants show rudiments of the same capacity; i.e. an activity neces- 
sitated in an organism by external influence, is performed with greater facility after frequent repetition than before.

We have learned that each action of an organism must have its sufficient stimulus - meaning by "stimulus," the action of force upon the nervous organisation. We are compelled to this belief by the law of the conservation of energy. No molecular, or atomic change or action can originate itself, but must be part of the universal series of cause and effect. The molecules of an organism must be subject to those laws of molecular mechanics, which, we have reason to believe, apply universally. We must therefore seek the cause of the actions of organisms in all the forces which operate actively on the organisms from the outside, or which may be stored as potential energy within; and this latter potential energy, we must remember, can have had ultimately no other source than the world outside the organism. If we undertake to treat of the forces acting upon organisms and the changes caused thereby, in the terms of force, molecular change, etc., we are quickly brought to a standstill. But if we treat of them in the correlative terms of stimulus, physiological reaction, and neroous or psychical response, we may proceed with some certainty, though not with mathematical accuracy. As every molecular change de- 
mands a sufficient cause in the form of force, so every activity of an organism demands a sufficient stimulus. If, now, we look for the stimuli which produce these activities, we are obliged to include every force that affects the organism; and such forces we must recognise as the causes of the activity, growth, and development of each individual organism, and also of the changes occurring in individuals during the evolution of the species.

Among the countless forces affecting organisms, we find a number which operate alike upon all. These are gravity, light, heat, electrical conditions, and the various combinations of energy comprised under the head of nourishment. To these therefore we may ascribe those characteristics common to all organisms; and to the nourishment especially may we ascribe that amount of energy which is expended in the motion, heat, light, and electricity, produced by organisms. But in so far as these forces are universal, they give us no clue to the origin of the diversity among organisms. The nourishment, it is true, differs in different organisms, but this seems a secondary rather than a primary cause of diversity. Evidently, then, it is to the varying conditions and quantities of the above-named forces acting as stimuli, and also to the great number of those particular stimuli which are always peculiarly affecting 
each individual, that we must look for the causes of the diversity of form and habit among organisms. The action of these stimuli is cumulative in its effect. After a stimulus has acted upon an organism, and the organism has returned to what is called its "normal condition," we must not suppose that the second normal condition is the same as the condition of the organism before the action of the stimulus; for the stimulus has caused a molecular change, and this change persists until some other force undoes it or intensifies it. The viscous living matter retains its impression, and is more impressionable than a solid body, of which Professor Maxwell has said, "the stress at any given instant depends, not only on the strain at that instant, but on the previous history of the body." When a stimulus has acted upon an organism, and called forth a responsive change or action, then at the second time that stimulus acts, and the third time, and always afterward, the tendency is to produce the same response. If we were now to take account of all the stimuli acting on an individual during its lifetime, we would find that the vast majority of them are constantly repeating themselves. By observing the world around us, we see that in the lives of animals - man included - each day is very much like the day before. The stimuli and their responsive 
actions form themselves into recurrent sequences, repeating themselves in groups with an established regular order in each group. Those stimuli, arising from chemical-changes in the process of nutrition, are always present; and though they have their variations, yet, in the healthy organism, they remain generally the same, save that they are subject more or less to recurrent periods of greater intensity. The stimuli causing muscular motion, or protoplasmic contraction, are also frequently repeated. In the animal kingdom, the muscular motions on which the life of the individual depends, are repeated daily and many hourly or even momentarily. Even the stimuli causing the process of reproduction are, in most animals, repeated many times during the life of an individual.

We have already observed it to be a nervous property of organisms, that a series of actions frequently repeated tends to become more and more readily performed. The repetition of the series establishes a co-ordination in the mechanisms governing the actions, so that each action seems to have some guiding stimulus in the action preceding; and though some of the stimuli which were originally necessary to the separate acts of the series may be withdrawn, yet under the influence of the remaining stimuli the whole series will be executed with its usual regularity. Series of actions 
frequently repeated become fixed in their relation to each other, and though the stimuli may vary slightly from what they originally were, yet the original series of actions will still result. The variation of the stimuli, however, if constantly repeated, finally makes itself felt in a variation of the actions of the series.

Professor Jos. Jastrow has recognised this law of nervous action of which we have treated in this chapter, and he has excellently described it as what he calls the law of habit. "This law declares that every reaction of an organism to a condition in its environment renders the repetition of that reaction quicker, easier, more certain, more uniform; and the existence of habits implies an environment sufficiently constant to repeatedly present to the organism the same or closely similar conditions. Mere existence in a world so full of regularities, of rhythm and law, of recurrence of the same needs, results in the performance of definite actions in definite ways; and it equally results that the earliest experiences will produce the strongest impressions, and will gradually render more difficult the learning of other modes of reaction, even though these others, owing to a change of conditions, would be more useful." 1

1 "Problems of Comparative Psychology," Professor Jastrow, Popular Science Monthly, November, 1892. 
If we could imagine an organism possessing the fundamental nervous properties described in this chapter, yet coming into existence with no inherited potential energy in shape of co-ordinations or tendencies, we could understand how, during an endless existence under the influence of stimuli of environment, it would acquire great facility of reaction to its every-day surroundings. It would acquire coordinations which would affect its entire life-activity, and thus influence its manner of growth and development. A change in the environment entailing new stimuli would effect after a while new co-ordinations, and lead thus to new directions of growth. 


\section{CHAPTER VI.}

THEORY OF DEVELOPMENT AND HEREDITY ILLUSTRATED AMONG PROTOZOA.

After we have made full allowance for the action of stimuli on an organism during the period of its growth from inception to maturity, and have allowed the great importance and necessity of this action to the developing organism, there still remains unaccounted for a sum of forces which are innate in the organism, and which determine its essential nature and specific character. The question arises, what is the origin of those innate forces which determine whether a developing organism will be a horse or a dog? If we accept evolution, even in its simplest form, we must believe that the peculiar co-ordination of forces necessary to produce a horse, could not have existed before the appearance of vertebrates on the earth. If the continuity of life remained unbroken, the co-ordination of forces which produce the horse, must have been gradually acquired by living matter in the long 102 
course of its unceasing development. Suppose the vertebrates to be descended from worms, then in like manner the co-ordination of forces necessary to produce a worm must have been acquired, and so on, back to the simplest form of living matter. The raw energy, and matter in a crude state, we may suppose to have existed anywhere at any time, but the co-ordinations of forces necessary to produce a vorticella, a worm, a fish, or a horse, have been acquired by the primitive form of living matter by a long and slow process. It must have been a series of causes and effects according to laws, with no fortuitous variations, - a process that acted in the living continuity of organic matter, without regard to the destruction of the "unfit" or the lopping off of side-branches of development.

This constant acquirement of new co-ordinations of directive forces, indicates a universal capacity of development, showing itself at every step in the long course of evolution and co-extensive with life itself. This capacity is that which makes possible every new variation and every advance in development. We are compelled to believe that it was present in the archaic protoplasm, the first living matter on the globe, just as much as in the living forms of to-day. If we seek to know this capacity in other terms, we can only ascribe it to the un- 
stable, impressionable constitution of living matter, and to the effects of repetition known as retention and association. An examination of the general method of development shows that it is everywhere the perfecting of a process by continued repetition of the process.

In nature we find that no individual organism acquires any of its parts or organs suddenly and in their full perfection. Each organ or part is the result of slow growth, and develops gradually from the imperfect to the more perfect state. Moreover, in tracing the course of evolution, we find the same law to be true of the appearance of organs in the species or class. The organs do not appear suddenly as new and perfect parts in any one generation, but they are the product of the long process of graded development through many generations. The proper development of each organ, and the function of the organ, are inseparably linked and interdependent on each other- The function must have a controlling effect on the development of the organ, and vice versa the structure of the organ must limit the function. It follows, therefore, that both in the individual and in the race, the organ and its function have been gradually perfected. Take, for example, the function of an organ like a leg or wing, which 
requires the co-ordination of the movements of several muscles. The nervous co-ordination necessary to perfectly regulate such muscles so that each shall act in its required time, and in proper succession one after the other, can only have been perfected by practice in the individual, and therefore by practice in the race. One of the effects of this practice has been an association of primarily independent activities, - subconscious nervous association similar to mental association. This association we must suppose to be a new arrangement of the nervous elements, whereby actions formerly independent should always occur most readily in a certain definite relation to each other. In this way only can we picture to ourselves the origin of such complicated muscular movements as the rhythmic beating of the heart, the origin of the mechanism by which the equilibrium of a living body is maintained, or the origin of any bodily agility or manual dexterity. It must be regarded as a universal property of living matter, that the effects of its activity are perpetuated in itself as the perfecting results of repetition, and as association, - the activity itself being caused, as we have seen, by energy absorbed from the environment. The effects, also, of organic activity, of practice and repetition, must, in some way, be transmitted from generation to generation. 
Let us now attempt to apply these general principles, and try to explain the development of a hypothetical first organism; for, since the state of living matter is dependent on all its past history, we must naturally begin at the beginning in order to explain the changes which living matter has undergone. It is possible in this way to illustrate the theory by a typical case, if we carefully keep within the limits of the general principles of evolution, as it may be inferred from the visible organic world and the traces of its past history. Let us imagine an organism, consisting of a simple, undifferentiated mass of protoplasm, to have come into existence without any inherited powers or tendencies. There are no nervous co-ordinations or associations. All of its movements and reactions are dependent merely on its chemical and physical conditions and upon the forces which affect it. In the first instant of its existence, this highly sensitive and mobile organisation of matter is subject to the action of a variety of forces. There are the forces of pressure exerted by the medium in which the organism lives, and by the supporting body upon which it rests. There are also the forces exerted by things brought into contact with the organism by movements of the surrounding medium. Some strike or press against the outer surface of the organism. Others are forced into the 
soft mass and dissolved; and if they be of a certain chemical composition, operate as nutriment, and liberate new forces internally or add to the potential energy of the living mass. The forces of light, heat, electricity, and gravity, all act upon the organism. To all of these forces the living mass reacts in a purely mechanical fashion. The reality of the effects of these forces upon inanimate matter is well known, and living matter, as we have seen, is also affected by them. The effects upon living matter are much more complicated than upon inanimate matter. This is due to the peculiar constitution of living matter, it being a viscous, semi-fluid mass, composed of a physical mixture of water and various chemical compounds of varying degrees of density and viscosity.

Under the continued action of the forces of the environment, the mass of living matter, like all other bodies, tends to attain a state of rest. In the nature of things, however, this equilibrium toward which the organism and its environment are tending cannot be attained, for the reason that the environment does not remain the same, but is continually changing. There is an alternation of day and night, light and darkness. The energy of the sun causes changes of temperature and of density in the medium in which the organism exists, be it either air or water. These changes of temperature 
and density cause currents in the medium. Surrounding objects are set in motion, and perhaps the organism itself is moved about. Some of the forces which act upon the organism are constant; such are gravity and the pressure of the medium. Other forces are regularly periodical, as the light and heat of the sun. Still other forces are intermittent and irregularly periodical, such as the contact and collision with surrounding bodies, the impulses that shove and transport the organism, and the contact with particles of nutriment. Some of this last class of forces may act very rarely, others at lesser intervals, and still others will act very frequently. Each of the forces which act upon the organism - be it constant, regular, or irregular - will produce its own peculiar mechanical reaction in the mass of living matter. Thus some of the reactions will be repeated at regular intervals, others will be repeated irregularly with greater frequency. In order to understand the effects of this repetition, we must recall to mind that peculiar property of living matter which we have called elementary nervousness, which makes possible and necessary the formation of co-ordinations and associations as the result of repetition of the necessitated reactions. As already pointed out, this property seems to be coextensive with organic life, and we must therefore give it 
due weight in estimating the effects of environment upon our hypothetical organism.

The forces of the environment have produced a deeper effect than we could detect from a physical point of view by a purely physical analysis. We know as a general fact that each reaction of a nervously constituted body produces an enduring effect within the body. Each separate action of force, or each stimulus, causes its peculiar mechanical reaction. Each sequence of stimulus and reaction will have its effect upon the nervous molecular condition of the organism; and the more often the sequence is repeated, the more marked will be the effect. With frequent repetition, the response comes more easily and more quickly. Should any of the stimuli form a regular series frequently recurring, then the series of reactions, often repeated, become associated together by co-ordination of the nervous elements. Because of this association, all of the reactions in the recurrent series tend to occur together. Each reaction of itself tends to produce the succeeding reaction. Thus several reactions in a series might ensue upon the action of a single stimulus. For example, let us suppose a nutritious particle to be borne by the current toward our first organism. The molecules which separate from the nutritious particle as gas will be the first to strike the organ- 
ism, and stimulate as smell; next, the particle itself strikes against the organism, and there is a stimulus of contact; then the process of absorbing - caused by contact, capillarity, etc. - brings the protoplasm to flow toward and around the particle. Thus the sequence of reaction is first smell, then contact, and then movement in the direction whence the smell and contact have come. If this simple sequence were repeated often enough, an association of the reactions would arise. This association might eventually become so strong - through repetition - that the movement in the direction toward the gaseous effluvia might follow after the smelling, even when the stimulus of contact did not occur. We can thus imagine how the co-ordinations arose which control the search for food and locomotion.

Let us suppose, further, that owing to scarcity of food or to increase of size, the organism is stimulated to movement by hunger, or perhaps by asphyxiation caused by remaining in water fouled by its own carbon dioxide. The loss of food and oxygen would cause a stoppage in the natural chemical change going on in the mass; thus there would be a disturbance in the inner equilibrium of forces, which might readily cause slight movement in different parts of the soft mass. The hunger and dearth of oxygen would probably be conditions frequently 
repeated. At any rate, there would be almost constant variation in the chemical changes of the protoplasm. Thus after each movement of the protoplasm, the stimulus remains to start a new movement. By constant repetition of the reaction, nervous co-ordinations would be formed and perfected, so that movements at first slow would become more and more rapid, until they finally resemble a tetanus, or else the quick movements of the cilia or flagella of the infusoria. Some of the shell-amobæ make movements intermediate in form and rapidity between the ordinary slow amoboid motion and the quick motion of the flagellum of an infusorian. Any movements of the body would thus constantly tend to become a means of locomotion.

The periodical and occasional stimuli acting on an organism so primitive would necessarily be of few kinds. The same stimuli and series of stimuli would be frequently repeated. Those which were repeated most frequently would of course have the greatest effect, while those that occurred very rarely would have little or practically no effect. In the course of time, therefore, as this process of repetition goes on, the organism would acquire a facility of reaction due to nervous co-ordinations. In these nervous co-ordinations we see a development caused 
by the forces of the environment acting upon the organism. This development is also an adaptation, inasmuch as it enables the organism to perform more readily those actions which the environment makes necessary for its existence.

It may be objected that the stimuli are too few in number and too constantly the same to produce any such variety of form and habit as is found even among many unicellular animals. But if we consider the matter more closely, we shall see that there is an inevitable gradual change in the influence of the stimuli, and that this change induces new effects, and opens the way for new stimuli to an almost infinite degree. Let us follow our hypothetical organism a step farther. By the assimilation of new particles of matter the bulk is doubled, and the mass is increased more rapidly than the surface. The amount of oxygen necessary for the life of the protoplasm increases as the mass increases; but the amount of oxygen that can be absorbed from the surrounding medium increases only as the surface of the protoplasm increases. Therefore in the process of growth the mass would at some time become too great for the amount of oxygen that can be taken in by the surface. The result would be the asphyxiation of the interior part of the mass of protoplasm. In the movements 
caused by this constant and severe stimulus, we may suppose the organism to have extended itself to the utmost in different directions, - for the less spherical its shape, the greater its relative surface, - until finally the protoplasm parted and segregated in two masses. This is the first step in the multiplication of individuals. The two masses of protoplasm are each of the same size, we will suppose, as was the original mass at the beginning of its existence. They are each, in the moment when they come into existence, subjected to the same permanent stimuli of the environment as acted upon the parent at the beginning of its existence. Also the occasional and periodic stimuli act upon them in the same manner as they acted upon the parent. Therefore, as a result of this similarity of conditions, the two organisms naturally follow the same course of development that was followed by the parent organism. But there is this difference between the parent and progeny: the two of the latter generation are, at the first moment of their existence, composed of protoplasm that has already reacted many times to all the stimuli that affect it. Once before it has been of the same size, and has responded to the same constant and periodic stimuli that affect it now. As those stimuli determined its growth then, so they determine it now. Owing to 
that associative property of protoplasm which we have discussed in the previous chapter, the reactions to stimuli, i.e. the growth or development, take place the second time more easily and more rapidly than the first time. Therefore, during the second cycle of life, this unbroken continuity of protoplasm, which now forms the second generation, would form its coordinations more easily and more rapidly. The reactions and co-ordinations of the first organism have left their impress upon the protoplasm, and this impress affects the development of the second generation. In the third and fourth and every succeeding generation we have a repetition of the entire process of development. This repetition tends to perfect the process of development, - to make it occur more rapidly and more easily. It tends to combine the reactions which we call growth and development in an indissoluble chain of association; and it tends also to make those reactions always the same.

The same permanent external forces acting upon an organism affect it differently at different periods in the development of the organism; for, though the forces themselves remain the same, they will necessarily produce different results in the organism as the size of the latter increases and as the complexity of its co-ordinations increases, i.e. as the internal 
conditions become more complex. We must bear in mind that all changes in the constitution of the organism are the result of the action of forces which are too numerous and intricate for us to follow. The illustrations here given, however, will show the nature of their action. Thus we see that, during the course of life of an individual, both the constant and periodical forces acting upon it produce a gradually changing series of effects, as the state of the organism is gradually changed by its continued reactions. These unchanged forces act as a gradually changing series of stimuli, and the life of the organism is thus a gradually changing series of reactions. The reactions follow each other in a certain regular order, as the organism changes in size and complexity, and they are the same in each succeeding generation. When the same protoplasm, or continuity of protoplasm, has repeated this series several thousand times in as many generations, we can easily understand how all the successive reactions in the series become so firmly associated and co-ordinated that they all tend to follow the first stimulus, even though many, or even half, of the succeeding original stimuli remain in abeyance.

Suppose all the forces of the environment to remain the same for a great length of time. As each generation differs from the preceding generations in the 
number of times it has reacted to the series of stimuli which make up an individual life, the conclusion follows, that in the latest generation the associations will be strongest and the co-ordinations most complex. This latest generation, owing to its more complex constitution thus acquired, will be affected by the same unchanged forces in a manner slightly different from the manner in which each of its predecessors was affected. The repetition necessitates that there will be a new element-i.e. the change in the internal resistance-added to the stimuli affecting each successive generation. The same unchanged forces of environment tend thus to produce new effects and increase the complexity of constitution in each generation.

As the difference between two successive generations depends on the fact that the later generation has performed the series of reactions constituting development one time more than the preceding generation, it is evident that the difference between the two will be most pronounced when the later generation has almost finished its round of developmental reactions. Therefore at this period in the life of the second generation, - when the organism is approaching maturity, - the element in the stimuli which is caused by the change in the relation between the unchanged external forces and the 
newly added increase of internal complexity, will be most effective in producing new features of development. This explains the general fact in the organic world that new variations of growth in organisms appear, as a rule, about the time when the individual completes its ontogenetic development, - after the ancestral or generic characteristics have developed. It would be difficult to determine to what extent an unchanging environment can produce changes of development in a long succession of generations, according to the principle under discussion. Unless we disregard the most general conclusions of Physics, Biology, and Psychology, we must believe that some change, however small, is produced in this manner in each generationjust as we must believe that even the first revolution of a steel shaft contributes its share toward causing the changes which, after many millions of revolutions, become apparent in the crystallisation and breaking of the shaft.

While we might suppose a certain amount of development to take place in an unchanging environment, yet, as a matter of fact, all environments change. Carrying analysis to the farthest limit, we find that a changeless environment does not exist; the planetary motions and the transmutations of solar energy are factors of constant change, and from these and 
other causes arise a constant succession of changes in the environment of organisms. Thus the combination of forces acting upon all organisms change more or less slowly. Thus the relation between the external forces of environment and the internal forces of the organism is changed; and some new adjustment of the structure and condition of the organism must be the result. As a species of organisms develops into more highly organised and more complex beings, the later generations will come under the influence of new stimuli occasioned by their own wider range of activity. New stimuli of this kind, too, can be effective in producing new developments only after the individuals of each generation have attained, in their ontogenetic development, to that degree of growth which brings them into contact with the new stimuli, _ just as a child cannot be developed by practising the physical and mental pursuits which are necessary for the development of a young man. New stimuli, thus brought to bear on an organism, are effective only toward the end of the already acquired course of development.

The course of development may be summed up as follows: the primitive mass of protoplasm with which we started acquires nervous co-ordinations which influence its activity and growth; as it divides 
and redivides, it adds continually new co-ordinations to those already acquired; the process of growth and development comes by repetition to have the character of reflex action, - becomes more rapid. As the same forces act on each generation, and form a series of stimuli which are similar for each generation, so each generation repeats in its life the course of development followed by all its ancestors; or, more concisely, the continuity of the protoplasm repeats in each generation the same series of reactions to stimuli that it has repeated, with additions, in each previous generation since it began its existence. We have here the explanation of growth, development, and inheritance. The illustration just given shows how fundamentally the three are related in their nature, being in reality only different phases of one process. 


\section{CHAPTER VII.}

APPLICATION OF THE THEORY TO MULTICELLULAR ORGANISMS, AND THE RELATION OF THE GERMCELLS TO THE BODY.

IF we admit the efficacy of the causes of which we have been treating, and believe that they have acted in the described manner so as to produce the diversity noticed among the single-celled protozoa, and also to account for the simple phenomena of heredity among them, then we are immediately led on to inquire how a theory, which may be plausible in regard to organisms composed of single cells, will appear when applied to those organisms which are each composed of many cells. Evidently, if there be a physiological difference between the many-celled and the single-celled organisms, their organic phenomena cannot be explained by the same theory. There has been a general impression among biologists, that the dividing line between the metazoa and the protozoa is peculiarly unique among all the divisions in the classification of organisms, and that it indi- 
cates a profound difference of constitution between the two groups. The importance of the division, from a morphological point of view, in its bearings on the cell theory, has, I think, led to the assumption of a physiological importance which has no sure foundation; for the assumed difference seems to be based wholly on morphological evidence, whereas what physiological evidence may be obtained points to a physiological similarity between the two groups. Thus, as nearly as can be ascertained, they have each nearly the same chemical elements for the basis of their composition; the general phenomena of nutrition are the same; they each alike react to anæsthetics and various physical and chemical stimuli; they each have the power of separating off a small portion of the substance of their body, and thus reproducing their kind. The prevailing difference which is generally agreed to exist between the two groups is, that in one case the protoplasm composing the body is intersected by the cell walls, running in all directions, while in the other case there seems to be no partition of the protoplasm ; and this continuous mass of protoplasm, which composes the entire body of one of the protozoa, is considered as equivalent to one of the cells of a metazoön. In the simpler forms of the metazoa, each cell has a nucleus; in the more complex of the protozoa, a single- 
celled animal may have several nuclei. Thus we see that the nucleus affords no basis for the assumption of such a profound distinction between the two groups. The presence of cell walls seems, therefore, to be the one distinguishing characteristic separating the metazoa from the protozoa. This characteristic, however, loses much of its importance in view of certain conditions obtaining among the protozoa. If we examine a Radiolarian, we find that its protoplasm is not perfectly homogeneous; it possesses a skeleton, which is partly internal, and this makes certain divisions in the protoplasm. Actinosphæra, which has no hard skeleton, has its protoplasm divided by membranes, in the form of concentric spheres, and intersecting radial planes, thus forming a true cellular structure, except that a nucleus is not present in every cellular space. I have seen a green zoöspore of $\mathrm{E}$ dogonium being digested in one of these cellular spaces of the Actinosphæra, and observed, after the chlorophyl bodies were broken down, and when the green mass of the zoöspore seemed completely dissolved in the protoplasm of the Actinosphæra, that the green colouringmatter fillee even into the corners of the cellular space, but did not penetrate beyond the membrane which limited it. We find here, among the Radiolarians, a plan of structure closely approaching that 
of the metazoa, and the reason for it seems to be not far to seek; for an animal as large as Actinosphæra, composed as it is of protoplasm, which is externally fluid and radiating, could not maintain its spherical shape without the support given by the intersecting membranes inside of it. This seems to be the primary function of cell walls, wherever we find them. No animal could attain to any more than a microscopic size, and possess any permanence of shape or rigidity of body, without the aid of cell walls; and we find in the simplest of metazoa, and in the simplest tissues of all metazoa, that the cell walls form an indispensable means of support. Wherever we find them, they are the means of support, and, in comparison of their supporting function, their function in limiting physiological activity sinks to a secondary importance. Among the protozoa, portions of protoplasm, which are not separated from each other by cell walls, perform separate functions, - as, for instance, the digestive and contractile parts of a vorticella, - thus showing that a physiological limit and a cell wall are not identical. Neither must we suppose that the many-celled animals are of a higher grade of complexity than the single-celled animals, for - leaving sponges aside - none can maintain that the sluggish Hydra is a more highly developed organism than the graceful Stentor or Paramocium, 
with their differentiated cilia, œsophagus, pulsating vacuoles, etc. We may therefore conclude that there is no justifiable ground for the assumption of any fundamental physiological difference between the protozoa and the metazoa, other than that difference caused by the greater size of the latter, and its consequent necessities of mechanical support. We are accustomed to consider the universal phenomenon of an embryonic organism passing from a unicellular to a multicellular stage without thereby inferring a radical physiological change. In the words of Professor Whitman, "the fact that physiological unity is not broken by cell boundaries is confirmed in so many ways that it must be accepted as one of the fundamental truths of biology."

It may be conceded, therefore, that such an animal as Hydra possesses its cell walls chiefly for support, that its protoplasmic continuity is unbroken, and the effects of irritability may be transmitted from any point to all parts of the animal; in short, that its physiological unity is complete. If we turn from the simpler forms of the metazoa to the more complex forms, we find a different condition of things. A mammal, for example, is composed of a variety of organs which make up an individual. These organs are separate from each other to a 
high degree of independence morphologically, and are different both in tissue and in function. It is difficult at first glance to conceive how the results of irritability and sensibility can be transmitted from one organ to another so perfectly as in the case of Hydra or the single-celled organism. But we find that all the organs of the mammal are united by particular nerve-tracts to a central nervous system, which is affected by nervous impulses from every part of the body, and in its turn is capable of affecting every part of the body. To make good the comparison between the Hydra and the mammal, we must try to conceive how the nervous system of the latter has been evolved from the generally unstable condition of the former, and for this I think no other explanation can be given than that usually set forth, - to the effect that nervous molecular impulses passing through a body would seek the channels of least resistance; by repeatedly passing through the same channels they would cause a differentiation of the tissue, thus forming definite nerve-tracts. Whether we refer it to the principle of natural selection or the principle of improvement by repetition of action, in either case the facts warrant our conclusion that the complex nerve-tracts perform their office more perfectly than the undifferentiated body tissue. In 
such an organism as the Hydra the effects of irritation spread in circles from the point stimulated, whereas in the mammal they are carried in definite channels to the nervous centre, and from there transmit their effects throughout the body, the nervous centre acting like the banker's clearinghouse in adjusting the balance of credit. Thus we see that the physiological union between the parts and organs of a mammal is as complete as the union between the parts of a unicellular organism. There is no reason to suppose that a change can be produced in one part of a multicellular organism without affecting in some way the entire organism.

But there remains a difference between the unicellular and multicellular organisms in regard to reproduction and inheritance. In the first the organism simply divides into a number of pieces of protoplasm, and each piece possesses the character of the entire mass. In the second, particles of protoplasm are separated off from the organism and continue to live and grow into new individuals, while the main body of the parent organism remains unchanged for a period, and then dies. An understanding of this phenomena is best obtained by following the generally accepted view that the metazoa are descended from the protozoa. The course of this evolution must have been something 
like the following hypothesis: The single-celled organism, by means of frequent repetitions, in the course of generations began to attain a larger size, and then to differentiate its external surface into a denser protective layer - the result of stimuli of contact. When such an organism as this would be divided into a number of pieces by the natural process of reproduction, those parts of the protoplasm which had not undergone a grosser material differentiation would be like the protoplasmic germs of all its ancestors, and capable of responding to the same stimuli, and therefore of developing in the same manner. The only difference between these and the ancestral germs would be the increased complexity of their nervous co-ordinations, as was pointed out in the previous chapter. But, on the other hand, the part of the organism which has been differentiated into the denser outer layer would be in structure so different from the germs of the species that it would be incapable of responding to any of their accustomed stimuli, and therefore incapable of repeating the development; but if some of the protoplasm remained within the denser protective outside layer, it might continue to live, thus continuing directly the life of the old organism. If all of the organism should be developed into highly differentiated parts or organs, and no part of it be 
like the original germ-like form, then the process of its development could not be repeated and its regeneration would be impossible. But at every step in the evolution a part of the protoplasm retains its original qualities, only changing its nervous condition to a condition of greater complexity of co-ordinations. In this way the original protoplasm gradually adds to itself the co-ordinations for developing in each generation, first cell walls, and then differentiated organs. Thus are produced parts which cannot subdivide in particles, and cannot, by reacting to the external forces, repeat in each particle the development of the species. The differentiated organs, for some essential reason that we will consider later, have not the power of enduring indefinitely, and therefore together form that part of the organism which dies. At one extreme of the scale we see the new-born protozoa bursting and casting off the dead membrane which protected the protoplasm during the period of "rest" or incubation; at the other extreme we see the body of an animal die long after it has ceased to produce young.

Professor Weismann has recently advanced a theory of heredity, in which he holds the view that the changes which occur in the body (soma) of an individual cannot affect the germ-cells. This view is 
so opposed to facts which show a most intimate vital relation between the body and the germ-cells, that I think it would never have obtained credit were it not a part of a theory which was developed with great ingenuity, and which was partly based on the profound truth of the continuity of the co-ordinations of living matter.

Professor Weismann has regarded the germ-cells as parts upon which no molecular change could be induced from without. All protoplasmic motion is generally believed to be due to molecular changes, and Professor Romanes has shown that in the undifferentiated tissues of the jelly-fish, an irritation at one part causes movement (molecular changes) to be propagated throughout the mass. We would be unable to imagine the evolution of nerves, did we not assume that all living matter possesses to some degree the property of transmitting nervous molecular changes; and wherever vital communication exists between two parts, it must be possible for molecular changes in one part to induce molecular changes in the other. The evidence on this point is somewhat obscured by the general presence of special nervous courses, yet the evolution of nerve courses compels us to the conclusion that their properties exist in some degree in the undifferentiated tissues, as in the case of the jelly-fish, where 
the nerve courses had been removed. The sensitiveplant is a notable instance of this transmission of molecular change from one point to another without the aid of nerves. There is, further, some ground for believing that a molecular change may be transmitted even where there is no vital connection between the parts. This seems to be the case in several observed instances, where the protoplasm of the egg-cell becomes unusually active at the approach of the spermatozoön, yet before the latter has touched the outer surface of the egg. Also, we have the well-known case of certain conjugating algæ (e.g. Spyrogyra), two cells of which, though not touching each other, are seen to exert a mutual influence, causing outgrowths of the cell walls of each cell toward the other, and inducing at the same time a peculiar molecular condition of the protoplasm. Some psychological investigators claim that molecular changes can be transmitted from one organism to another through considerable distances of space where there is no vital connection. ${ }^{1}$ Hence it seems not only unnecessary to suppose that the changes in the body (soma) of an animal cannot change the molecular condition, or nervous co-ordinations, of the germ-cells, but rather, it seems impossible that the somatic changes should not affect the germ-cells.

1 See Reports of British Association for Psychical Research. 
The effect of changes in the body upon the germcells is a subject at which we can only arrive by indirect evidence; but when we come to examine the converse of the proposition, the effects of the germ-cells upon the body, shown by their presence or absence, a mass of direct evidence lies at hand. It is a matter of almost universal observation. The removal of the germ-cells seems to affect profoundly the constitution of the animal. If the operation be performed on a cow at a period of full flow of milk, the secretion of milk is said, in some cases, to become permanent. If performed on a very young cow, the growth becomes more rapid and the beef will be more marketable. It might be supposed from this that the germ-cells act in some way as secretory glands, diverting nutriment from the body; but that this is not their only nor their strongest action is shown by the marked change of instinct caused by their degeneration or eradication. In his book, Animals and Plants under Domestication, Darwin speaks as follows on this subject:-

"It is well known that a large number of female birds, such as fowls, various pheasants, partridges, peahens, ducks, etc., when old or diseased, or when operated on, assume many or all of the secondary male characters of their species. In the 
case of the hen-pheasant this has been observed to occur far more frequently during certain years than during others. A duck ten years old has been known to assume both the perfect winter and summer plumage of the drake. Waterton gives a curious case of a hen who had ceased laying, and had assumed the plumage, voice, spurs, and warlike disposition of the cock. When opposed to an enemy, she would erect the hackles and show fight. .. . The females of two kinds of deer, when old, have been known to acquire horns; and, as Hunter has remarked, we see something of an analogous nature in the human species. On the other hand, with male animals, it is notorious that the secondary sexual characters are more or less completely lost when they are subjected to castration. Thus, if the operation be performed on a young cock, he never, as Yarrell states, crows again; the comb, wattles, and spurs do not grow to their usual size, and the hackles assume an intermediate character between true hackles and the feathers of the hen. Cases are recorded of confinement, which often affects the reproductive system, causing analogous results. But characters properly confined to the female are likewise acquired by the male; the capon takes to sitting on eggs, and will bring up chickens; and what is more 
curious, the utterly sterile male hybrids from the pheasant and the fowl act in the same manner, 'their delight being to watch when the hens leave their nests, and to take on themselves the office of a sitter." "1

When we consider these facts and remember how large a part of all the instincts and activities of animals are dependent upon the influence of the germcells, it seems highly probable that the growth and activity of an animal should exert a retroactive influence on the germ-cells.

In most animals the period for the ripening or maturation of the germ-cells is determined by the changes of season - influences which can only affect the germ-cells through the medium of the body. Finally, since the germ-cells possess the potentiality of producing all the nervous and mental traits of the body from which they are derived, we cannot suppose them utterly disconnected from the nervous system and inaccessible to its influence. There seems to be a most profound and intimate connection between the two.

We find, therefore, no essential difference between the development and reproduction of the protozoa and the same process among the metazoa. If inheritance of acquired characters be admitted for

1 Vol. II., pp. 26, 27. 
unicellular organisms (and I can conceive no other reasonable interpretation of the facts), then the same must be admitted for multicellular organisms. For, in neither case, is it a process dependent on the malleability or plasticity of the body or soma of the organism; but it is a process of acquiring new nervous co-ordinations, - just as it is a chiefly nervous difference which we observe to exist between the amœba, with its slow pseudopoda, and the infusorian, with its quivering cilia. 


\section{CHAPTER VIII.}

THE INHERITED IMPULSE OF DEVELOPMENT, OR TENDENCY OF GROWTH.

WE have seen that the process of development of living things was somewhat as follows. The first living matter was subjected to a variety of constant and intermittent forces, and frequent action of combination of forces. These caused mechanical reactions. Repetition made these reactions more rapid and easy, and association combined them into reflex series of co-ordinated actions. For the most part, these forces acted on the living things in monotonous rounds of repetition, which would have admitted of no change in the individual were it not for two peculiarities of living matter. First, the process of assimilation caused an increase in bulk; and second, the constant repetition of reactions caused by association an increase in the complexity of structure of the paths through which the forces expended themselves in the organism. The repetition and association developed the nervous elements into 
combinations and co-ordinations which were always becoming more and more complex. In the interaction of the environment on the individual, the environment always remained the same, but the individual was constantly changed by the action of the environment as each new development in the individual brought it into a new relation with the environment. Thus the life of the inclividual would consist of constant growth and development.

When now a small part of the living matter of this individual separates from the main mass and begins an independent existence, it cannot continue the progress of development without a break; for, owing to its small size, and perhaps its lack of certain organs, the forces of the environment do not act upon it in the same way as upon its full-grown parent, and so the reactions of the small germ cannot be the same. But the environment must act upon the small germ almost exactly as it acted upon the parent at that time when the parent was a small germ of similar size and conditions. Thus the second individual would follow almost the identical course of development that the parent followed, and so on, generation after generation. The continued sameness of environment is the cause of the similarity of successive generations.

The unbroken continuity of living matter thus 
expands itself and goes through the same series of activities in each generation, - activities which are familiarly classed as the phenomena of birth, growth, and development. This repetition has the effect of making the processes easier and more rapid, and by association they become interlocked as links in a chain of events which make up the life of each individual.

Reasoning from analogy and the general principle of evolution, we may suppose the first living matter to have made only the simplest mechanical responses to stimuli; but as the effect of each repetition of the same actions impresses itself on the living matter, the latter becomes more complex with each repetition, and thus we can imagine how, with the increasing complexity of living matter, there arose a correspondingly wonderful complexity of responses to stimuli.

As the round of activities which make up the life of each generation is constantly repeated by each generation, it follows that the continuity of living matter must become more and more complex; that is, the associations of actions - both animal and vegetable processes - become more strongly bound together and fixed in relation to each other. As each generation, therefore, possesses a greater complexity of structure than the previous generation, so 
each generation will present new characteristics to be acted upon by the forces of environment. Thus, though the environment remain the same, the simple continuance of a race is continually bringing that race into new relations with the forces of nature. This developing action of the environment is somewhat modified by death and the process of reproduction. The same relation of force and matter is necessary each time to produce successively the same result, and so if any generation is to resemble the one preceding, it must pass through the same course of growth. When the first living organism had attained its maturity, and part of it had separated off to form a new generation, the second organism could only come to resemble the first by possessing the capacity of responding in the same way to the stimuli of environment. Thus it would pass through the same process of growth, and when it had reached a development equal to that of its parent, it would nevertheless be different, for it would be composed of living matter which had twice passed through the same round of activities. The same would be true for the third and each succeeding generation. But this added complexity of co-ordinations, or fixity of associations, would be apparent as such only when each generation reached a point of growth equal to that of its parents at their maturity. 
That is, when each repetition was completed, its effects would be equal to a new element in the result produced by the action of the environment on the organism. Thus all generations, from the first to the last, must begin alike, and start alike on the same course of growth, but each repetition adds something to each generation not possessed by the preceding generation, until the full-grown of the ten-thousandth generation may differ vastly from the adult of the first generation. We see here the explanation of the greatest general law of embryology, - that each individual, in its development from inception to maturity, repeats the history of the evolution of its race.

This added complexity in each generation may at first thought seem inadequate to account for such great consequences. But we must remember that this repetition is constantly strengthening and co-ordinating those nervous elements which control the entire growth and development, and which, above all things, chiefly receive and transmit the influence of the formative forces of the environment.

This principle which I have endeavoured to set forth here explains a number of well-known facts. Since each generation begins its life by responding to the customary stimuli that caused the growth of all its ancestors, and, when it has finished that 
round of responses, - that is, has attained maturity, - it then stands in a new relation to its environment through the changed state of its nervous system, therefore we should expect any change of growth, any variation new to the race, to follow at or near the period of maturity. As is well known, this is what really occurs in nature; the newest variations in the race are the last to appear in the growth of the individual, the specific differences appear later than generic differences, and these latter later than class differences. Remembering that growth, development, and reproduction are merely forms of organic action, and under the control of nervous force, we must believe that they are subject to the fundamental laws that control nervous action in general, as we discern those laws in the involuntary movements of our bodies and in the working of our minds. Now it is a familiar fact that repetition increases facility and rapidity of action, and thus we observe that the frequent repetition of the processes of growth and development have rendered it possible for the brief life of an individual to encompass the development which the race has been untold ages in acquiring. We find the proofs abundant in nature that new characteristics of animals tend to appear earlier and earlier in each subsequent 
generation. Mr. Francis Galton has described some wonderful cases where diseases which were hereditary appeared earlier by a great many years in the children, and also still earlier in the grandchildren.

This general principle has been summed up by Professor Weismann as follows :-

"The line of direction of development is essentially the following :-

"I. The development commences with a state of simplicity and advances gradually to one of complexity.

"2. New characteristics first make their appearance in the last stage of the ontogeny.

"3. Such characters then become gradually carried back to the earlier ontogenetic stages, thus displacing the older characters until the latter disappear completely." 1

We come now to consider the important part played by nervous association. Since growth and all the customary responses to stimuli of the environment are carried on only through the mediation of nervous forces, it follows that these responses will be subject to the laws of nervous phenomena. We have already seen that we must regard living matter as something that is constantly repeating

${ }^{1}$ Weismann, Studies in the Theory of Descent, Vol. I., p. 274. 
a certain round of activities, - birth, development, growth, and reproduction. This round takes place over and over again, the result of the same round of stimuli acting on living matter in each generation, with only slight variations, which, as already explained, are generally added only at the end of the round. Now as this round, which we call the life of the individual from inception to reproduction, repeats itself, there is acquired not only facility of response to stimuli, but those responsive actions become associated together by the fundamental property of nervous association, in such a way that the chain of associated activities becomes almost inseparable. On the same principle that a thought in the mind calls up an associated thought, or one tone of music calls up another, or one action in an oft-repeated series of actions calls up the next subsequent action or actions, so the initial stimulus being given to an incipient organism, its responsive activity each time tends to produce by association the next activity in the oft-repeated series, and so on through the successive steps of growth and development. By association the tendency to develop in a given direction is already present; but in point of fact the same succession of stimuli which has acted upon previous generations is also continually present to compel the same routine 
of growth activity. Now in this succession of stimuli, suppose one of them to be dropped out through some change in the environment, as pointed out in Chapter V: the mere power of association will remain sufficient to retain the corresponding response in the chain of responsive activities. The gap becomes bridged over; and, though the stimuli change within certain limits, the series of responses remains the same for a time, though the change in stimuli must eventually make its impression on the chain of activities. Thus we see in the incipient organism an indwelling. potential energy which, to some extent, independent of the environment, impels the organism along that course of growth which repetition has made customary to its race, and thus determines the specific character of the organism - whether it shall be dog or horse. This, then, is that inherited impulse of growth which, in combination with external forces, constantly drives the organism forward on its course of development, and, even while the environing forces remain the same, is continually exposing the developing individual to new stimuli, because it is continually changing the individual. This constant change in the stimuli which act upon an organism is a point which cannot be too strongly emphasised in our effort to imagine the immediate 
causes of growth and development. The forces of the environment may remain the same, but the instant they act upon an organism they produce a change in the organism; this change puts the organism in a new relation to the forces of the environment, which again alters the action of the environment upon the organism; i.e. makes it a new stimulus, and a new change in the organism ensues, and so on, to an apparently infinite extent. I have used the word "stimulus" as indicating the action of a force on an organism at any one instant. The stimulus is dependent on the relation of the forces of the organism to the forces of the environment; while the latter may remain unchanged, the organism changes, and the relation between the two being changed, the stimulus is changed, i.e. the force effects the organism differently.

The inherited impulse, which is produced by the association of an often-repeated series of activities, must, from its nature, be strongest in the initial stages of the life of an individual, for those stages have been oftenest repeated. The impulse will be weakest for those characteristics which were the last to be developed in the species, for these have been repeated the least number of times, or generations. We see thus the aptness of Darwin's method of statement, that "characteristics become fixed by 
inheritance." As the latest stages of development have been repeated the least, we see the explanation of the fact that these newest characteristics are the most likely to vary slightly in consecutive generations and in different individuals. Professor Haeckel remarked that "heredity is memory"; and in this sense we may say that the latest developments have not been thoroughly committed to memory, i.e. have not been repeated often enough to become indissolubly associated in the inherited impulse. 


\section{CHAPTER IX.}

ILLUSTRATION OF THE MEIHOD OF GROWTH AND DEVELOPMENT, AND OF THE ORIGIN OF VARIATIONS.

In the previous chapter it was said that, while the forces of the environment remained the same, yet the constant change in the relations of the organism to the environment, might produce new changes in the organism to an apparently infinite extent. (I refer to the organism here as a species, something which passes through a succession of rounds of life, i.e. generations.) Should any one be inclined to doubt this statement, let him consider for a moment that the very fact of life implies a constant change, - metabolism and katabolism of the body substance. In order that this may go on, food must be supplied. There are alternate periods of hunger and satiety, for, in the animal kingdom, food is obtained periodically. This brings periods of activity and rest, and thus already we have the elements of nervous change and development. After a number of such periods, the animal may return to its previous condition in 
every respect except as regards its nervous system. This, by necessity of its nature, bears the record of the changes, and is changed by them. As the nervous system is changed, so the rest of the organism, which is dependent upon it, must eventually be effected by that change. And such change is going on constantly. The importance of the diversity of influence upon the nervous element of living matter is shown by the relatively low state of development among plants, where all periodicity and alternation of condition is reduced to the minimum of day and night, summer and winter, and different soils and climates.

But while theoretically organic evolution may proceed indefinitely without a change of environment, yet I am disposed to believe it would be like one of those infinite curves which forever approaches a straight line. There would come a time when the evolution would be inappreciable. Practically, however, we know that all organisms, in the course of their evolution, have been subjected to change in their environment. There have been geologic and climatic changes, and changes caused for each one by other organisms, affecting mutually the conditions of existence. All the facts of natural history tend to prove that the most highly developed organisms have, in their evolution, suffered the most numerous and extensive changes of environment. 
On the other hand, animals whose environment has changed little or not at all in the course of geologic time, have changed very little. Thus take the marine fauna, for example: the sharks of to-day differ very little from the oldest fossil fishes, and the echinoderms seem, in some cases, scarcely to have altered since archæan times. The echinoderms are so well defended by their armour that they have but few enemies. Their greatest struggle is with their own kind; and this is not battle, but simply crowding each other out of existence. They have nearly the same conditions on the sea-bottoms of to-day that existed there in past geologic ages. The same is true for the sharks. They were lords of the earliest oceans, and have remained so until now. In that earliest time when all fishes were nearly alike in structure, great size would have been an advantage, and it is apparently by their size that the sharks have held their own. Fishes that were unable to cope with them must have been driven to the estuaries and rivers, where, among the rocks and débris of flooded currents, we may suppose they developed their ganoid armour. A few ganoids of great size still inhabit the fresh water, whence their descendants must have returned, as the osseous fishes to the oceans. Farther on in the course of evolution, we must suppose that forms which could not 
maintain themselves against the competition in the water were driven to living an amphibious life partly on land, and so gave rise to reptiles and mammals. A similar course of evolution seems to have occurred from the worms through the crustaceans to the insects. We see, therefore, how important has been the effect of change of environment. It is suggestive also to observe that, in primitive types, development of size seems to precede development of diversity in structure, - thus, the sharks in salt water, the ganoids in fresh water, the carboniferous amphibians and reptiles, and, finally, the modern whale and elephant, as primitive forms among marine mammals and herbivores.

In order to clearly illustrate this idea of the nature of variations of growth and development, let us suppose that a species of carnivorous animals should gradually accustom themselves to live more and more around and in water, in order to eke out the naturally insufficient food supply, by feeding on fishes, and also to render themselves securer from larger enemies. Where the life of the animal had been previously passed on land and its motions had been running and leaping, it would now pass its life in water, and its chief motions would be swimming and diving. A different set of muscles would be called into play; there would be a differ- 
ent stress on the bones; and a different pressure of the surrounding medium would affect both circulation and respiration. In short, the sum total of the forces acting upon the organism would be radically changed. Can we imagine, then, in the interplay of the internal and external forces which mould the structure of the animal, that no change will appear in the structure as the result of the changes in the moulding forces? Let us follow the development of one of the young after the species has made the change in its mode of life. The germ begins existence with its inherited impulse of development, and up to the moment of its birth is subject to the same conditions and the same stimuli that have been customary in its race; therefore, through this period of its life it grows and develops in the same way that its ancestors developed during the corresponding period of their lives. But soon after it is born, and Iong before it has attained its full growth and development, it follows its mother into the water and begins to swim. The change of condition chiefly affects the legs. In the first place the extremities of the legs, which are deepest in the water, are subjected to the greatest pressure of the medium, and therefore the blood circulation in those parts meets with greatest resistance. Many of the 
muscles used in running are not called into play at all, while those of the shoulder chiefly used in swimming are employed almost constantly. The muscles of the lower part of the legs not being used, and the blood supply there being hindered by the pressure of the water, it follows that growth in those parts will be hindered, and the legs tend to become shorter. Again, the legs no longer support the weight of the body, and a different stress and tension is therefore brought to bear on the young developing bones, thus introducing a new element of change. Further, the buoyancy of the legs will tend to float them upward and outward, causing eventually a change of position. Again, we must take account of the new co-ordinations and new training of the nervous system under this new system of stimuli. The land motions of the animal - walking, running, leaping will never have been properly learned, perhaps the two latter not learned at all, through want of practice, while through practice it grows more and more perfect in the art of swimming. A young animal growing to maturity under such circumstances as we have pictured would, without a doubt, show in its locomotive mechanism and nervous co-ordinations a noticeable difference from another of its species which might have lived the 
normal life of a land animal. The amount of difference is immaterial; we may suppose it greater or less. In the production of this difference there are two kinds of influences at work. First, a negative influence, from the withdrawal of the heretofore normal stimuli of growth, and second, a positive influence, in the application of an entirely new system of stimuli; and, in either case, we must remember that these stimuli form a system, i.e. by their sameness and constancy they tend always to produce a certain definite impression on the organism, - a certain definite direction of growth. A system of stimuli calls forth a corresponding system of reactions, which comprise the nutrition, growth, development, and other exhibitions of energy by the animal. Through frequent repetitions in previous generations, this system of reactions has become welded together in all its parts by the power of association; therefore, when some of the stimuli are withdrawn, the inherited impulse is not immediately affected. So that, after a number of generations had led an aquatic life, if the ordinary stimuli of exercise on land were restored, the young would develop after the fashion of its land ancestors, as has generally been observed to be the case in similar circumstances. While we do not understand, with any exactitude, the laws of association and "forgetting," 
yet we are certain of the fact that long clisuse weakens co-ordinations, and a cessation of stimuli weakens associations and tends finally to obliterate them. Therefore the withdrawal of those stimuli sustaining that part of the inherited impulse which causes the development of the peculiarities of a land animal would, in the course of generations, destroy that part of the inherited impulse. A gradual retrogression must precede the addition of new parts. Thus it seems probable that the legs of such carnivores as we have imagined would first go through a period of shortening before they would assume the breadth of flippers like those of a seal.

It is not so difficult to imagine how, under such conditions as I have just mentioned, a limb might gradually grow smaller, its growth being checked earlier and earlier in each generation. Since, in its early development, the brain surpasses all other organs of the body, we may suppose that the part of the nervous system which governs the growth and action of a limb would be developed - in fact, must be developed - before the limb shall have attained any size or functional power. But if, through untoward circumstances, that part of the nervous system be not stimulated to activity, then its co-ordinations which govern the growth of limb in both individual and species, will gradually be weakened, and 
its efficiency be lost, thus causing a degeneration of the limb in succeeding generations.

The question, how does growth begin in a new direction, and how do new parts originate, involves the whole problem of the physiology of growth. The human body may need four or five years to attain the last twenty pounds of its weight, and yet if twenty pounds' weight be lost by sickness, it may be recovered in as many weeks. Why should this be so if it be not that the nervous elements controlling assimilation are more perfectly developed and more efficient because of their continued exercise? Again, why does a muscle grow larger and stronger by exercise? The contraction of the muscle actually weakens it, and also consumes its substance, so that each contraction causes loss of both strength and material. Therefore, after each contraction, there must be a restoration of strength and substance; and, as the muscle grows stronger and larger by repetition of the exercise, it follows that each restoration must give the muscle more than the previous exercise consumed, i.e. the restorative process becomes more and more perfect by repetition. Thus we see that the trophic nerves, like all others, gain facility by practice. And we must remember also that the trophic nerves, like all others, are only active as the result of stimulation. 
Another case, parallel to the preceding, is found in the thick growth of skin on the palms of the hands and soles of the feet, and sometimes the elbows, of children who play a great deal on the floor. The wear and tear of the skin on these places stimulates the trophic nerves to activity, and by practice, the restoration soon surpasses the destruction. From these parts which are exposed to blows and friction, we must distinguish those parts, like the toes in a shoe, which are subject to a constant pressure. As is well known, the natural growth of such parts may be greatly hindered and changed, even though the pressure be never strong enough to cause pain.

Let us look again at the supposed case of a transformation of a carnivore from a terrestrial to an aquatic animal. While the absence of the terrestrial stimuli have been reducing the length of the limb and the former vigour of development, its constant use in swimming will tend to produce some new changes. As the foot is moved backwards and forwards in the water, the parts corresponding to the palm and back of the hand will receive alternately a greater and lesser pressure. This alternation of pressure, however, will make the greatest impression on the edges of the paw. The middle part of the paw is supported by bones, but the softer, pliable 
edges will be bent first one way and then the other by the resisting water as the paw is moved forward and backward. No matter how small a part of the edge of the paw be thus affected, there will be in that part of the paw a greater wear and waste of tissue, and a correspondingly increasing restoration, which would cause a growth on the edges of the paw, and thus increase the area of its flat surface. It will perhaps be objected to this that the edges of the paws of land animals are also continually subjected to the alternations of pressure, and pulling and pushing in all directions; according to the roughness of the ground on which they tread, and yet, nevertheless, the paw does not increase beyond a certain small surface. But notice the difference between the great variety of stresses brought to bear on a land animal in walking, running, jumping, and in striking against various obstacles, and then contrast the simple alternation caused by swimming. We must believe that the shape of the paw of the land animal is the result of all the forces acting upon its development, and in the same way the different shape of the aquatic animal's paw is the result of the different forces acting upon it; and one cause of difference we may recognise, I think, in the conditions I have here mentioned. Any plastic viscous body may be moulded by separate repeated blows. 
On such bodies it is not necessary that the pressure or blows on different sides of it be simultaneous. But every blow will have its effect in the end upon the ultimate shape. Now if the various blows and pressure upon a plastic body, like a limb, be limited in their direction and force, though unlimited in number, they must of necessity repeat themselves, and thus tend to force the limb into a certain definite shape, - just as when we roll a piece of soft clay between the palms of the hands, the equal pressure applied successively to all parts of the lump forms it into a sphere, though the pressure is never applied at more than two points at once. When this pressure is no longer applied the ball may at once begin to lose its shape.

It would be almost impossible to analyse fully the action of new forces on a mechanism so complex as the leg and paw of an animal, but they must always be subject to certain fundamental mechanical laws. Thus, the larger the flat surface of the paw becomes, the more powerful must be the muscle, or the slower must be the swimming stroke. Such laws as this must limit and determine development in a variety of ways. For instance, the slower the swimming stroke became, the less would be the alternation of pressure on the edges of the paw, and thus the resulting stimulus of growth would be lessened. It is 
interesting to note, in this connection, that different groups of fishes, also whales, sea-cows, seals, and porpoises, all preserve the same general proportion between the size of the body, and the size of the fin or flipper.

If we admit, as I think we must, that one of the most conspicuous properties of living matter is its power to restore losses caused by waste and wear, and to increase the restoration beyond the loss so that the result is growth, then we have one of the keys to unlock the mysteries of development. We have already seen one application of this principle in the previous paragraphs. We have next to consider its application to the bones, the hard parts which determine the shape of the body. According to Professor Martin, "the experience of physicians shows that any continued pressure, such as that of a tumor, will cause the absorption and disappearance of bone almost quicker than that of any other tissue; and the same is true of any other continued pressure." 1 The bones, though apparently so unyielding, are among the most easily modified parts of the body. Remembering that, as heretofore, we have in mind a succession of generations acted upon by the environment as though it were a single individual, I think we can explain the shape of the bones

1 Martin's Human Body. 
as resulting from various applications of pressure, strain, and shock. The characteristic structure of the joints is chiefly due to pressure. As is well known, constant pressure prevents growth, as is shown in the artificially compressed heads and feet of some races of people. Let us suppose the development of a typical ball and socket joint from the apposition of the undifferentiated surfaces of two bones. We would have a surface of a highly movable bone opposed to a large surface of a relatively immovable bone. The permanent tension of the muscles keeps up a constant pressure of one bone upon the other. The movement of one bone, which we will suppose to be a long bone, brings different parts of its end surface in opposition to the larger surface of the other bone; but whichever way the long bone points, its end presses against the same spot on the other bone. That part of the immovable bone would therefore be checked in its growth as compared with the surrounding part, or its waste would not be repaired, and a depression would result at that point, forming a socket. Suppose the movable bone has at first opposed a sharp point to the immovable bone, - in that case, that point of the movable bone would be under constant pressure, and by the stoppage of growth would tend to become blunt and rounded. Wherever, through roughness in the first 
form of this rude ball, a point is subjected to greater pressure than the surrounding parts, that point will be reabsorbed or hindered in its growth until the ball finally presses evenly on all parts of the socket. We know that the toes of civilised people become reduced in size and changed in form by the wearing of shoes. Also, it is stated by medical authorities that the wearing of corsets changes the shape of the ribs. In these two cases it is not necessary that the pressure be great enough to be uncomfortable, and during the periods of sleep the pressure is entirely removed. This shows that, in order to change the shape of bones, the pressure need not be constant, if it be only long continued each time, and active the greater part of the time. The pressure of the tendons, nerves, arteries, muscles, etc., upon the bones must also have its effect upon the shape of the latter. The strain, or pulling of the muscles, ligaments, etc., upon the bones must produce a great effect. This is shown by the ridges caused by the insertion of the muscles, and by the long projections of bones where great tendons are inserted. As pressure on a bone, at any spot, prevents growth at that spot, so strain or pull seems to induce growth; though, where there is a constant changing in the direction of the pull, the varying effects would tend to be neutralised, and, therefore, 
in most cases we would find only a slightly raised ridge. An illustration of the effects of pressure and pull on the bones may be found in the flattened shape of the ribs, caused by the pressure of the internal organs and the external muscle and skin, and by the pulling of the intercostal muscles. At the back, where the spinal muscles arise from the ribs, their shape is nearly round in cross-section. The spines themselves may be regarded as chiefly due to the steady pull of the symmetrical dorsal muscles. The effects of a pulling upon growth are more easily seen on the softer parts of the body, as the elongation of the lobes of the ears and of the lips caused by the strain of the ornaments of savages. The mere absence of a pressure in some cases causes growth. Thus the removal of one of the molar teeth causes the growth of a protuberance of flesh from the inner wall of the cheek into the empty space. We cannot, of course, trace out with accuracy the causes of the various effects which we see in the shaping of the skeleton and flesh, but we know that these forces which I have mentioned do act, and that their action is extremely complicated. How powerful their action is, may be readily seen by instituting on a growing limb, or even a fullgrown one, some abnormal conditions of pressure and pull. It is well known that there would be a 
pronounced result. At first glance, one might say that such an experiment was merely interference with the natural growth, and no true test of the forces causing the shape of organs. But a moment's reflection shows that if we can prove that a certain condition of stress produces one arrangement of the component particles, then every other arrangement of particles must be due to some other condition of stress, and a normal limb must have its condition of stress as well as an abnormal one.

The effect of shock or sudden jarring upon bones may be compared to the effect of exercise upon muscle-i.e. it causes the repair to exceed the damage or waste. Shock differs from pressure in that pressure does not relax often enough to admit of the repair of its ravages, whereas shock is only momentary, and not only admits, but seems to stimulate, repair. Pressure is like the over exercise of muscle, causing degeneration; shock is like exercise, causing growth. If a bone be struck on one end, or if a row of articulated bones be struck, the shock is passed from one end of the bone, or the row of bones, to the other. According to the discoveries in the science of physics, the continued repetition of such shocks tends to cause a new arrangement in the particles of the object struck. A bar of metal takes on a new 
molecular arrangement, and may become crystallised in structure. A bone presents this difference: its particles are undergoing a gradual change all the time, and this mobility of its particles must, from its nature, take away from the elasticity of the bone. When a bone is compressed by a blow, its imperfect elasticity would prevent it from returning to its original shape. We must suppose, therefore, that those vital restorative processes in the bone which prevent it from crystallising under the many shocks it receives, at the same time cause a repair in such directions that the bone resumes its former shape. It is well known that in many cases such shocks, repeated blows, or friction cause the repairs to exceed the waste, and excrescences of bone are the result, as on the hands or feet. The bony excrescences on the heads of horned animals have generally been explained as having arisen in this way under the intensifying effects of inheritance and selection. The action of shocks would naturally cause the restoration and increase to take place in the direction of the compression caused by the blow; nor must it be supposed that the effect of the shock and its consequent increase is merely on the surface of the bone, but it takes place wherever the shock causes a molecular displacement. The structure of the 
spongy part of bones shows that the bone septa between the cavities are arranged along the lines of greatest stress. To such causes must we ascribe the length of the bones in the legs of quadrupeds which run and do not use their legs for climbing, digging, or swimming. The shock of the feet striking the ground furnishes the motive for the lengthening of the bones. In recognising this as an efficient cause, we must not forget that other forces, which cannot be defined, are at work limiting and modifying the effects.

The giraffe seems to present the most remarkable illustration of the lengthening of the bones as the result of the frequent repetition of such shocks. As is well known, this animal feeds on the foliage of trees. From the earliest youth of the species, and the earliest youth of each individual, it must have been stretching upwards for food, and, as is the custom of such quadrupeds, it must have constantly raised itself off its fore feet, and as it dropped must have received a shock that made itself felt from the hoofs through the legs and vertical neck to the head. In the hind legs the shock would not be felt. It is impossible to imagine that an animal which, during the greater part of every day of its life (both its individual and racial life), performed motions so uniform and 
constant, would not be peculiarly specialised as a result. The forces acting upon such an animal are widely different from the forces acting upon an animal which eats the grass at its feet like an ox, or one which must run and climb like a goat or a deer, and the resultant modifications of growth in the several cases must also be different. The principle of increased growth in the direction of the shock resulting from superabundant repair of the momentary compression, explains how the giraffe acquired the phenomenal length of the bones of its fore legs and neck; and the absence of the shock in the hind quarters shows why they remained undeveloped and absurdly disproportionate to the rest of the body. We may thus recognise in this principle not only the cause of the peculiar difference between the giraffe and other animals, but even of the difference in size between its fore and hind quarters.

The disturbance which permanently changes the complex combination of forces acting upon a living organ, as has been pointed out, must change the mobile equilibrium existing in the organic processes of growth, waste, and repair. A change in one set of organs entails a change in their relations to adjacent organs, and the forces acting on the latter are accordingly modified. Thus the 
change in the fore quarters of the giraffe produce a peculiar relation to the hind quarters, whereby the gallop of the animal is rendered unlike that of all other hoofed animals, as Mr. Herbert Spencer has pointed out. ${ }^{1}$ The unity of action, however, is still preserved, and the parts, though changed by their mutual interaction, still work harmoniously together. The changes by which the hinder parts have adjusted themselves to the gradual changes of the fore quarters, we can only attribute to the change in the forces which the two sets of organs bring to bear on each other. These secondary changes, due to the mutual action of parts on each other, embrace a large class of phenomena, and probably the effects thus produced cannot always be distinguished from those effects directly due to primary external causes. We see from this example that a comparatively slight change in the habit of an animal may, in the course of generations, produce a profound change in its growth, affecting every organ.

From what has been said of the nature of the hereditary impulse and of the action of the forces which produce the growth of organisms, it follows that any alteration of the forces, in order to produce the greatest change in the organism, must act upon

1 The Factors of Evolution, 1885. 
the organism during the period in which the development of the parts, and the greatest amount of growth takes place. In the growing and developing animal there is a constant and rapid physical change taking place, a process of building up which may be easily modified. In the adult the physical change is not so great; the ordinary restoration does not exceed the waste and wear, and any pronounced change in the forces acting on the organism is likely to interfere and decrease the restoration without causing growth in any new direction. This seems probably due to the fact that in the adult the nervous associations are stronger, and co-ordinations once broken are not easily replaced by new ones.

The phenomena of acclimatisation illustrate this principle. One cannot read the passage relating to this subject in Darwin's Plants and Animals under Domestication without being convinced that it is the action of the changed environment upon the young and developing organisms which produces the changes of constitution which are denoted by acclimatisation. The fact that acclimatisation does not take place in plants propagated by buds and grafting seems to show that, in order that the changed forces may produce their greatest effect, they must act upon the organism during the period 
of development of parts, as distinguished from the period of simple growth in size.

When the development is modified by a change in the forces of the environment, the change of forces will produce its effect first upon those parts which are the last to perfect their development; i.e. the parts which, in their developing state, are subjected longest to the action of the new arrangement of forces will be the first to succumb to their modifying influence. We find a striking illustration of this in the observations of Professor Eimer on the lizard's tail. The tail of the lizard is the last organ to lose its embryonic character. At a time when the other organs are all well developed, the tail still retains at its tip end the neurenteric canal, which joins the central canal of the spinal cord with the cavity of the rudimentary caudal intestine. At the same time the tip of the vertebral column shows only the embryonic notochord. ${ }^{1}$ This method of growth, viewed in the light of the present theory, explains the following quotation from Professor Eimer: "The appearance of new characters always takes place at definite parts of the body, usually the posterior end, and during development - with age - passes forwards, while

1 "Contribution to the Embryology of the Lizard," Henry Orr, fournal of Worphology, 1887 . 
still newer characters follow after from behind. Thus during life, e.g. in lizards, a series of markings pass in succession over the body from behind forwards, just as one wave follows another, and the anterior ones vanish while new ones appear behind. (Law of wavelike evolution, or law of undulation.)"1 Even more striking is the following quotation in the same connection: "Wurtenberger finds that in ammonites all structural changes show themselves first on the last (the outer) whorl of the shell, _ as in living animals, e.g. in my lizards, at the tail, - and that then such a change in the following generations is pushed farther and farther towards the beginning, - as, e.g. in my lizards, towards the head, - until it prevails in the greater number of the whorls. . . Then still newer characters may arise again on the most external whorl - just as in lizards at the tail - and drive back the former, and so on. The ammonites also only at an advanced age, only when they have as exactly as possible gone through the course of development inherited from their parents, acquire the power to vary in a new direction; but this power can be inherited in such a way that in following generations it always appears a little earlier, until it itself characterises the 1 Organic Evolution, Eimer. Trans, by Cunningham (Macmillan \& Co.). 
greatest part of the period of growth. This 'Law of precocious inheritance,' as Wurtenberger calls it, also holds - for it obviously coincides with the law of abbreviated development - for living animals." 1 This passage is one of a very large number in Professor Eimer's work on Organic Evolution in which not only the facts recorded, but also the very phraseology, lends itself unchanged for the illustration of the present theory.

These examples given in this chapter are not intended to set forth exactly how the parts attained their present form and function, but to indicate the class of forces which has produced the given result. We know that these forces do act, and we know also that the action of any force must produce its effect. When we admit the existence of the hereditary impulse as I have described it, with its capacity for modification by the action of these forces through long series of generations, then we have the explanation of development. And, understanding the action of the forces and the nature of the hereditary impulse, we have no necessity to suppose any other occult factor or agent. We see the result before us, we know that the forces act, and the theory of the hereditary impulse makes the process intelligible and the result logical.

I Organic Evolution, p. 3I, Eimer. Trans. by Cunningham (Macmillan \& Co.). 


\section{CHAPTER X.}

CORRELATION OF GROWTH.

IN considering that elementary form of reproduction, in which the small mass of protoplasm which constituted the parent organism simply divides and gives rise to two similar but smaller organisms, we saw that the plan of development, or rather the co-ordinations which determine future development, are not destroyed. The same is true of the germcells, or embryos, of many higher animals. They may be divided into several parts, and each produce a complete animal. The embryo of the small marine animal, Pyrosoma, divides regularly into four parts, each of which produces an individual. And in the group of the Tunicata, to which Pyrosoma belongs, there are many forms in which, as soon as the embryo is differentiated into the three cell layers, hypoblast, mesoblast, and epiblast, - it divides itself into several similar embryos, which may develop into complete individuals, or may, perhaps, first divide again before attaining maturity. We see this same 
thing illustrated in other animals. Many worms may be divided into a number of parts, each of which will grow again into a complete individual. The Hydra may be chopped to small bits, and the pieces will develop into an indefinite number of Hydras. There are some conclusions to be drawn from these phenomena; namely, the co-ordination of forces, which determines development, is not to be regarded as a definite, localised mechanism, wound up and ready to go when touched. If such were the case, we ought to find one such mechanism allotted to a certain definite number of cells; but, instead, we find that each piece, regardless of the number of cells, or whether it be the half or the twentieth of the Hydra, is capable of producing only one new individual. The power of living matter to produce new individuals is dependent, therefore, not on the quantity of that matter nor, apparently, upon the unfolding of any limited mechanical arrangement of latent energy. The quality upon which development depends seems to reside in a small piece as well as in a large piece, and, moreover, equally in all parts. How this may be, it is not easy to conceive and much less easy to express. I think we can best compare the inherence of the plan and potentiality of development in the clump of protoplasm to inherence of ideas and potentialities of volition in the brain substance, not as 
though each idea and potentiality were located there in its own minute definite limit of space, and attached to a definite mechanism of matter, for, says Professor Ladd: "Everything which psychology teaches as to the character of the mental phenomena, and everything which physiology teaches as to the nature of cerebral functions, discourages the puerile attempt to connect separate mental images or ideas with isolated nerve-cells as their product." 1 But, rather, we should think of development and mental potentialities as dependent upon certain states of living matter, which states are the results of the entire past history of that living matter, and which thus determine the method of response to external stimuli, and the direction which shall be taken by the new energy constantly entering from the outside. However, I do not venture here to attempt an elucidation of that point.

What it concerns us to observe is, that a simple piece of living matter, torn from an individual, may grow into a single individual, or, the piece being further divided, it may give rise to several individuals. But all the individuals are alike. There was but one plan of development in the piece, no matter whether it was producing one individual or a dozen. In other words, the piece of living matter could react

1 Ladd, Elements of Physiological Psychology, p. 555. 
to the forces of the environment only in one manner. If it were torn into two pieces or into a dozen, each could still react in only one given manner, and in all cases with the same result. While there is but a single plan of development possible to the larger mass, yet each separate part of the mass has the power of carrying out that plan. The potentiality of development is divisible, and yet in each part the potentiality is complete. The single plan of development might, of course, be modified in some of the separate pieces by exposing them to peculiar conditions of environment.

These inherited co-ordinations of growth, or the inherited impulse of growth, as I have called it, tend to guide the development of each separate piece of a living mass in the same direction. The living matter in each particular environment can respond to the combination of forces acting upon it in only one way. It repeats this response over and over again, and thus has learned in its past history only one plan, and it must always follow that as nearly as the circumstances of environment will allow. To this singleness of plan must we attribute all such phenomena as the appearance of rudimentary mammæ in the male animal. These differ from many other rudimentary organs in the fact that in one sex they are necessary for the life of the species, 
and therefore cannot be regarded as in a process of gradual disappearance owing to the loss of function and stimuli of growth.

We find the same singleness of plan influencing growth where the growing parts are not completely separated but remain dependent upon one another. Thus the different segments of a worm, which grow by budding from one another, are similar both in external appearance and in internal organs. In ascending the scale of segmented animals, we find more and more that the different influences of a more complex existence have modified the particular growth of the various segments, preserving only a general fundamental similarity of structure. However, the change in the development of one segment of an animal seems to influence a change in the development of the other segments - as though the living matter would not learn an entirely new plan for only one segment, but applied it as far as possible to all. Thus Professor Weismann mentions certain eye-like markings which appeared first on one of the anterior segments of a caterpillar, and then developed on the other succeeding segments. ${ }^{1}$ Professor Weismann explained satisfactorily the first appearance of the marking on one segment as an instance of protective colouring, whereby the eye-

1 Weismann, Studies in the Theory of Descent (Macmillan \& Co.). 
like spots gave the caterpillar a reptilian aspect calculated to terrify its feathered enemies. The spots on the other segments, however, are useless and inexplicable, I think, except in the way I have suggested. In the same way among other arthropods, where we find the appendages of one segment developed in a peculiar manner for a particular purpose, the appendages of adjacent segments tend to show a similar modification of growth, though purposeless and without particular function. For example, the appendages of the crawfish behind the pair of great claws are similarly modified in shape, but are too small and weak to perform anything like the same function. The large claws were undoubtedly developed by certain stimuli of growth, which modified the co-ordinate forces controlling their development; but those co-ordinate forces controlled not only the development of the large claws, but also the development of the other appendages, so that consequently the adjacent appendages became secondarily modified in the same manner, but in a lesser degree. This singleness of plan in living matter, or the inability of one mass to contain more than slight variations of one arrangement of developmental forces, is illustrated in a striking manner in the similarity of the fore and hind limbs of vertebrates, even when in man the uses of the two pairs of limbs are so different. 
When we consider how every activity of living matter has been gradually acquired through constant repetition, each new method of activity or growth being added to and conditioned by that method of growth which already existed, we can understand how this singleness of plan necessarily arose. Every new part and function could only be a modification of that which already existed. Bearing in mind this singleness of plan, and remembering the power of the hereditary impulse in preserving shape, we can attain to an understanding of the phenomena of nearly similar parts performing different functions, in cases where, upon the old theory of use and environment, we might expect as great a difference between the parts as between the functions. For example, if we expected use and function alone to determine the shape and structure of different parts, we could never explain the similarity between the human toes and fingers. For the toes and fingers are very similar in form, in spite of the fact that their functions are widely different. This similarity of form is due originally to the singleness of plan, and secondarily to the strength of the hereditary impulse which has not yet fully succumbed to the influence of the change of function.

But apparently, the leg and arm being developed from a single co-ordination of forces, the one limb 
cannot be greatly changed without changing the fundamental co-ordination of forces, and thus changing the other limb. Thus the development of the leg is not the result of forces and stimuli acting upon it alone, but it is also modified by forces acting upon the arm, and vice versa. To this same principle must we also attribute the exact (symmetrical) similarity between right and left limbs. The slightest deviation from the type of growth in the right limb tends to appear equally in the left; if one hand is large or small, the other is the same, and the feet correspond in relative size to the hands. Little things only skin-deep, as moles, may be found exactly corresponding on opposite sides, and even the ridges of the skin on the finger-tips, which are said to differ in every individual, resemble each other in the right and left hands. That the development of one arm influences the development of the other is most strikingly shown in the nervous and muscular co-ordinations and changes acquired by the practice of writing. Generally, the right arm alone has been trained to write. But if we take a pencil in each hand, we can write with each hand the same letters, except that the left hand, according to its symmetrical relation to the right, produces the letters in a symmetical reverse order. If a name written thus with the left hand be held before a 
mirror, it will appear in the mirror often with all the peculiarities of the writer's signature. The significance of this fact is appreciated when we remember the long and difficult practice which was necessary before the right hand attained its present power of writing, and how profoundly this practice has, unknown to us, affected the left hand.

There is still another kind of correlation of parts which is, not like what we have discussed, dependent upon the similarity of form, but rather is dependent upon a similarity in the origin of the tissues of the correlated parts. In every species of multicellular animals, the egg, or fertilised germ-cell, divides into a number of parts, each forming a cell ; this division is repeated many times, forming thus a cluster of cells which gradually arrange themselves around a central cavity in two or three layers, one inside the other, generally in a spherical or oval shape. The outer layer is called the "epiblast," the inner is called the "hypoblast"; the middle layer, called the "mesoblast," is secondary, being an outgrowth of the hypoblast. In all embryos the epiblast produces the skin and nervous system, while the hypoblast and its product, the mesoblast, produce respectively the digestive and muscular systems. In the group of Ascidians it is very common, as we have seen, for embryos which have reached 
the stage where they consist of epiblast and mesoblast, to divide by budding or constriction into a number of separate embryos. Further, there is, in this group, a truly wonderful variety of methods by which the young animals grow out as buds from the older ones. Now, a careful examination of all these methods of budding shows that invariably there enter into the composition of the bud, or new individual, parts of both the original epiblast and hypoblast, also of the mesoblast, if it be already developed. Not only is this true of the budding of the ascidians, but also of large groups of the hydroids, and, I believe, wherever this method of reproduction obtains. Apparently, each layer has the power to develop, under favourable conditions, into certain organs, and into these definite organs only. Not as though one layer should produce an arm and another a leg, but one layer produces the muscles of the body, including muscles of both arm and leg; and another layer produces the skin of the entire body, including arm and leg. Thus in each germ-layer there is a singleness of plan which permits each layer to produce only certain kinds of tissue.

We see, therefore, that, at a very early stage in the development of the embryo, the parts which are to develop into the various systems of organs become 
distinct from each other. Consequently, we might expect that whatever would retard or accelerate the development of one single layer would affect in a similar manner all the parts derived from that layer, i.e. there would be a correlation between all the parts derived from the same germ-layer. This kind of correlation we find between the hair, teeth, and claws of animals, all of which are derived secondarily from the skin and primarily from the epiblast. The single origin of all parts of the muscular system explains why relatively strong muscles in one part of the body are generally accompanied by strong muscles in the other parts. Since we have observed a similar origin for the skin and nervous system, it is interesting to note in man the curious correlation between the colour of the skin, or "complexion," and the mental or nervous temperament.

The analysis of the correlation of parts helps us to apprehend, if not the method, at least the degree in which the conditions and interacting forces of a developing organism are complicated.

The specialisation of growth of the tissues goes farther than the primary division into the three germ-layers. Each of these three layers is further divided into a number of secondary tissues, each layer developing only its own peculiar tissues. Any one of these tissues, if partly destroyed, has the 
power of reproducing itself and developing new tissue of the same kind, but only of the same kind, and no other. Muscle tissue will not produce epidermis, nor will glandular tissue produce muscle. We see thus that there is in each tissue but a single plan of development, - a single set of co-ordinations which guide and limit the activity of the tissue.

There is still another example of the singleness of plan found in the reproduction of lost parts among the lower animals, such as the reproduction of the lost tail of a lizard, or the lost leg of a newt. There is not, in these cases, a simple addition of new tissue layer by layer on the wounded stump; but the part to be reproduced is formed first in embryonic size and condition, and passes thus through nearly the same phases of growth that were followed by the original part, repeating the original single plan of growth. 


\section{CHAPTER XI.}

DIMORPHISM AND POLYMORPHISM IN SPECIES.

We have seen that the growing time of seeds, and the time for putting forth leaves, is determined by the annual changes of the seasons and by the approach of the season of rapid increase of temperature. We find an almost exactly similar series of phenomena among animals, and especially is it the case among insects. Insects, like plants, can flourish only in warm weather, their lives being dependent, in a large degree, both on the warmth and on the plants. Each species of a temperate climate, therefore, is subjected by the regular return of the seasons to a regularly recurring alternation of its environment. Among many kinds of insects, only the adult forms remain over from season to season, passing the winter in a state of torpor. The young are developed only in summer time, and, accordingly, all generations are developed under the same conditions. Consequently, all these generations, as we would expect, are alike. On the other hand, there 
are certain insects, like the butterflies, which develop to maturity perhaps two generations in the summer, the latter giving rise to a third generation, which passes the winter in some larval form, and does not reach its full development until the following spring. This winter generation thus takes a much longer time for its development, and also develops under very different circumstances from the summer generations. It would seem, therefore, that the winter generation ought to be different from the summer generations, as a result of the different combination of external forces to which it was subjected during the time of its development. Such is found to be the case in many species which have been most carefully examined. According to Professor Eimer, "the majority of the species of our (German) white butterflies (Pieridæ) show very strikingly a winter and a summer form." Several species of butterflies, showing this alternation of form, have been subjected to numerous experiments, especially the species described in the following passage from Professor Eimer:-

"Since the fourth decade of this century, it has been known that the two butterflies, Vanessa Levana and Vanessa Prorsa formerly considered as different species, are really one and the same. And, indeed, in these two forms of the butterfly we have 
two generations developed at different seasons of the year. $V$. Levana is its winter form; $V$. Prorsa the summer form. The chrysalis of Levana remains dormant during the winter. The butterfly emerges in the spring, breeds immediately, and its progeny go through their whole development in the summer; from their chrysalids emerge the $V$. Prorsa whose progeny then pass the winter as chrysalids, and in the spring produce the Levana. These two forms of butterflies are clifferently coloured and marked, and it is in complete agreement with many other examples of the effect of warmth on the formation of pigment in the integument that the summer form (exposed to warmth), Prorsa, is much more deeply coloured than the winter form (exposed to cold), Levana. The former is deep black, the latter brown-yellow, in its ground colour."

The caterpillars, pupæ, and eggs are perfectly alike in both summer and winter forms. Experiments have shown that the chrysalids, which would naturally produce the summer form, can be made to produce the winter form if they be kept at an unusually low temperature. The application of warmth to these, however, ensures the production of the summer form. On the other hand, every second or third generation - according to the species - assumes the winter form, no matter how much heat 
be applied to it. Among a large number of specimens of this winter generation which were developed under high temperature, there were a few generally imperfectly developed - individuals of the summer form, showing that heat is not altogether without effect upon this generation.

When we seek for an explanation of this phenomenon of a periodic change of form in insects which spring successively from the same lineal stock, we can compare it to the periodic change in the rootpressure of plants, which we have discussed in Chapter IV. In both cases, when undisturbed, the periods of change are coincident with periods of profound changes in the environment, - in the one case the periods of day and night, and in the other, periods of winter and summer. We have seen that light caused the increase of root-pressure, and we have seen that cold caused the development of the winter form of the butterfly. We may therefore safely conclude that as day and night cause the periodic changes of root-pressure, so summer and winter cause the periodic change of form of the butterfly. In the one case the daily alternation of stimuli have effected co-ordinations in the living matter of the plant, which cause a periodicity in its activity; in the other case, the annual alternation of stimuli have effected co-ordinations in the living 
matter, which, possessing a continuous life itself, develops periodically into the different forms of successive generations of butterflies. We have seen that the periodicity of the root-pressure does not cease immediately upon the removal of the stimuli which originally produced it; in the same way we observe that the periodic development of the winter form of the butterfly persists in spite of the application of heat. The fact, however, that the winter form, as we have seen, may be somewhat affected by heat, strengthens the belief that the periodic difference of development is due to co-ordinations of a trophic-nervous nature, which have become ingrained in the living continuity of matter, by the long exposure to the successive changes of summer and winter. Whether the periodicity could be changed by a long exposure to a different succession of stimuli, as was done with the root-pressure, is an interesting though difficult problem; but, reasoning from analogy, we might look for a result similar to that of the experiment on the rootpressure.

In the case of the dimorphic butterflies which we have been considering, if the chrysalids which are about to produce the summer form be subjected to different degrees of cold, there will be developed several forms intermediate in appearance between 
the extreme summer and winter forms. Each form, therefore, must be regarded as the result of the influence of a particular environment during development. Of a number of such possible forms, we may suppose the average alternations of seasons to produce alternately only the two extreme forms; or, on the other hand, a change in the climate toward greater heat might cause the omission of one of the extreme forms, and instead, the production alternately of one of the intermediate forms instead of the extreme cold form. The following illustration of this refers to Lyccena agestis: "This butterfly occurs in three forms: $\mathrm{A}$ and $\mathrm{B}$ alternate in Germany as winter and summer form; $\mathrm{B}$ and $\mathrm{C}$ are the winter and summer form in Italy. Thus the form $\mathrm{B}$ occurs in both climates, but appears in Germany as the summer, in Italy as the winter, form. The German winter form $A$ is completely wanting in Italy, while the Italian summer form (var. Allous) does not occur in Germany."

It is evident, from the facts and principles which we have discussed in previous chapters, that a permanent new form is not the result of the brief action of a new set of forces upon the individual during the short period of a single lifetime. A new form is produced by the long-continued action of the changed environment, which causes the gradual 
acquisition of new methods of growth responsive to new stimuli. Since each organism in its development passes through the various stages of growth which have been attained successively by its ancestors, it follows that when any organism fails to attain its full development, it must remain at some point of development which, while incomplete for the present generation, was complete for some past generation. A careful study of the dimorphic butterflies has led the authorities on those points to the conviction that some of the forms - the winter forms - are the incomplete or ancestral stages of development. So that while the species in the course of its existence has gone on developing new characteristics, it has been forced by the alternation of seasons to reproduce an ancestral form every second or third generation. Thus we see that neither the extreme summer nor winter forms are forms which are newly and suddenly produced; and the same is true of the intermediate forms, which represent an intermediate stage of development.

The main point to be deduced from all this is that as a result of peculiar conditions of environment, ancestral or imperfectly developed forms may exist alternately or simultaneously in the same species with more advanced and more highly developed forms. This fundamental principle explains, I think, 
the wonderful polymorphism of bees and ants, and other insects living in organised societies. The application of the explanation will be made more intelligible by the following interesting account of the humblebee, which I take from Professor Eimer, on Organic Evolution: "In spring, when the allvivifying sun has warmed the ground to a certain depth, a female humblebee creeps forth from a hole dug by herself in the ground, - usually in a position exposed to the sun, - or from a rotten tree-bark, or from a clump of moss, or from some other retreat in which she has passed her winter sleep.'

"Thus Professor Eduard Hoffer commences his description of the humblebees of Styria, ${ }^{1}$ and he goes on to describe the formation of the humblebee family as follows :-

"At first the female humblebee flies from flower to flower, sipping honey; then she seeks a place in which to build her nest. When she has found a place, - any suitable hole, - she carries into it moss, grass, leaves, hairs of animals, and fine needles of the fir or pine, and builds a nest closed on all sides, and provided with only a single opening directed towards the rising sun, and usually concealed. Then she collects honey and pollen, makes a cell

1 E. Hoffer, Die Hummeln Stiermarks, Lebensgeschichte und Beschreibung derselben. Graz. 1852. 
of wax, fills it with pollen soaked with honey, and lays a pair of eggs in it. From these, larvæ soon emerge, which grow rapidly, and therefore require much food. The mother now toils energetically day and night for the welfare of her children, by clay collecting, and feeding the larvæ, by night biting up and arranging the materials of the nest, coating it with wax-like material, and warming the young. She allows herself little rest, except when the weather is bad. At last, in the beginning of May, or, in some forms, several weeks later, the first young humblebees creep forth. These are the workers, much smaller than the mother or queen — are, in fact, stunted queens. They fly forth at once to collect honey and pollen, which they bring into the nest. As long as there are but few of these workers the mother continues to fly out also to the fields and collect industriously, but afterwards she goes out less; she now remains much at home, laying eggs and tending them. At last she ceases entirely from going out, her wings, as a rule, becoming useless. Some of the workers tend their younger sisters who are still in the cells, and feed them, work at the construction of the nest, keep it clean, and lick and warm the young bees when they creep forth. The workers raise a great humming if the nest is disturbed, and defend it by stinging the intruder. 
Thus the queen lives with her handmaids several weeks, - about three months, - continually adding to their number. As a rule, about July, young of a much larger size emerge, likewise resembling the queen, the so-called 'small females,' or large workers, - i.e. females whose reproductive organs are developed, but who generally only produce drone eggs, though under certain circumstances they can lay eggs which hatch into females or workers. These large workers and the small workers and the old female, all three kinds, now lay drone eggs in large numbers, from which males are hatched. Not till the end of the summer does the mother again lay queen eggs. There exists now, therefore, in the family - (I) the old queen, who is perfectly incapable of flight and destitute of hairs; (2) numerous young queens ; (3) the ordinary or small workers ; (4) the large workers or small females; (5) the drones or males. All the workers throughout the summer fly forth to collect, about a quarter of an hour before sunrise, awakened by a peculiar humming, the voice of the trumpeter. The males also go forth to the fields, but only from ten in the morning to four in the afternoon, and only for themselves. They do no work in the nest - although Hoffer saw them occasionally assist, but only when the roof was taken away from the nest. On fine sunny days in July, 
August, September, and the first half of October, the young queens fly away from the nest, settle on flower stems, broad leaves, fences or walls in the sun, and are there sought by the drones of their own or other nests, and fertilised during flight. When the young queens are all thus in a condition which enables them to found new colonies in the following year, the whole family gradually disperses.

"The influence of nutrition is here directly before our eyes. The first brood of workers, laid at a time when the queen has to do everything herself, or with the aid of a few workers, can, of course, not be so well fed as the second brood, produced when the whole of the first brood render assistance. This better nourished brood, according to Hoffer, have developed sexual organs; their more highly nourished condition shows itself also in their greater size, and they sometimes lay eggs from which females are hatched, which must, therefore, be fertilised. Lastly follow the young queens, whose larvæ, with the assistance of both broods of workers, can be fed best of all, and the eggs of which have likewise received by fertilisation an important addition of nutritive material."

In this description we see a succession of three different conditions of environment which act upon the developing young bees, so that each 
brood develops under circumstances which are different from those of the other broods. The difference lies chiefly in the amount of nourishment supplied to each brood. These varying conditions occur every year, and always in each year in the same order, thus forming regular cycles in the life of each species. We must recognise the cause of the three unlike broods of females in the three conditions of food-supply. While the species has been advancing in its development to the production of the new and more perfect forms of the large queens, the regularly recurring period of the meagre food-supply has caused each year the reproduction of the imperfect ancestral form - the stunted worker.

The honey-bee is a species which has developed further along the same lines. Its forms are more specialised than those of the humblebee, and seem to be more differentiated from one another. But the difference is not so great that intermediate forms may not occasionally occur.

In the case of the butterflies we have seen that the change of the seasons was the cause of the existence of two or more forms in a species, but we have previously seen that heat and cold are not the only conditions which advance or retard development. Light is almost as important, and 
the quality and quantity of food are more important in the variety and extent of the effects dependent upon them. The number of different forms which might thus arise in one species would depend on the number of different regularly recurring conditions of development to which the young would be exposed in the long course of generations. Suppose two forms already existing, then we can imagine a new condition to recur periodically in the environment, which, without affecting the conditions which produced the first two forms, would by its continued action eventually produce a third form. This new form would produce additional complexity in the social organisation, which might of itself tend to produce a fourth form. It would be impossible to follow out in detail the conditions which gave rise, for instance, to the eight forms which exist in a species of white ants (termites). The causes may lie untraceably hidden in the geologically ancient history of the species.

Suppose a case where, in some such manner as among the butterflies, two forms of ants have developed-one much advanced in structure beyond the other, but both being fertile. Suppose now, while both are produced simultaneously in the species, that through some change in environment the advanced form should become sterile, though 
still produced in equal numbers. Further changes in environment might entail some periodic change in the food-supply, or some periodic struggle with enemies. In the former case we might have the original form gradually producing an alternate new form to meet the periodic demand for the new method of getting food. In the latter case the tendency would be to produce an alternate new form to carry on the regularly recurring wars. Through later changes of environment these new forms might also lose their fertility, the old original form being the only form remaining fertile. At the same time, instead of being alternate or periodic generations, all four forms might become simultaneous, the difference of development in each form depending on the treatment received by the embryo. Forms of this kind once produced would persist unless some hostile change of environment and natural selection should eventually obliterate them.

We must not forget to make allowance for the effect of instinct in modifying the growth of these social animals. While many are to be regarded as imperfectly developed, some particular instinct seems to be perfectly developed, or, perhaps, over-developed, thus influencing them to a particular line of activity, which must have its effect upon their 
growth. Thus we see, in the workers which have been deprived of their full growth by lack of nourishment, the strongly developed female instinct of caring for the young and building the house. This instinct is probably perfected in each individual largely by its constant exercise. It is probable also that the growth of individuals in a social body, especially the psychic growth, would be affected in some way by the mysterious sympathetic nervous influence which shows itself among animals in the stampeding of cattle, the orderly wheeling and circling of flocks of birds, in the movements of droves of caterpillars and swarms of insects, and by the phenomena of suggestion and hypnotism in man. These instincts might be cultivated by some psychic influence, and, in turn, the instincts may influence the bodily growth. The final conclusion of modern science is, that no cause is too slight to produce an effect. 


\section{CHAPTER XII.}

DEGENERATION AND LAWS OF VARIATION.

THE growth of every organism is the result of a certain combination of forces. If any change, therefore, takes place in this combination of forces, then a change, as the result of their action, must follow. We have seen that a change in the daily illumination of plants can change their periodic sap-flow. Also we have seen that various coloured lights influence differently the development of tadpoles, and that a special diet changes the proportion of the sexes. Exactly how particular forces cause particular effects, we do not understand; but that they do. act, we are compelled to believe, not only by the general principles of physical science, but by the special experiments upon organisms. In the course of generations, the change of forces produces a change in the hereditary impulse of the organism, and thus a new specific character appears. The hereditary impulse, which is the result of the long previous history of the organism, is not immediately changed 
by a change in the environing forces. There is a certain inertia in the nervous co-ordinations. Any single nervous reaction in a connected and oft-repeated series does not disappear the instant its original stimulus is withdrawn. It will last for some time afterward under the influence of association with the rest of the series. Eventually, however, it must disappear, - sooner or later, according to the firmness of the association. Thus when the forces, acting as stimuli, which have directed the growth of any part, are withdrawn, the power of association will still tend to cause the growth of the part, though less perfectly. If an organ be no longer stimulated to perform its function, it is left without one of the chief directive forces of its growth. The power of association, which at first maintains its normal growth, gradually diminishes; the inherited impulse weakens, and the organ gradually degenerates. Those organs will degenerate most slowly which have existed longest in the race. As examples of this may be mentioned the pineal and thyroid glands among vertebrates; and these degenerate organs probably owe their persistence partly to the fact that they are associated in growth with such important and unchanging organs as the brain and alimentary canal.

The blindness of animals which dwell in caves 
is an interesting example of degeneration resulting from a withdrawal of a single one of the growthstimulating forces. These animals, including fishes, amphibians, crustaceans, and insects, are descended from animals which lived above the surface of the earth and possessed eyes. In the blind descendants the eyes are present, but imperfectly developed. There can be, I think, only one explanation of this blindness, namely, that the eyes of many successive generations have never been stimulated to their full growth by light. If we admit the influence of any force of the environment upon the development of individual and race, then we must believe that the action of light as a directing force was of prime importance to the development of the eye. It is a force which has always acted upon organisms wherever eyes have been developed, and the eyes have always stood in a direct relation to this force. To suppose that eyes would develop and grow equally well in darkness, is to accept a doctrine of effects without causes, and causes without effects. The theory has been advanced that the degeneration of the eyes of cave-dwelling animals is due to natural selection. It is supposed that the energy which would be used in perfecting the eyes (which would be useless in darkness) is saved in these blind animals for other purposes. Therefore those with 
the least developed eyes would save the most energy, and so have an advantage over others in the struggle for existence. This advantage, according to that theory, would lead to the establishment of a blind race, and the extinction of races with eyes. When, however, we examine into the supposed relation between the abundance of energy at the disposal of an animal and the perfection of its development, we find that the two conditions by no means coincide. No animals have such an abundance of energy at their disposal as those parasitic animals which live in the bodies of their hosts, continually bathed by nutritive juices, and yet those animals have, above all others, degenerated most in the growth and development of their parts. They have abundance of energy at their command for the performance of growth, development, and all their functions, and yet from the time a race begins a parasitic life, the evidences of its history show that it constantly deteriorates. In some of the crustaceans the organs of sense and locomotion disappear, and the animal becomes a sac, incapable of every function save nourishment and reproduction. Evidently, the abundance of readily convertible energy is not the cause of a complete and perfect development of an animal. And the fact that an animal which is supplied only with an abundance 
of convertible energy cannot maintain the complete development which characterised its ancestors, proves that the formative forces causing development do not all reside in the organism. Some of them must come from the outside. A cursory view of the animal kingdom shows that those races which have been subjected to the greatest variety of action of external influences have attained the greatest complexity of development.

Wherever any force is withdrawn that has always played a part in the development of any organ, that organ will be changed in its development and will be less perfect. Wherever many or all of the forces of the environment are weakened, we may expect an arrest of development or a case of atavism. Whenever there is a general change in the forces of the environment, we may expect a general change to gradually ensue in the race of organisms. This must, however, be limited in two ways. First, the change cannot exceed certain limits without destroying the species. These limits of change are narrower according as the species is more accurately adapted to its environment, i.e. the more its life depends upon minute details. This fact precludes the survival of species under extreme changes, and the changes under which a species can survive are generally so slight that the effect of the change can- 
not be immediately detected. It is only after successive generations have been subjected to the change, that its effect becomes apparent. In the second place, the change is limited by the past history of the species, by its constitution, the strength of its hereclitary impulse, and also by the amount and rapidity of the changes which have been induced during the time immediately preceding. Organisms under changed conditions can only produce slight variations of such structures as are already developed in the species. The changeability of any part seems to be partly dependent upon the length of time it has existed in the species. Darwin expressed this fact and conclusion, as it appeared to him, by saying that "characters become fixed by inheritance," which means, that characters which have appeared through many generations are less apt to vary than perfectly new characters. When a character appears and continues through many generations, its growth is due, not to a temporary, but to a permanent, cause acting upon each individual. As the growth of the peculiar character is repeated generation after generation, it becomes firmly associated with the nervous co-ordinations controlling the general growth of the organism, and forms part of the inherited impulse. Naturally, therefore, characters will vary less the longer they have been subjected 
to the same unchanging environment. Darwin speaks of the changes of growth, in a species resulting from a general change in environment, as the "breaking of the constitution of the species." After the constitution is broken, the species produces many variations of growth. It is to be supposed that, if the new conditions were to endure for a great length of time, the constitution of the species, with its newly induced characters, would again become "fixed." Our domesticated plants and animals are species which, being subjected to a change of conditions from their wild state, have had their "constitutions broken," and ever since, being subjected to constantly changing conditions of locality, soil, climate, cultivation, and breeding, have continued in a highly variable state.

Any change in the stimuli acting upon a species, in order to produce a change in the hereditary impulse, must continue its action long enough to affect the nervous co-ordinations. As a rule, the hereditary impulse is not affected by a change which acts on only one generation. The so-called "individually acquired characters," which are produced by the temporary action of peculiar forces upon a single individual, are not inherited, because the nervous coordinations are not so greatly disturbed that they cannot, in the next generation, under the normal stimuli of the species, react in the normal method of devel- 
opment. It is essential that the inertia of the nervous co-ordinations be overcome, and that there be made a permanent change in associations, otherwise any enforced change of growth will not pass over to succeeding generations. A slight disturbance in the manner of growth may be produced artificially in many successive generations, without producing a permanent change in the hereditary impulse. Thus, for many successive generations, the tails of certain breeds of game dogs have been cut off ; and yet, the tails of the latest generation continue to grow if not disturbed. The explanation of this, and of all phenomena of this class, seems to be, that the artificial change of growth, acting late in the period of development, and upon a single unimportant part, has not produced so profound an impression upon the nervous organisation as to overcome the powerful associations which unite the co-ordinations governing the growth of the tail with the co-ordinations governing the growth of the rest of the body. While the tail is not important to the life of the dog, yet the co-ordinations governing its growth have been associated, by repetition, with the co-ordinations governing the growth of the trunk since the earliest appearance of the vertebrates, the tail being phylogenetically a much older organ than the legs. Therefore, when there is a reaction of the co-ordinations of growth of the trunk, there will also be, through 
association, a reaction of the co-ordinations causing development of the tail. To eventually destroy this association might require a more profound disturbance of the nervous organisation than the mere cutting off of the tail after it has developed.

A more profound disturbance is caused when the nervous system itself is directly affected. The operation of such a disturbance may in one or two generations produce an effect in changing the hereditary impulse. Thus general intemperance and drunkenness in one or two, or a few generations, may produce insanity or other mental weakness, which is handed on and reappears again and again in future generations. This same principle is illustrated in the celebrated experiments upon guinea-pigs by Professor Brown-Séquard. By operating directly upon the nervous system, he was able to cause certain well-marked changes of growth to appear in the succeeding generation.

The strongly hereditary nature of insanity and other mental diseases, - they being of all diseases the most certain of inheritance, - and also the frequency of their appearance in combination with other deformities of growth, both of these facts emphasise the relation of the nervous organisation to the phenomena of development and heredity. 


\section{CHAPTER XIII.}

EMBRYONIC ORGANS. - METAMORPHOSIS AND ALTERNATION OF GENERATIONS.

IN our analysis of the development of an individual organism from the germ to maturity we saw that two kinds of causes were at work in the process. One set of causes comprises all those conditions in the living matter of the germ which are the result of the entire past experience of the continuity of living matter of which the germ formed a part. We have seen also how these conditions have arisen as the result of long continued repetition of the reactions of living matter to the forces of the environment, - the effects gradually accumulating by the power of nervous association through the long course of ages and generations, and forming what we have called the hereditary impulse. The other set of causes controlling individual development are those combinations of external forces which act constantly and periodically upon the developing organism, supplying to 
it the matter and energy requisite to its growth, and stimulating its activity. These two sets of causes produce the development of every individual, and no change can occur in the development of new individuals except through some change in the causes. These two sets of causes, however, are not independent of each other. The whole chain of associations comprising the hereditary impulse may be present in the germ, but there will be no development unless certain definite external forces, in their proper sequence, supply energy and matter to the organism as it progresses in its growth.

As the development of an organism is a process of constant change, there must arise at every moment a new relation of the forces which cause the change. At each moment the action of the various forces causes the developing organism to change. This change results in a new arrangement of the parts of the organism, i.e. a new combination of its internal forces. Now, whether the external forces remain the same, or whether they change, we have in either case a new combination of the whole complex arrangement of forces which act to produce development. This new combination we must regard as the cause of the immediately ensuing step in development. Thus every step in development is the result of a partic- 
ular combination of forces acting at the proper moment. These combinations of forces follow each other in fixed and regular sequence, and blend one with the other. As the sequence is generally the same for all organisms of a species, so the organisms resemble each other. Where the sequence for any individual differs from the sequence for the rest of the species, that individual will differ in growth from the rest of the species, provided always that the difference be not so great as to destroy the life of the individual.

The changes of these combinations of forces are not equal in extent or activity at all points of the sequence. Thus in the earliest development of an organism, the changes of development are more marked and more rapid - the earliest stages of development having been repeated most often. In the latter stages, as the organism approaches maturity, the changes become slower, less marked in degree, and less certain - the very last stages that appear in some cases being wholly omitted in others. Apparently, these very last reactions of the organic matter to the forces at work upon it have not been repeated often enough to become firmly associated with the older and stronger part of the hereditary impulse. The power of the hereclitary impulse, in the latter stages, loses strength 
as its associations become weaker and as its reactions are less practised. Growth, therefore, becomes more sluggish. The internal arrangement of forces is not so quickly and easily changed; the external forces remain unchanged, and thus the successive combinations of the two sets of forces change less and less, until finally growth and development practically cease.

If, at any intermediate stage in this course of development, the particular combinations of forces causing growth of that stage should be changed, it follows that the growth itself at that stage would be changed. We have reason to believe that the manner of growth for some particular period of development may be secondarily changed without radically affecting either the preceding or succeeding growth. As an example of this, may be mentioned the embryonic organs and embryonic modifications which adapt the embryo to undergo a partial development in the body of the parent, and allow it to receive nutriment from the parent, e.g. the placenta. According to the generally accepted theory these modifications have gradually developed upon a form of embryo that was originally adapted to perform its whole development outside the body of the parent. Such modifications cannot have arisen by the backward transference of 
acquired characters, but must have developed solely for the period of embryonic life for which they are useful, and they must, further, be the result of the peculiar conditions which came gradually to surround that period of the life of the animal. The placenta, etc., have probably been caused by the new and peculiar stimuli which began to act on the organism when the egg remained so long in the body of the parent that part of its development was performed under these novel conditions. This belief is strengthened by viewing the similarity of embryonic conditions, and the consequent similarity of modifications which have arisen in such widely different groups as the mammals, the selachian fishes, the lophobranchiate fishes, and Doliolum among the tunicates. We see therefore that this associated chain of nervous reactions which form the hereditary impulse resembles in its nature the ordinary chain of associated reactions which are established in an individual by practising any regular series of movements. For in such a series of reactions the middle part of the chain can be gradually modified and changed without destroying or weakening or changing the other associations in the first and last parts. In such a series of wellpractised movements as the playing of a passage of music upon an instrument, the first effort to 
change the movements in the middle of the passage will be resisted by the strength of the associations, but by a continued change of the stimulus this resistance will be overcome, the movements will be changed, and new associations will be established. The modified series differs from the original series by only a few links in one part of the chain. The method and nature of the associations in this illustration and in the hereditary impulse, I believe to be essentially the same.

In the same manner may be explained all the temporary embryonic organs and conditions of growth which exist in the embryo, but which cannot be regarded as ever having existed in any adult ancestral form. Thus the gill-clefts of the mammals can be regarded as inherited from some adult fishlike ancestors, but not the placenta; and the first stage of the cranial flexure we cannot imagine to have ever existed in any adult animals. The placenta is undoubtedly the result of its immediate surroundings, while the cranial flexure seems to be due to its peculiar method of rapid increase of bulk, and to be the manner of closing the neural canal.

Another class of phenomena suggests itself here, as being somewhat akin to the phenomena of embryonic growth; namely, the development of larval forms and metamorphosis. An examination of the 
embryology of the different groups of the animal kingdom reveals the fact that in no case does the development proceed with equal rapidity at all points of its course from inception to maturity. As before remarked, toward the end of its course, development becomes slower and less marked in its changes. As pointed out, this is due to lack of strength in the association of the hereditary impulses, and consequent lack of progressive change in the sum and relation of the internal and external forces. This progressive change in the relation between the internal and external forces is the cause of development. The progressive change is most constant and invariable for long successions of generations, in the earliest stages of development before the animal leaves the egg, or the body of the parent, and therefore at this period the development is most rapid and uniform. When the animal leaves this earliest protection, and goes forth a very imperfectly developed creature to shift for itself, it then meets with conditions that are slightly different for each generation and each individual. At this period of its life, therefore, because of its variable relations to variable conditions, the associated reactions of the hereditary impulse will not be so strong, and development will accordingly be slower and less uniform. For it is a general fact, that those associations are 
the strongest where the separate acts of practice, i.e. the successive repetitions, are exactly the same; any slight changes in the successive repetitions tend to lessen their power to form nervous associations.

This larval period, when the imperfect animal is shifting for itself, living a free life in a variable environment, might be a period of considerable diversity of individual conditions, and be followed later by a period in which the conditions would be the same for all individuals. Take, for example, the development of the butterfly. First, comes the embryonic period, where the conditions are the same for all individuals of the species; the hereditary impulse is accordingly strong, and the development rapid and alike in all individuals. Then comes the larval period, when the organism must seek its own food, and the individuals must meet with diverse experiences of life. In this period the development is slower, and individuals of the same brood sometimes develop slight differences, e.g. in coloration. Third, comes the chrysalis stage, when the conditions are again uniform for all individuals. In this stage the hereditary impulse is again very strong, and the greatest changes of development take place, and follow with great certainty and uniformity for all individuals and generations. The rapidity of development, however, at this stage, is modified by and 
largely dependent upon, external conditions of temperature, season, and climate.

In order to explain the origin of this complicated method of development, we must look to the lower and ancestral forms of insect life. In the gradual evolution of the hereditary impulse, as I have described it, we cannot suppose the ancestral line of the butterfly to have come by a simple and direct manner to its present complicated method of development. The simple manner of development of the hereditary impulse is by constant and similar repetition in each cycle of life with the resulting associations, the adding of new slight characteristics at the end of each cycle, the more rapid repetition of that earlier part of the cycle which has been repeated most often, and thus the backward transference of the newly acquired characters. The result of such a simple manner of evolution of the hereditary impulse, would be that the earliest part of the development of an individual would be most rapid and invariable, and the later part would become slower and slower as it progresses toward the end of its course, and would be also less certain. There could be no period of slow and variable development succeeded by a period of decisive and invariable development. The lower orders of insects, we find, follow the simpler method of development, - the 
changes from egg to maturity occurring with gradually decreasing rapidity throughout the whole period of development, and no sudden and striking metamorphosis takes place in the last stage. This method we must suppose also to have been followed at some time in the past by the ancestors of the butterfly. What causes may have effected a change in this simple manner of development and produced the present method, we cannot definitely determine. But still, from our knowledge of the nature of the hereditary impulse on which this change has been wrought, and from our knowledge of the present manner of growth, we may gain some idea of the nature of these causes. Imagine some ancestral form of the butterfly in which the development was simple and gradual from beginning to end, without any sudden metamorphosis, in fact, such a method of development as that of the grasshopper. Suppose such a change in the environment of this organism that on reaching the stage of development equivalent to the caterpillar stage, the organism should meet with conditions of existence much easier than hitherto. Let its food become very abundant, and let its external conditions remain for a long time unchanged. This of itself, we have seen in discussing parasitism, would be enough to hinder its development, through the withdrawal of its customary 
stimuli of development. Suppose, further, that the new conditions of existence while remaining for a long time the same for each individual, should differ slightly for successive generations. The effect would be to hinder still further the action of the hereditary impulse. The total effect, therefore, of these new conditions would be to prolong the caterpillar state, - there would be a tendency to remain in this state. But the hereditary impulse is not destroyed, and the mature development of the insect eventually occurs, the only change being the extreme prolongation of the caterpillar stage. Suppose now some change of climatic conditions, whereby as each generation is about to abandon its protracted caterpillar stage, it encounters cold weather. Each caterpillar protects itself with a wrapping of leaves or a web of its own spinning; and because of the strong associations of hereditary impulse, development proceeds - a supply of energy from the previous abundance of nutriment being on hand. In this quiet, motionless, and protected state, the conclitions of development are the same for each individual and each successive generation, therefore the hereditary impulse for this period thus becomes invariable in its results, more rapid, and its various stages become compressed. The last changes of development, as is universal in the organic world, tend to occur earlier 
and earlier in successive generations, i.e. tend to be transferred from the end of development back toward the beginning. But in the butterfly the backward transference is limited by the slow and variable development of the caterpillar stage. The changes of development are therefore compressed and heaped up, in the period during which each generation lies quietly protected in the shelter it has made for itself. Thus the greater part of its development may take place in the chrysalis stage.

By following this line of supposition, we can see how forms might arise in which, the larval life being greatly prolonged, and the chrysalis life being abbreviated, the stored nutrition or potential energy of the larva might suffice not only for the chrysalis stage, but also for the adult stage, so that the mature forms might reproduce before they had ever partaken of food. The result would be that, in the course of generations, the habit of taking food would be lost by the mature form, especially if the supply of food for the mature forms failed. When the habit of eating were lost, the corresponding organs would degenerate and disappear by reason of disuse. But since it is necessary for an organism to attain maturity in order to reproduce, the mature state, however brief, must be its final stage of development so long as the species exists, - even though it be in the 
larval stage that the organism. acquires the potential energy that keeps the species alive.

The above explanation seems to me to account not only for insect metamorphosis, but also for the curious cases of extremely long larval life and very brief maturity, such as the Ephemera and seventeenyear locust (Cicada septemdecim). The great length of the larval life of the latter is probably due to the unchanging conditions of its existence underground, especially the sameness of temperature and the darkness. In this connection, another curious fact suggests itself, namely, that the wings of certain ants drop off after the hymeneal flight, a few hours after the completion of development, which is ended by the emergence of the young ants from their cells. Apparently, the wings are developed through the strength of the hereditary impulse. Long-continued habit has made it necessary for the ants to fly up in the air for the act of reproduction. For this, wings are necessary, and, by virtue of their powerful association with the reproductive act, they are still retained among the associations of the hereditary impulse, though they are otherwise degenerate organs, and not developed by the worker ants. That they should drop off immediately after the hymeneal flight, seems to be a curious case of the transference of a degeneration backward as far as possible without interfering with the reproduction of the species. 
The principle which I have illustrated by the case of the butterfly seems to me to be applicable to all cases of animal metamorphosis. Wherever animals with an established method of development are in active intercourse with their environment, and struggling for their existence through a long period of immaturity, it must follow that when the conditions of their larval life change, the course of their larval development must be affected. In any change of environment it is hardly possible that all the stages of larval life could be equally affected. The change would probably be more favourable to some stage or stages of life, and less favourable to others. The result would be a prolongation of the favourable stages of life, and an abbreviation and compression at other stages. Thus may be explained the origin of periods of sudden changes, or metamorphosis.

In the same category with metamorphosis should be placed another class of phenomena, which is usually described as "alternation of generations." But we must except here dimorphic species, already discussed, and that kind of alternation of generations which consists in the alternation of sexual and parthenogenetic generations, as in Aphis and other arthropoda. This latter is a phenomenon that truly deserves its name. The cases, however, of many of the Hydroids and Tunicates are of another char- 
acter. Let us consider Salpa as an example. In this genus the fertilised egg develops into a small transparent barrel-shaped creature, which swims free and near the surface of the ocean. When the animal has attained its growth, there appears on the ventral side of it a very small stem or rod-like prolongation of the internal tissues, which is destined to develop into a colony of individuals. This stem, or stolon, as it is called, is made up of tubes developed from the entodermal and mesodermal tissues, covered externally by ectodermal tissue. As the stolon becomes longer, its distal portion enlarges and divides - without complete separation - into a series of transverse segments. Each segment receives thus a part of each of the three fundamental tissues. As the segments are increased in size, they are squeezed alternately right and left, though all remain connected by a common circulation. Each segment develops into modified barrelshaped individuals with male and female productive tissues. At length the oldest part of the stolon, having developed thus into a colony, breaks loose from the rest of the stolon, which, in its turn, follows the same course of development. The individuals of the now free-swimming colony proceed to reproduce sexually the eggs from which the first described single form of Salpa develop. One thing 
remarkable about the development of the colony lies in the fact that the eggs develop in the tissue of the stolon before the stolon segments itself to form the individuals.

For explanation of this method of growth, we naturally turn to the ancestral forms of the Tunicates. We find among single Ascidians growing fast to rocks, etc., some forms which mature and reproduce sexually, and at the same time produce by simple budding one, or perhaps three or four individuals, which remain fastened to the first near its base. All of these individuals are essentially alike. A grade higher in the scale, we find the group of Botryllus, also stationary, where the young one developed from the egg does not mature, but buds into four individuals, and is said to disappear by absorption into the four. These in turn, before maturing, give off other buds, all of which together form a colony. In these later buds, long before development is complete, the egg-cells appear well differentiated, showing that in this respect Salpa is not unique. This early development of eggs, and the rapid reproduction by budding are probably both the result of a great abundance of food. In another stationary group, Perophera, we find a manner of growth more nearly according with that of Salpa. From the egg of Perophera 
arises an individual which, long before it has completed its development, sends out a comparatively large bud or stolon composed like all such buds of entoderm, mesoderm, and ectoderm, and comparable to the first bud of the single Asciclian. When the stolon of the young Perophera has attained a considerable length, there appear at intervals along it, several small swellings, comparable to the subdivision of the young bud of Botryllus. Each of these little swellings of the stolon develop into sexual individuals, which remain united in one colony, and never have an independent existence. In external appearance all the individuals of the Perophera colony are alike. Let us compare now the development of the Perophera colony with what seemed like the two generations of Salpa. In each case there is a first individual which produces a stolon. From the different portions of the stolon are produced the other individuals which make up the colony. Suppose a fixed - Perophera-like colony to change its habit of life and become free-swimming. Evidently a weak immature individual dragging a long stolon would be at a great disadvantage. The probable result would be that the single individual would attain its full growth before the appearance of the stolon, and the stolon would be much diminished in size. 
This is apparently what has happened in the phylogenetic development of Salpa. Here the stolon is not only much diminished in size, but to prevent its retarding the progress of the animal through the water, it is coiled up and enveloped in the wall of the body. When a portion of the stolon has developed into nearly perfect individuals, it becomes pushed out and hangs free in the water, and is finally broken off. The first individual of Salpa is therefore homologous with the first individual of Perophera. The free-swimming life of Salpa is most favourable to a single untrammelled individual, or to a perfect colony ; accordingly these two stages in the growth of the colony become more pronounced, and the intermediate stages become abbreviated and compressed. Instead of two distinct generations of Salpa, we have only two peculiarly modified forms of the same colony, which eventually separate by force of circumstance.

An extremely interesting example of metamorphosis is presented to us by the Medusæ. The study of morphology has shown us that these freeswimming animals were originally derived from stationary Hydroids. As was explained in the case of the butterfly, this phylogenetic development must have been gradual, and individual development must have been originally without sudden jumps or metamorphoses. The individual Medusa 
developing simply, after the gradual manner of development, would have repeated regularly all of the stages of development through which its ancestors passed. But apparently secondary conditions of environment have arisen which favour the hydroid stage and the perfect medusa stage, and at the same time tend to eliminate the intermediate stages. We see the result in the luxuriant development of the hydroid state, with its fixed colonies of variously differentiated individuals, and then the sudden metamorphosis into the widely different form of the Medusa with its new addition of nerves and sense organs, indicating the total suppression of a long series of intermediate stages of ontological development. On the other hand, the secondary changes of environment were in some cases unfavourable, not alone to the intermediate stages of development, but also to the hydroid stage itself, and resulted in the suppression of the latter also. Thus we find Medusæ in which the hydroid stage of development is completely absent. This seems to me the only way in which we can explain the great similarity in the various adult Medusæ, and the great dissimilarity in their methods of individual development. It would be impossible to explain the details of these changes; the theory indicates the manner in which their investigation should be approached. 


\section{CHAPTER XIV.}

ORIGIN AND SIGNIFICANCE OF SEX.

IN order to understand the nature of sex, let us return to the consideration of the processes of life among unicellular organisms. In the first place, we see that those constructive changes of the protoplasm which are caused by the environment are not destroyed when the protoplasm divides into two parts. The elementary nervous organisation remains effective in each of the two parts. The results of the original stimuli acting upon the single mass are shown in the development of each part, as the magnetising of a steel bar will cause each piece of the bar, when broken, to form a magnet. What the nature of these changes in the protoplasm may be, from a physical point of view, we cannot conjecture. We have seen that they are not destroyed by a division of the protoplasm, and we have further to notice that they are not destroyed when two separate bits of protoplasm unite and fuse together in one mass. Here the illustration 
of the magnet again holds good. The two masses blend in their union the effects of their past experiences as individual organisms. From the union of the two organisms there may arise one or many organisms, each displaying the results of the influence of environment upon the two parent organisms. This is the process of conjugation which prevails largely among unicellular organisms. If we may judge from the phenomena of heredity in higher organisms, we conclude that each parent organism transmits the effects of its already induced changes to the progeny, thus producing new and generally intermediate forms. We know, from the observation of the higher animals, that the potentialities of development of both parents are present in the initial stages of the embryo, and that the development proceeds this way or that way, according to the stimuli brought to bear upon the embryo. Thus the young of frogs have the power of developing like the mother or the father, and, as shown by Professor Yung, their manner of development is dependent upon the quantity and quality of their food. The honey-bees furnish another illustration, for among them the food and treatment which the embryo receives, determines whether it shall grow into a queen or a worker. Also there have been described a large number of cases showing that 
under peculiar and little known conditions male characteristics may develop in the female, and female characteristics may develop in the male. The different characteristics of the parents seem capable of almost infinite variations of combinations, and even the most distinguishing characteristics of the two sexes may be combined in one individual.

It is within the bounds of legitimate inference to believe that inheritance among unicellular organisms is fundamentally the same process as in the higher organisms. Therefore we may assume that we are right in our conclusion that the conjugation of two individuals combines two potentialities of development, - or combines two hereditary impulses into one. But, as has been pointed out heretofore, the hereditary impulse does not alone determine the development, for the development is dependent on the action of external forces or stimuli, which sustain and guide its activity. The environment modifies the hereditary impulse, and determines within limits the intensity and direction of its development. We may suppose the hereditary impulse to be made up of two sets of potentialities of growth - one set derived from each parent. Each of the two bits of protoplasm which mingle to form an individual has its associated co-ordinations of reactions; which of these reactions shall take effect depends upon the 
stimuli of the environment, for each developmental reaction is caused only by certain definite stimuli and cannot occur without them. The facts of inheritance show that the stimuli of an environment may produce developmental reactions, some of which are inherited from one parent, and some from the other parent. If the stimuli acting on a developing individual resemble more closely the stimuli that have acted for a long time upon the protoplasm derived from one parent, and differ slightly from the stimuli that have acted upon the other parent, then the individual will develop more after the fashion of the parent whose environment was like its own present environment. Mr. Herbert Spencer, after discussing some of the phenomena of breeding domestic animals, seems also to arrive at this same conclusion. ${ }^{1}$ When the conditions of stimuli have long been the same for both parents, or both parental races, then we might expect the union to intensify the hereditary impulse, and, under the same conditions of stimuli, to produce a more perfect development along the same line - as in our most approved cases of artificial breeding. On the other hand, when the stimuli acting on the developing organism are a selected combination of two different

1 "Inadequacy of Natural Selection," by Herbert Spencer, Contemporary Review, March, 1893 . 
series of stimuli that have acted separately on the two ancestral lines, then we might expect the individual development to combine characteristics of the two parents, - the mixture of stimuli calling forth a corresponding mixture of developmental reactions.

Experiments in crossing breeds, varieties, and species of plants and animals, show that the hereditary impulses of the two organisms united in the cross must be very similar if a perfect development is to result. When the two organisms differ enough to be classed as separate species, the offspring of the union is rarely perfect. Two allied species have the greater part of their development alike, - it is only as their development nears its completion that the lines diverge. In the same way, they have had a common ancestor in comparatively recent times, and before their divergence from that ancestor, they have had a common ancestral history. From what we have learned of the origin of the hereditary impulse, we may conclude, therefore, that two allied species have their hereditary impulses identical up to a certain stage of growth - the stage represented in their racial history by the common ancestor; from this point, through the latter part of their development, the hereditary impulses proceed in opposite directions. The offspring of a cross of two such species might therefore continue its devel- 
opment so long as the two inherited impulses were alike, but when the impulses begin to impel growth in opposite directions, the development must cease. This explains why the imperfectly developed offspring of a crossed species resembles an ancestral form. For, when the method of development of two animals proceeds for a time on the same lines, and then diverges, the result of the cross will develop only as far as the point of divergence. Thus the fancy breeds of pigeons, when crossed, produce the ancestral form of the rock-pigeon. Also the stripes on mules show a partial reversion to a zebra-like ancestor of the horse and the ass. Since reproduction is a superabundant growth, these hybrid organisms which do not attain a perfect development, nor a full growth, are generally sterile.

Conjugation, or union of two cells to produce the one or more individuals of the succeeding generations, is generally admitted to be the first step in the evolution of the sexual method of reproduction; and in this connection $\mathrm{I}$ wish to direct attention to some points which have not generally received the consideration which their importance seems to demand. From its almost universal existence among the more complex organisms, the sexual method of reproduction, whereby each individual born may inherit from two parental races, appears to play a 
very important part in organic evolution. It seems as though it might have originated among singlecelled animals, by the effort of simple protoplasmic masses to absorb each other as food. Such a mutual effort between two individuals would, in all probability, end in a drawn battle by the commingling of the two masses of protoplasm. The sudden superlative growth - the doubling in size - would of itself induce reproduction, i.e. subdivision, - the new generation would be formed of protoplasm derived from the mixture of both parents, and would inherit developmental potentialities from each.

But, beside this double inheritance, there is another very important feature of sexual reproduction; for although each of two organisms may be capable singly of reproducing, yet the process of conjugation gives a peculiar stimulus to the developing germ, which entails a more complex or a more complete development. That this mixture of protoplasm derived from two organisms is largely of the nature of mere stimulus to growth activity, is shown by the fact that among many organisms accustomed to reproduce asexually, there may be produced, without fusion of protoplasm, a germ which will attain only a partial development soon arrested, or perhaps develop into a weak individual. A germ thus produced, and a germ produced by 
the fusion of two protoplasmic cells, have in other respects the same surroundings, so that we cannot attribute the lack of development of the former to a lack of nutriment, but must regard it rather as owing to the absence of that stimulus derived from the fusion and mutual influence of two cells of different potentialities, that is, different ancestries. That this latter is important, is shown by the fact that many plants cannot be fertilised by their own pollen, when the same pollen is efficient with other plants. This self-sterility of plants seems most plausibly explained as the result of too close interbreeding, whereby the sexual elements of the same growth have lost that peculiar differentiation which is necessary to produce the mutual stimulus for development of the germ. Says Darwin, "Both with plants and animals, there is the clearest evidence that a cross between individuals of the same species, which differ to a certain extent, gives vigour and fertility to the offspring; and that close interbreeding, continued during several generations between the nearest relations, if these be kept under the same conditions of life, almost always leads to decreased size, weakness, or sterility"; and again, "slight crosses, that is crosses between the males and females of the same species, which have been subjected to slightly different conditions, 
or which have slightly varied, give vigour and fertility to the offspring." Mr. Havelock Ellis, after investigating in detail the ancestry of men of genius, comes to the following conclusion: "Wherever we find a land where two unlike races, each of fine quality, have become intermingled and are in process of fusion, there we find a breed of men who have left their mark on the world, and have given birth to great poets and artists."

We have therefore to regard the consequences of the sexual method of reproduction as of two kinds first as a profound stimulus to the general development of the germ; and second as a combining of two sets of potentialities of development. The full bearings of this latter consequence seem to have been hardly recognised. The most certain and most striking conclusions deduced from experiments in breeding are - first, that uniting dissimilar forms tends to produce an intermediate form; and second, that uniting similar forms tends to intensify the peculiar characteristics of the parents. If new variations in form were really so scattered in time and space, and affected only exceptional individuals here and there, as has been sometimes supposed, it would be difficult to imagine why "natural selection" should maintain a method of reproduction which would be constantly tending to obliterate all varia- 
tions; for if the organisms were interbred closely enough to preserve the variation, degeneration and sterility would probably result. On the other hand, crossing would obliterate the new variation. It is equally difficult to imagine how new characteristics can arise by means of the sexual method of reproduction, when the weight of evidence goes to show that its strongest tendency is either to obliterate peculiar and rare characteristics, or to intensify those already existing in both parents. It seems, therefore, that the sexual method of reproduction must have some other reason for existence than the production of new forms by the mixture of different germ-plasms. We must attribute all new changes in the construction of organisms to changes in the forces that act upon the organism while in process of construction, - and, as I have pointed out, in each generation forces are indirectly acting on the construction of all generations to come after. Every generation helps to form the hereditary impulse which determines the developmental reaction of each succeeding individual to its environment. Where a species continues for a great length of time in unchanged conditions, the constant sameness of successive cycles of life makes the hereditary impulse fixed and invariable, and the species becomes highly specialised to suit its surroundings. Eventually the lack 
of some change of stimulus seems to cause a lack of development and growth. We can imagine a number of individuals reproducing asexually, forming a variety so highly specialised and completely adapted to certain limited local conditions that a comparatively slight change of the conditions might cause the total destruction of the variety. The ill effects of too great a degree of specialisation are well known. On the other hand, a sexual mixture with individuals living under slightly different conditions - that is, a commingling of different developmental potentialities - seems to give a greater power of adapting to changes of environment. Each individual, instead of inheriting, so to speak, the experience of a single straight line of ancestors, inherits from a geometrical progression of ancestors almost the whole experience of his race, and comes into the world equipped with an hereditary impulse capable of responding to all the conditions under which any one of his race can survive. Sexual reproduction thus appears in a new light, as a means of widening the range of responsive power by combining a great number of inherited potentialities, and so enabling the developing organism to cope with any of the various conditions which have been met by its numerous ancestors. 


\section{CHAPTER XV.}

\section{CONDITIONS OF DEVELOPMENT. - DEATH. - CONCLUSION.}

THE different methods of development of various organisms cannot be accounted for by difference in the chemical composition of the germs, nor by difference in their cellular structure. We must recognise some general property of living matter, by virtue of which the individual and racial development of organisms takes place. We can only express it as that which is the basis of nervous co-ordination and which makes all nervous activity possible. It is something which is not destroyed by the division of an organism, nor by the fusion of two organisms into one. The latent potentialities of the two organisms, which are based upon this property, may be mixed in a great variety of combinations, combinations which are, however, dependent upon the stimuli to which the organism is subjected during its development. In no case can we recognise this property of development as acting independently 
of the stimuli applied to the organism. Remembering that by stimuli we mean all of the forces acting on the organism, we must believe that every change in the stimuli necessitates a change in the organism, - or else we are left to suppose that the processes of development transcend the law of the conservation of energy. We have seen how unnecessary and erroneous it is to suppose that the germ is a complex mechanism of molecules so charged with potential energy that it will unfold and evolve itself into a predetermined adult form, without regard to the stimuli of its surroundings. All such suppositions fall short of explaining the real nature of developmental change. They do not touch the fundamental nature of the property which makes development possible, nor explain how the complexity of development has originated in the course of evolution. From the manner in which this property of development is exhibited in organisms, from its retention of latent potentialities, from its ability to survive division and commingling of the protoplasm, and from its power of reacting to stimuli, we must conclude that it is a fundamental property of living protoplasm. When we consider the protoplasm's responsiveness to stimuli, and to the effects of repetition or practice, with the intricate co-ordinations that may thereby be effected, also 
the impressions made by stimuli which remain long fixed as "memory," we are led directly to suppose that the property which is the basis of bodily development in organisms is the same property which we recognise as the basis of psychic activity and psychic development. A broader view of living organisms will only strengthen the supposition; for when we know that certain purposeful material changes begin in a germ and continue in an unbroken causal series, until this finally becomes the series of brain changes concomitant with the thinking processes of a Shakespeare or a Newton, we can readily suppose that the whole series rests upon the same property of organic matter - the property which is at once the basis of development and of psychic activity. It would be difficult in the face of the facts to imagine that organic development differs in its nature from psychic activity, or rather - to speak more accurately - from the material accompaniment of psychic activity. For instance, the nest memory of birds is transmitted by the sexual germs; now, can we imagine that all the psychic qualities congregate in one portion of a certain blastoderm cell which shall later produce the epidermis, and does that one portion of the blastoderm cell produce those particular epidermis cells which later form the brain? We have no evidence for such a view, 
but on the contrary, the facts of embryology and morphology point to a negative conclusion. The epidermis cells from which the brain develops seem to be like all the other epidermis cells, and among worms and other lower animals parts of the nervous system when cut out may be replaced by a new growth from other cells around them. Since, therefore, the brain cells possess the power of purposeful response to stimuli, can the purposeful response of the other cells, sprung from the same blastoderm, be attributed to a totally different property?

An instinct or habit of action is not essentially different from a habit of growth. We have seen how the habits of growth and development were formed by long continued repetition of mechanical reactions, and how they perpetuate themselves in the hereditary impulse. In the same way, the more complex reactions of an animal, such as feeding, reproducing, nourishing, and protecting the young, being repeated in each generation, tend by repetition to become as much a part of the hereditary impulse as the growth or development itself.

It is interesting to note the fact, that when any action is repeated a great number of times, although at first it is only with great difficulty that the action can be performed twice exactly alike, yet finally, after a great many repetitions, the successive per- 
formances of the action assume almost an exact similarity. This principle of nervous action explains why the instinctive actions of all individuals of a species resemble each other so closely.

There is, however, generally a slight difference between the instinctive actions of different individuals. This is due to a difference in surroundings. The delicate organisation with which the instinct is connected responds to very slight differences. This peculiar response to new conditions is what is called "intelligence." It is, however, only the necessary response of a complex organisation to new and unusual conditions. Instinct is the necessary response to usual conditions; intelligence is the necessary response to unusual conditions. Thus by instinct a bird's nest is planned; by intelligence it is adapted to the peculiar requirements of the location and materials at hand. The difference between instinct and intelligence is therefore neither fundamental nor very wide. The great impelling motives of mankind may be classed as instincts. Such are the instincts of self-preservation, procreation, loving and caring for one's children and friends, with the consequent desire for power, knowledge, and wealth. The responsive adaptation of each individual to those conditions of environment which are new and unique in his 
own life, is the exercise of "intelligence," and varies with the fineness and perfection of the organisation. To realise the instinctive character of the great mass of human action, we have only to look at a large collection of mankind as a whole, and notice the monotonous sameness in their actions from year to year, as shown by statistics of birth, marriage, pauperism, crime, illegitimacy, commerce, and manufacture.

The intelligent human action and the simplest process of growth are thus alike the necessary result of the stimuli which are momentarily acting, and those which have acted upon the organism through its racial and individual existence. This is the logical outcome from the doctrine of the conservation of energy. The evidence is such that we cannot escape the conclusion. We must accept it in spite of the serious problems which it raises in regard to free will and moral responsibility; the solution of the paradox thus raised seems to lie in the proper conception of Being, and the relation of its parts.

The view that mind has developed according to the principles of the theory here explained; will, I think, simplify and elucidate some of the problems of psychology. At a glance one can see how far Locke was correct in this theory of the mind 
beginning its existence as a "tabula rasa." The mind truly began its existence as a blank sheet, but that was in the very first of the whole series of living organisms, and by the inherited results of the experience of every succeeding generation it has attained its present development. It is not within the scope of the present work to explain in how far mental phenomena are due to properties of some mode of Being, and how far they are the result of processes of development. It is enough to say that all material form and activity (as of brain and nerves) come under the latter category. Professor Höffding ${ }^{1}$ has pointed out in an admirable manner the parallelism existing between the material and mental the body and mind.

The history of philosophy and of nations shows how the development of knowledge and institutions has followed the general principles of the theory of development here set forth. For while the material world has remained unchanged, each successive generation of mankind has been altered by the slowly accumulating mass of human experience, and so has reacted to the demands of environment in a slightly different manner. The great minds who have added to human knowledge have but reacted in a natural way to the influence of

1 Outlines of Psychology. Macmillan \& Co, 
human experience and the ideas and conditions of the age and environment in which they lived. An illustration of this is the fact that so momentous a theory as that of organic evolution by natural selection was discovered simultaneously and independently by two great naturalists. The knowledge already existing determines what shall be the.next advance. Thus Aristotle, though as gifted as Newton, could not discover the law of gravity, for the idea was too remote from the knowledge of his age. Newton could only succeed Copernicus, Galileo, and Kepler. We are accustomed to say that the development of human knowledge and institutions has been logical, which is the same as saying that their development follows the laws of mental activity.

The similarity or identity of the general laws of mental activity with those of development, points to a fundamental identity in the nature of the two classes of phenomena. The laws of mental activity are more easily studied and more generally known in their details than the laws of development. If the identity, therefore, be real, we shall get a more accurate understanding of development by explaining it according to the laws of mental action. This method will be found to yield at least very suggestive results. 
It is a matter of common observation that the human mind will not develop to full power without a certain amount of stimulus from its surroundings, without something to urge it to activity. All systems of primary education are based upon this fact; and even after the schools have done their work, unless some change of conditions of life, infusion of new ideas, or adversity and misfortune, occur to compel the mind to great activity, it will not attain its greatest development. It will not only lack the power of rapid calculation and comprehensive judgment, but will be narrowed in the range of its feelings, and wanting altogether in certain sympathies. A general proof of this is furnished by comparing the average mental development of those who, having no high intellectual interests, live always without change in quiet villages and on farms, with the development of those who dwell in cities and also travel. We see also that the mind and the brain - its physical mechanism not only need an active stimulus from the environment to attain their normal development, but need constantly new stimuli to retain those powers in perfection. This principle has a very wide and important application, as can be seen by reviewing the conditions necessary to the development of animals. They all require the action of stimuli 
in order to develop; and the degree of development which they attain is greater as the number and variety of the stimuli increase.

In the lives of human beings, at periods when the intensity of the general stimuli to life and action is greatly increased, there is a corresponding increase in the emotional or bodily activity resulting in a change of bodily conditions or a change of character. The history of nations shows certain periods when the imagination has been strongly stimulated by the infusion of new ideas from abroad, or by ideas evolved at home, or by great discoveries, so that for a few generations the material and intellectual activity of the people has displayed wonderful vigour, - the unusually strong stimulus thus making an epoch of greatness in the life of the nation, far above the average level of the national existence. As examples of ideas or events which have exerted a profound stimulus upon the life of nations, may be mentioned Mohammedanism among the Saracens, the crusades preached by Peter the Hermit, the introduction in Europe of the art of printing, the revival of classic learning, and the discovery of the new world. Geographical position, the opening of new routes of trade, civil and foreign wars, have also had their effect in promoting suddenly the intellectual and moral development 
of nations. In regard to individuals also, we notice that the great stress of social and political crises produces great men; and lives filled with many events and strong and varied emotions produce the greatest characters. The greater the strength and variety of the stimuli have been, the greater has been the resulting progress of development, - provided the stimuli did not pass the limit beyond which they become destructive.

When we extend the application of this last conclusion to the physical development of organisms, it is found to explain a peculiar phenomenon. It has been observed that the human race, under the strenuous conditions of life existing in newly settled countries, shows a higher birth rate of males than of females, while in the easier conditions of older countries the opposite is the case. The male organism is - from a morphological point of view a more advanced or specialised development than the female, and the conclusion is easily drawn, that the stronger stimuli of the life in a new country cause greater activity of the vital forces in the parents, which expresses itself in the production of the more specialised sex. So the production of females may be regarded as a form of atavism induced in easy circumstances by the relaxation of the stimuli of life. In the same way, among many 
of the lower animals which reproduce parthenogenetically, when food is plenty and other conditions favourable, only females are produced, but when the conditions of life reach a certain degree of severity, males are produced. In Professor Yung's experiments with tadpoles, we saw that reducing the variety of stimuli by limiting the food to only one kind, had the effect of greatly increasing the percentage of females above the normal ratio.

To the inquiry, what are the most advantageous conditions for life and development, not only for the lower animals, but for man also, it may be answered - great variety and strength of stimuli. As the stimuli cannot all be of the same kind or cannot all be pleasant and agreeable without decreasing the variety, so adversity has its uses; and the strength of the stimuli of adversity counts equally with the stimuli of prosperity; and perhaps more, for adversity has more varieties than prosperity. What counts chiefly is not the available supply of simple energy, but the complexity of the forces acting. The parasite buried in the body of its host, has a comparatively boundless supply of energy at its command, but nevertheless degenerates, for it is removed from the operation of the forces which cause development. Great wealth, unless accompanied by corresponding anxieties, duties, and responsibilities, removes its 
possessors from the operation of many of the stimuli of life, and a corresponding degeneration ensues.

The last phenomenon we have to consider is death. We have already given a hint of its origin in discussing the reproduction of the metazoa. In the reproduction of the metazoa there is a division of the protoplasm of the organism - certain parts divided off repeat in each case the cycle of life from the beginning. Another part, however, which has become too highly specialised by the forces acting upon it, cannot return to the original condition, cannot repeat the cycle of life, - but must continue, without a break, its reactions to its environment. There is an approach to a condition of the continuous action of the same forces upon a body. A force acting continuously on any inanimate body composed of a complex molecular or mechanical system, shows two phases of action. First, there is a time when the force is used in producing changes within the body, overcoming resistance and friction, and changing molecular conditions. This time may be compared with the period of development of living bodies. It is followed by a time when the force acting reaches an equilibrium with the resistance, no longer produces internal changes, and in its continued action none of it becomes latent in the body, but escapes in the same quantity as it entered. This 
seems to be the state which the living body is constantly approaching after it has finished its development. The conditions of life, however, are too complex to offer more than a general simile, but it is enough to give an idea of the nature of life and death. Development and life consist in internal changes; death is a cessation of change. In the living body changes are most frequent and pronounced in the earliest stages and gradually decrease as life approaches its end. By the long continuation of the same stimuli the reaction to them gradually becomes less. This phenomenon is familiarly known as the ability to grow accustomed to things. We may become unmindful or even unconscious of impressions which at first affected us either pleasantly or painfully. When growth has ceased, new co-ordinations and new adaptations to external changes are not easily formed. Also, as the energy of internal changes is lessened, the restorative and trophic processes become weaker, and all the phenomena of senescence follow, the earliest and strongest associations remaining to the last, - second childhood in man. Finally the weakest wheel in the machine breaks, and dissolution takes place.

The causes of death, then, may be summed up as, - first, the inability of the specialised body (soma) of the protozoa to form new adaptive co-ordinations, 
and this is perhaps included in the second and main cause; namely, the decrease in the internal changes of the body, produced by the continued sameness of the stimuli acting upon it. If the continued sameness of environment tends to weaken the reactions and processes of life and bring on senescence and death, then we would expect that changes of environment would sirengthen the reactions and exert a favourable influence upon the processes of life. The following passages from Darwin's Origin of Species gives the reply to this supposition: "It is an old and almost universal belief, founded on a considerable body of evidence, which I have elsewhere given, that slight changes in the conditions of life are beneficial to all living beings. We see this acted on by farmers and gardeners in their frequent exchanges of seed, tubers, etc., from one soil or climate to another, and back again. During the convalescence of animals, great benefit is derived from almost any change in their habits of life . . the principle of life, according to Mr. Herbert Spencer, being that all life depends on, or consists in, the incessant action and reaction of various forces, which, as throughout nature, are always tending towards an equilibrium; and when this tendency is slightly disturbed by any change, the vital forces gain in power."

In concluding this brief exposition of the theory 
of development and heredity, it may be well to point out its relation to other scientific theories. In the first place, it is an effort to extend the application of the law of the conservation of energy to the phenomena of living matter, and to resolve the premises given us by the science of physics to their logical conclusion in the realm of Biology. On the other hand, it is the extension to all living matter of certain fundamental properties of life which psychology has either proved or tacitly assumed to exist in the higher animals, the possible existence of which in the lower animals has aroused so little interest that it has perhaps never been discussed. I mean here those properties expressed by the law of repetition and association. I think none who will review the facts of animal existence will deny the universality of those properties.

By pursuing the method of applying these wide generalisations to the phenomena of life, the latter appear in a new light before us, and a harmony heretofore hidden becomes apparent. Growth, development, and heredity are all due to one common principle. The complex relation of organism to environment may be better understood; the broad facts of embryology and morphology are explained, and fall harmoniously into their place in the system. Much, of course, is lacking in detail, 
and it still remains to test the theory in all its applications. It opens up a new method of exploration. Its bearing on psychological problems seems especially important, as having to do with the development of mind, and there seems to be a new field opened in the direction of comparative psychology. I have not attempted to include this investigation in the present work, and what little I have indicated in this line is not meant to be applied in a materialistic sense to explain or suggest the nature of mind.

It may be objected that by using psychic processes and properties of living matter as means of explanation of heredity, I have departed from the modern purpose of natural science, which is to give a mechanical explanation of the universe. But I have in this only anticipated the conclusion which all biological facts render most probable, that psychic processes have always their physical counterpart. When physiological psychology can discover and express the exact inter-relation of the physical and the psychical, then general biology can make use of the expression; but meantime it were foolish to neg. lect the facts of psychology. Even though arrived at indirectly, we can accept no other conclusion than that all evolution, psychic and organic, is a definite causal series. The theory here given seems to em- 
phasise this conclusion, and to exclude utterly chance as an agent of development. If we apply the theory to our own development, we must recognise ourselves and our actions as the result of a definite, accurate activity of creative force; and if we believe there is what we call "purpose" or "intelligence" in our actions, which are the latter end of the causal series, then we must believe that purpose or intelligence was displayed in all other parts of the causal series, for they appear to be all of the same nature. There is here a suggestion as to the nature and relations of the creative power and the creation.

As before observed, this theory of development and life, as a series of necessary causes and effects, makes our ideas of our free will and moral responsibilities seem paradoxical. This is not the place to attempt the solution of this problem, though I believe it capable of satisfactory solution. There need be no haste to reach a final conclusion in the matter, for we are all convinced that we have a certain degree of freedom of will. According to this theory of heredity, there is a great responsibility resting upon each generation, since its actions are helping to mould the character of its posterity. There is a hopeful thought also in the idea that heredity is not all powerful, 
and that environment may tend to correct a heritage of evil character. A heritage of good character also may be warped by environment, so that excellence of parts in successive generations can be maintained only by constant vigilance and effort in every succeeding generation. The moral development of our race may be viewed as the "forgetting" of our heritage from the brute and the savage, and the "learning" of the higher modes of thought and emotion which are possible to us. 



\section{ESSAYS UPON HEREDITY}

AND KINDRED BIOLOGICAL PROBLEMS.

By DR. AUGUST WEISMANN,

Professor in the University of Freiburg, in Breisgat.

Vol. I., Second Edition, \$2.00. Vol. II., \$1.30.

"Weismann's attempt to solve an old problem has excited great interest in scien-
tific circles, and furnishes a fine example of legitimate scientific speculation." - Prof.
G. MACLoskie, in The Presb́yteriat and Reformed Review.

"For some years students of biology have been aware that Dr. August Weismann, professor in Freiburg University, has materially contributed to the solution of important biological problems, not so much, indeed, by the discovery of new data as by a more searching analysis and more trustworthy interpretation of facts already known. Now, however, for the first time the outcome of his inquiries is made accessible in English to the general reader by an authorized translation issued from the Clarendon Press. That the version correctly reproduces the German original, we have the assurance of Dr. Weismann himself, and that it is made in admirable English the reader will at once acknowledge. The essays collected in the volume before us were published at divers times during the years r88r-r888. They all deal either exegetically or controversially with two fundamental problems; namely, the origin and significance of the phenomenon which we call death, and the limitations of the phenomenon which is termed heredity. We should also premise that the discussion of the latter subject leads him to dissent from one of Darwin's conclusions by denying the transmissibility of acquired characters." - The New York Sun.

"American students of the more profound biological problems are fortunate in having these important essays in so good an English form. Romanes has recently said of Weismann's works, 'A remarkable series of papers, the effects of which have been to create a new literature of such large and rapidly increasing proportions that, with the single exception of Mr. Darwin's own works, it does not appear that any publications in modern times have given so great a stimulus to speculative science or succeeded in gaining so influential a following.' The work before us is a series of essays presented at various times and in various forms, but all bearing upon one central thought, - that acquired character cannot be transmitted by heredity. The idea is a startling one, and is wide-reaching in its consequences. If demonstrated, it demolishes Lamarckism at nne blow. With it, it destroys the whole theory - a favorite one with American workers - that a species may be directly modified by its environment. It does away with the theory of the disappearance of parts from disuse. It establishes the idea that nothing can be transmitted to posterity but what is congenital in the ancestor. In other words, it reduces the working force in development or evolution of species to natural selection operating upon variations in the germ cell. The importance of these essays is thus clear. The essays are eight in number, - the duration of Life ; on Heredity; Life and Death; on the continuity of the Germ Plasm as a foundation of Heredity; Significance of Sexual Reproduction in the theory of Natural Selection: the number of Polar Bodies and their Significance in Heredity; on the Supposed Botanical Proofs of Transmission of Acquired Characters; the Supposed Transmission of Mutilations, - are devoted to stating the theory and meeting in detail objections that have been urged against it. Some of the essays are too technical for the general reader; but the first three and the last two are simple, and clearly place the theory, its bearing, and the two factors that must appear in the discussion, before the reader." - Old and New Testament Student.

\section{MACMILLAN \& CO.,}

\section{FIFTH AVENUE, NEW YORK.}




\title{
THE HISTORY OF HUMAN MARRIAGE,
}

\section{BY EDWARD WESTERMARCK,}

\author{
Lecturer on Sociology at the University of Finland, Helsingfors.
}

8vo. Cloth. $\$ 4.00$.

\begin{abstract}
"Even those whose views are here opposed will, I think, acknowledge that $\mathrm{Mr}$. Westermarck is a careful investigator and an acute reasoner, and that his arguments, as well as his conclusions, are worthy of the most careful consideration. ... Every reader of the work will admire its clearness of style, and the wonderful command of what is to the author a foreign language." - AlFREd Russel Waldace.

"The author... is known throughout Europe as a scholar of unusual attainments and ability. His work is introduced to the reading public by Professor Alfred R. Wallace, who says of it: 'I have seldom met a more thorough or a more philosophic discussion of some of the most difficult, and at the same time interesting, problems of the day. The origin and development of human marriages have been discussed by such eminent writers as Darwin, Spencer, Morgan, Tylor, Lubbock, and many others. On some points, $\mathrm{Mr}$. Westermarck has arrived at different, and sometimes at diametrically opposite, conclusions; and he has done so after a most complete and painstaking investigation of all the available facts. With such an array of authority on the one side, and a hitherto unknown student on the other, it will certainly be thought that all the probabilities are against the latter. Yet I venture to anticipate that the verdict of independent thinkers will, on most of these disputed points, be in favor of the newcomer who has so boldiy challenged the conclusions of some of our most esteemed writers.' Professor Westermarck could hardly have had a better presentation to scientific readers than these few words of Professor Wallace....

"The exhaustive researches of the author (the bare list of titles of authorities examined and quoted covers twenty-nine closely printed pages) culminate in the following paragraph: 'Marriage, generally speaking, has become more durable in proportion as the human race has advanced. Marriage has thus been subject to evolution, in various ways, though the course of evolution has not always been the same. The dominant tendency of this process, at its later stages, has been the extension of the wife's rights. A wife is no longer the husband's property; and according to modern ideas, marriage is, or should be, a contract on the footing of perfect equality between the sexes. The history of human marriage is the history of a relation in which women have been gradually triumphing over the passions, the prejudices, and the selfish interests of men." The work is one of remarkable interest, and will undoubtedly arouse lively debate in scientific circles." - Boston Transcript.

"This is the most scientific treatise yet produced in this special field of investigation, and we note three prime characteristics of a scientific method. The facts upon which its theory is based have been collected in enormous quantity from the literature and the observation of all ages, for, as the author says, the first condition of success is that 'there should be a rich material; what is wanting in quality should be made up in quantity." Again, in the interpretations of existing phenomena the writer has sought to guard against the double danger of "putting into them a foreign
\end{abstract}


meaning,' and of 'inferring, without sufficient reasons, from the prevalence of a custom or institution among savage peoples, that this custom, this institution, is a relic of a stage of development that the whole human race once went through.' Finally, Mr. Westermarck is never satisfied that a custom or institution is explained until he has endeavored to trace it to something fundamental in the physical or psychical nature of the race. . . . We lay the volume down with the conviction that it is a masterly contribution to a growing science, and that its author's argument will stand, even although one may not accept with him the anthropoid ape as a man and a brother." - John J. Halsey, in The Dial.

"It is scholarly, thoughtful, and comprehensive. There is nothing in it to stay the souls of persons having 'advanced views' of the marriage relations; the author finds that nature, like sentiment, reason, and religion, has decreed that one man shall be the mate of one woman, and that any deviations from this rule bring enduring penalties with them. The book contains much curious information about the marriage customs of various countries, savage and civilized, but is devoid of anything that can stimulate erotic imaginations. A portion of Professor Westermarck's work which might be read to advantage by almost any one is the chapter showing the changes which have been made from time to time in woman's degree of dependence upon man and independence of him. Since the earliest period of written history, woman, in most civilized countries, has been regarded as the inferior partner in the family relation, and often has sunk to the position of a mere dependent. One of the boasted glories of modern civilization is the elevation - too often nominally only of the wife to equality with the husband. Yet traditions of the oldest races, and the practice of some modern peoples who are scarcely civilized, show that woman has been at times the head of the family and absolutely her own ruler. . . . The world would not willingly go back to all primitive customs, ignorance, and discomfort, that woman might fully reassert herself; but it is one of Civilization's satires upon herself that woman was never so independent of man as when she supported herself." - The New York Herald.

"This is one of the most elaborate works on the history of social institutions that we have met with. The author is lecturer on sociology in the University of Finland at Helsingfors, yet his book was written by himseif in English, which is to him a foreign language. He modestly tells us in his preface that, as originally written, the book contained some un-English expressions, which were correcred by his English friends; but the ease and clearness of his style show that he is a master of the art of expres. sion, and make his work far more interesting than works on such subjects are apt to be. . . . As a descriptive history of marriage in the many forms it has assumed, the work could hardly, in the present state of our knowledge, be surpassed. . . . He shows a very wide as well as intimate knowledge of the facts, so far as they have been discovered, and both his facts and his arguments will have to be considered by all who may write on the subject hereafter. His opinions on certain fundamental points are at variance with those of most previous writers, and hence his work is likely to give rise to some controversy. He rejects the hypothesis that promiscuous intercnurse was once everywhere prevalent, and his arguments on this point deserve careful attention. . . . Whatever may be thought of some of Mr. Westermarck's theories, his work will be indispensable to all students of the early history of marriage." - Science.

\section{MACMILLAN \& CO., \\ 66 FIFTH AVENUE, NEW YORK.}




\title{
DARWINISM :
}

\section{Being a Systematic Exposition of the Theory of Natural Selection, with Some of its Applications.}

\author{
By ALFRED RUSSEL WALLACE, LL.D., F.L.S. \\ pp. xiv., 494. \$1.75.
}

"In all the mass of books that has appeared since The Origin of Species, no one volume is more valuable as a statement of theory, or more fascinating to the reader, than that by Alfred Russel Wallace, on Darwinism." - The Plain Dealer.

"The book is written with all of Wallace's usual clearness and force. . . It is full of suggestion, and will repay careful reading better than any scientific work of recent years." - The Chronicle.

"The book is hardly less important than those of Darwin himself. . . In popular as well as scientific interest, this may justly be called a fascinating book. Its highest significance is that it still allows to man a spiritual meaning." - Cinctinnati Commercial Gazette.

"A most stimulating and delightful work. Certainly no scientific writer has set forth the principal points of Darwinism with more brilliant and convincing clearness, or has thrown more light, for the ordinary understanding, on phases of the question which are obscure and difficult to grasp. It is only proper to call attention to the style of the author, which is simple, bright, and vivid, a model for the scientific expositor. Mr. Wallace has that most desirable of all gifts for the scientist, a powerful and well-ordered imagination, which shows itself not only in its higher uses, but in the charm which it lends to presentation." - Eclectic Magazine.

"Dr. Wallace's book is necessary to a thorough understanding of the present status of conservative thought on the doctrine of evolution. To the student of science, to the theologian, and to the cultivated layman, it alike appeals. Those who master it will owe the distinguished author a debt of gratitude." - The Beacon.

"The number of writers on questions connected with Darwinism is so great, and their views so varied in detail, that it would puzzle most people to tell exactly what the Darwinism of Darwin really is. A book, therefore, which defines Darwin's theory simply and definitely, restates the old and adds the new evidence that has been collected to uphold it, indicates what has been contributed since Darwin's day to the strengthening of his theory, carefully criticised in order to dispose of what has been brought against it, so that within itself it contains all that is necessary to a complete understanding of the evolutionary theory as it was held originally, and as it stands to-day, is a book which is in the nature of a boon to a bewildered public. Such a book is this one by Mr. Russel Wallace. This author is beyond question the best man to undertake the task of elucidation and exposition. He was, be it remembered, co-originator with Darwin of the theory of the origin of species. He has always been in close agreement with Darwin's views, and worked with him for the establishment of the theory as a friend, not as a rival. By intimate knowledge of Darwin's ideas, and of the multitudinous facts in natural history that go to support them, Mr. Wallace is pre-eminently fitted for the task he undertonk. Moreover, he has the literary ability to make both easily intelligible and interesting. His unpretending style is very attractive in its clearness and simplicity, and for orderliness and compactness his arrangement of agreement and example could hardly be excelled. Finally, his tone is admirable, calmly judicial, and without the least touch of polemical aggressiveness. ... The book is, of course, a treasury of curious knowledge in all branches of natural history, and, read on that account only, would prove abundantly interesting; but in addition it is valuable to the reader, as an authoritative and skilfully prepared resume, and to scientific men, by reason of the fresh material and argument it contains." - Boston Advocate.

MACMILLAN \& CO., 66 FIFTH AVENUE, NEW YORK. 


\title{
NATURAL SELECTION AND TROPICAL NATURE :
}

\author{
Essays on Descriptive and Theoretical Biology.
}

\author{
By ALFRED RUSSEL WALLACE, LL.D., F.L.S.
}

\author{
8vo. pp. 492 . \$1.75.
}

\begin{abstract}
"This is a new, corrected, and enlarged edition of two volumes of essays printed in 1870 , $187 \mathrm{I}$, and 1878 . They are now re-worked into the present one-volume edition, with some additions and some omissions. Mr. Wallace's scientific position remains in them unchanged. The somewhat free and miscellaneous arrangement of the contents relieves to some extent the strain on the reader, and adds much to the pleasure of reading. We note with interest his strong re-assertion of the fact that there are limits in Nature to the operation of natural selection, and that it cannot account for the development of man." - The Independent.
\end{abstract}

"Among interesting subjects treated here are the tendency of varieties to depart indefintely from the original type, mimicry, and other protective resemblances among animals. The remarks on the general phenomena of color in the organic world gives very great enjoyment to the reader, who finds, in Mr. Wallace's work, reverent studies of the beauties and harmonies of creatures, and a conviction that the most insignificant parts of tiny organisms are worthy of earnest study, and capable of exciting iutelligent admiration." - Public Ledger.

" Biologists of the present, though perhaps unanimous in acceptance of some form of evolution, are divided into two camps as to what factor has been most potent in the progress, - the direct modificative influence of the environment, or natural selection. Wallace stands for the latter. In 1870 he presented to the world a little volume of essays on Natural Selection. In 1878 appeared a similar volume on Tropical Nature. Both were delightful, even charming, reading. They have been out of print for some time. Just at this time, their reprinting, as in the volume before us, is certainly desirable. . . To differ with a few of his statements and some of his conclusions, is not to lack appreciation of their value and beauty of style." - Christian Union.

"Somewhat more than one-half of the book is occupied with the subject just named in this title, - Natural Selection. By this is meant, of course, that process in nature by which organic life, in its 'struggle for existence,' parts with those forms which are feebler and less equal to such a 'struggle,' while the more vigorous ones become permanent. ... It is, in other words, the basal principle in that doctrine of 'evolution' of which we hear so much. 'This doctrine Mr. Wallace adopts, although under limitations which the extreme advocates of the evolution school in science do not recognize. He believes in a creation and a Creator; but it is "creation by law, that is to say, the establishment, by the Creator, of a law and method in the physical universe, in accordance with which all organic life develops and multiplies. ... He is, then, a Darwinian within limitations. His treatment of the principles which characterize this school in modern science is very lucid, while his array of facts shows fruits of a lifetime devoted to studies of this nature. On one side, his book may be read with a sensation of relief; it is a relief to follow in such studies a man who, while thoroughly at home in his subject, a profound observer and a skilful reasoner, is at the same time not an atheistical fanatic. The other essays in the book, descriptive of organic life in tropical countries, will very much delight those whom researches of this kind interest." - The Standard.

\section{MACMILLAN \& CO.,}

\section{FIFTH AVENUE, NEW YORK.}




\title{
INQQUIRIES INTO HUMAN FACULTY, AND ITS DEVELOPMENT.
}

\author{
By FRANCIS GALTON, F.R.S., etc.
}

8vo. Cloth. pp. xii., 387. \$3.00.

"The larger part of this book has already appeared in various periodicals; but the matter is so interesting, and the treatment of the subject so unique, that it is well worthy of preservation in this permanent form." - The Literary World.

" Scientific students of all kinds, especially psychologists, have anxiously awaited this suggestive volume. . . The volume contains colored plates and other illustrations, among them interesting specimens of composite portraiture. Although the author intends it to be suggestive, and 'renounces all claim to be encyclopedic," he has given the world another important chapter of the new branch of science which he mapped out in his remarkable book on hereditary genius."- Philadelphia Item.

"Mr. Galton has worked a complete revolution in the study of man. . . The book is of universal and profound interest to every human being. It is the beginning of a new study of an old subject, which, if we are wise, will one day far in the future make the human race a race of aristocrats. But the aristocracy will not be based on money, nor on mere names, but on the proper breeding of men, and the proper laws for human development, physical and mental." - New York World.

"Mr. Galton's exceedingly interesting Inquiries into Human Faculty are so novel and suggestive that they open the way for many extended lines of discussion and argument concerning the future evolution of man. The book is made up largely of magazine articles, but these are held together by the thread of a common purpose, and form a connected outline. ... His book affords a great amount of instruction, and cannot fail to stimulate inquiry into the fascinating themes of which it treats." Boston Traveller.

\section{HEREDITARY GENIUS :}

\section{An Inquiry into its Laws and Consequences.}

\author{
By FRANCIS GALTON, F.R.S., etc.
}

8v0. pp. 379. $\$ 2.50$.

"Hereditary Genius is the title of a volume written in the sixties by Francis Galton, F.R.S. To say that it created a sensation is to put it mildly, for a sensation seldom lasts very long; but better would it be to say that by its subtle reasoning and arrangement of facts, it made a deep impression on the minds of inquiring people. The title hardly explains the contents of the book, as it is rather a study of vital laws which governed the past and will govern the future. It strives to show the reader the means by which the condition of the race may be ameliorated, and the standard of mentality raised by natural methods. Many old precepts which have firm hold on the mind are dissipated by an indisputable array of evidence, as by one fell blow; and, while we are startled and surprised, we are pleased with the carnage and advance of science. The book will open to one a field in which he can study with profit, and make one the better for knowing a few vital principles which govern life, and upon which the future happiness and usefulness of posterity largely depends." - Brookiyn lliustrated Church History.

\section{MACMILLAN \& CO.,}

\section{FIFTH AVENUE, NEW YORK,}




\title{
NATURAL INHERITANCE.
}

\author{
By FRANCIS GALTON, F.R.S., etc.
}

\author{
8vo. Cloth. \$2.50.
}

\begin{abstract}
"Mr. Galton is a specialist in this department, and he has collected a vast amount of material. His conclusions do not favor the extreme ideas of heredity held by many writers. His argument seems to establish the fact that "the chain of natural endowments remains essentially the same through all ages, and of equal size throughout.' There is a tendency, in spite of peculiarities, to return to about the average size, height, intellect, etc. It is an interesting and valuable work." - The Sicnday School Fournal.
\end{abstract}

"Mr. Francis Galton's studies of the science of heredity have an athoritative value in sociology, since his arguments are based upon thorough investigations, and accompanied by careful comparisons. Natural fuheritauce, his latest study upon the subject, is a valuable illustration of his manner in arguing from collected data. . . . Tables and appendix add to the scientific interest of the work, which may be regarded as a most suggestive and valuable contribution to the study of modern society." The Boston Fon rual.

"The general feeling with which one leaves the book is an admiration of the powers of method to give meaning to facts; an appreciation of the complex system of inferences that make each individual what he is; and a hope that posterity will be able to utilize the fruits of such workers as Mr. Galton for the amelioration of mankind." - The Christian Union.

"Mr. Galton is the highest authority on this subject; a new book by him is an event in the scientific world. . . Scientific men will enjoy particularly the study of Mr. Galton's processes, the usefulness of which is by no means limited to the investigation of heredity." - Bostor Advocate.

"Mr. Francis Galton, whose studies in heredity have been life-long, whose methods are so patient, is the last man in the world to ventilate startling theories, or to assert ill-digested things as facts. ... For perfecting philosophical inquiry, for prudence and good judgment, Mr. Galton is to be considered as presenting the highest examples of modern research." - The New York Times.

"This is Mr. Galton's latest treatise on a subject and in a field of investigation which he has made almost exclusively his own. Whatever one may think of his conclusions, no one who has any adequate conception of 'Science" can find fault with either the spirit of the author or the manner in which his investigations are carried on. It would be impossible here to do anything like justice to the details of his method, which is in general observation, experiment, ancl generalization; but it is simple justice to say that no effort to reach general laws by an induction from phenomena was ever made with more scrupulous method. The problem he has undertaken to solve is one of extreme difficulty, and he does not profess to have done more than furnish a contribution toward its solution; but, by publishing what this work contains, he has made it possible to secure the intelligent co-operation of hosts of coworkers wherever his book is read, and in this way he has done a far greater service to Science than perhaps he thought of when he wrote it. Whether Science will ever be able to find out to what extent the nature of the child is determined by conditions antecedent to birth is still very doubtful; but if the doubt on the subjeat is hereafter set at rest, much of the credit of getting rid of it must always be accorded to Mr. Galton for the labor, the patience, and the ingenuity which he has brought to bear on the question of heredity." - Toronto Week.

\section{MACMILLAN \& CO.,}

\section{FIFTH AVENUE, NEW YORK.}




\title{
ORGANIC EYOLUTION AS THE RESULT OF THE INHERITANCE OF ACQUIRED CHARACTERS ACCORDING TO THE LAWS OF ORGANIC GROWTH.
}

\author{
By Dr. G. H. THEODORE EIMER. \\ Translated by J. T. Cunningham, F.R.S.E. \\ 8vo. $\$ 3.25$.
}

\begin{abstract}
"Professor Eimer believes that he has demonstrated, contrary to certain portions of Professor Weissman's argument, that external conditions do modify organisms, and that characters so acquired are veritably inherited. If he is right, then Darwinism receives a powerful support, for Darwin did not work out this part of his theory as well as others. But he does not maintain (and this he dwells on) that adaptation to surroundings will explain all phenomena - that it has exclusive dominion. 'If this exclusive dominion did belong to it, if everything were adapted, all evolution of the living world would be also excluded; there would be stagnation.' $\mathrm{He}$ brings combinations of characters into play. Supposing that when a given animal became adapted in a certain way other less necessary changes occurred in its frame, as, when horns appeared, other parts of the body changed in sympathy. He is fond of an analogy with crystals, which do not only form at the point of impact, but when once started branch far and wide in certain lines of direction, changing the whole mass. It would be impossible to follow Professor Eimer through the organic grow th of the living world, the influence of adaptation on the formation of species, and the sections or acquired characters, mental faculties acquired and inherited, function as the cause of evolution without and within, and the Law of Organic Form. Readers may be warned that the earlier sections are the difficult ones, while those that follow contain a very interesting and attractive store of information, anecdote, and running argument applied to animal life. It may merely be said broadly that Eimer represents more nearly the kind of scientific mind that Darwin had than do men like Kölliker, Von Nägeli, and Weissman, who call themselves physiologists, and base their arguments on studies with the microscope rather than on wide generalizations on visible facts concerning animals. Professor Eimer is a zoölogist rather than a physiologist. To laymen the distinction is fine; but when we discover that one scientist assumes that another must err because that other is a zoölogist, for example, we begin to perceive that the training a man has undergone may plausibly enter into account." - New York Times.
\end{abstract}

\section{MACMILLAN \& CO.'S NEW SCIENTIFIC BOOKS.}

HERTWIG (0.). A Text-Book of Embryology: Man and Mammals. Translated from the third German edition by Dr. EDward L. Mark, Hersey Professor of Anatomy in Harvard University. Illustrated. 8vo. \$5,25 net.

HATSCHEK (B.). The Amphioxus and its Development. Translated by James TUCKEY, M.A. \$ r.50 net.

MIGULA (W.). An Introduction to Practical Bacteriology. Translated and edited by M. and H. J. Camprelu. Illustrated. $\$ 1,60 n e t$.

SHIPLEY (A. G.). Zoölogy of the Invertebrata. 8vo. \$6.25 $\mathrm{ket}$.

\section{IN PREPARATION.}

GAMGEE (A.). A Text-Book of the Physiological Chemistry of the Animal Body. With illustrations. Vol. II.

KORSCHELT and HEIDER. Text-Book of the Developmental History of the Invertebrates. Translated under the supervision of Dr. E. L. MARK, Harvard University, Mass. Fully illustrated. 8vo.

\section{MACMILLAN \& CO.,}

\section{FIFTH AVENUE, NEW YORK.}






? ? SEP TOS

00T $31 \cdot 1900$ 

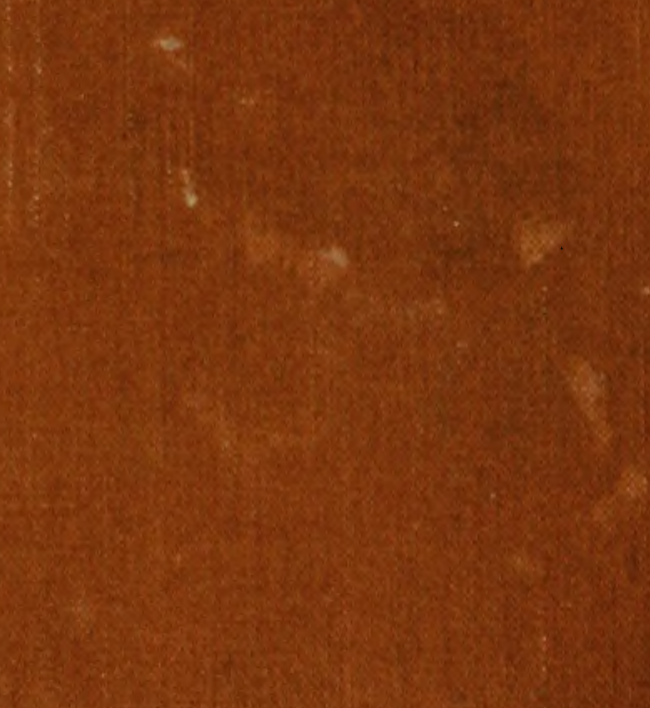<smiles></smiles>
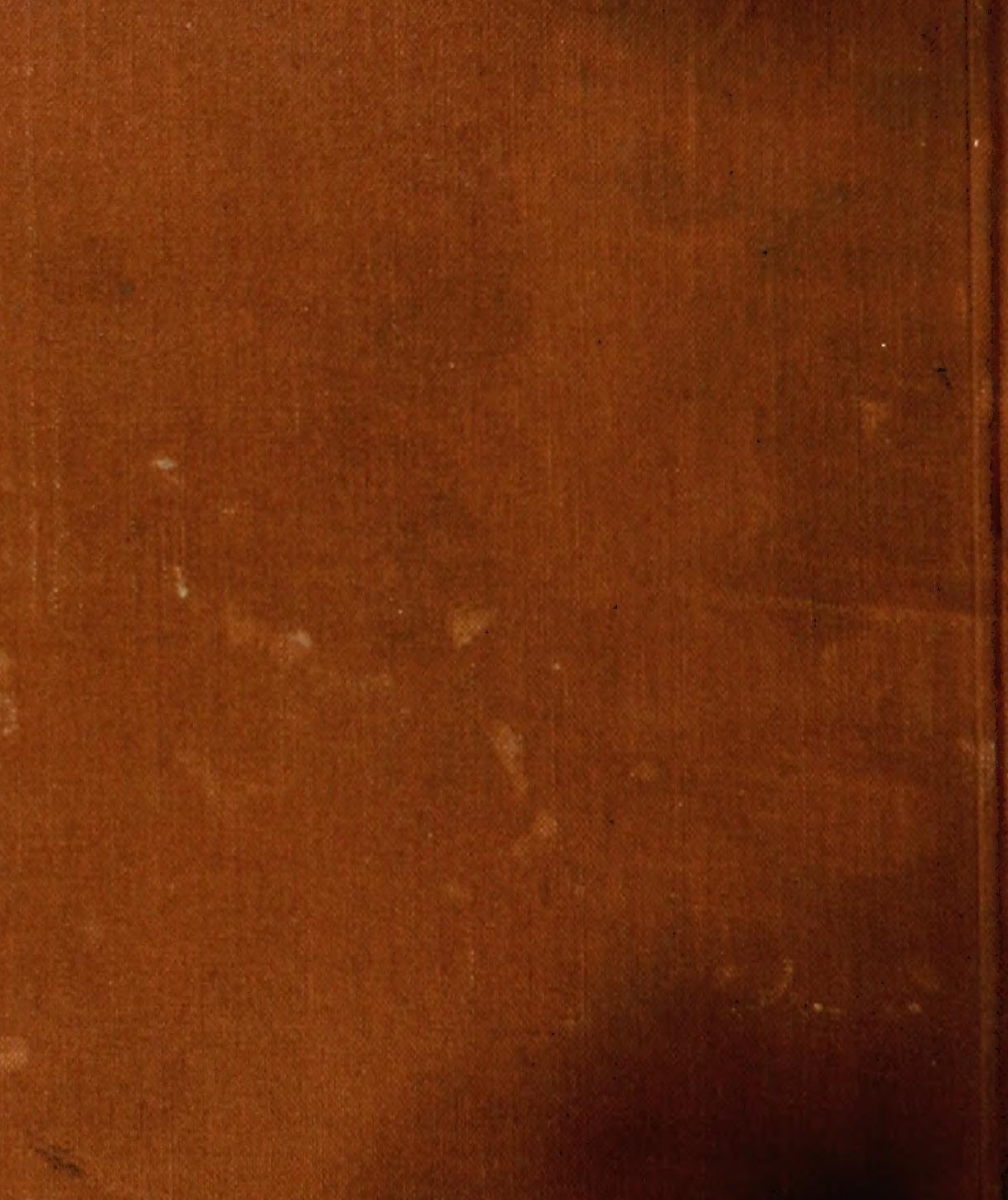